\title{
Advances in understanding, models and parameterizations of biosphere-atmosphere ammonia exchange
}

\author{
C. R. Flechard ${ }^{1}$, R.-S. Massad ${ }^{2}$, B. Loubet ${ }^{2}$, E. Personne ${ }^{3}$, D. Simpson ${ }^{4,5}$, J. O. Bash ${ }^{6}$, E. J. Cooter ${ }^{6}$, E. Nemitz ${ }^{7}$, and \\ M. A. Sutton ${ }^{7}$ \\ ${ }^{1}$ INRA, Agrocampus Ouest, UMR1069 Sol Agro-hydrosystème Spatialisation, 35042 Rennes, France \\ ${ }^{2}$ INRA, UMR1091 INRA-AgroParisTech Environnement et Grandes Cultures, 78850 Thiverval-Grignon, France \\ ${ }^{3}$ AgroParisTech, UMR1091 INRA-AgroParisTech Environnement et Grandes Cultures, 78850 Thiverval-Grignon, France \\ ${ }^{4}$ EMEP MSC-W, Norwegian Meteorological Institute, Norway \\ ${ }^{5}$ Department Earth \& Space Sciences, Chalmers University of Technology, Gothenburg, Sweden \\ ${ }^{6}$ National Exposure Research Laboratory, Office of Research and Development, US Environmental Protection Agency, \\ Research Triangle Park, NC 27711, USA \\ ${ }^{7}$ Center for Ecology and Hydrology (CEH) Edinburgh, Penicuik, UK
}

Correspondence to: C. R. Flechard (chris.flechard@rennes.inra.fr)

Received: 1 March 2013 - Published in Biogeosciences Discuss.: 21 March 2013

Revised: 25 June 2013 - Accepted: 26 June 2013 - Published: 30 July 2013

\begin{abstract}
Atmospheric ammonia $\left(\mathrm{NH}_{3}\right)$ dominates global emissions of total reactive nitrogen $\left(\mathrm{N}_{\mathrm{r}}\right)$, while emissions from agricultural production systems contribute about twothirds of global $\mathrm{NH}_{3}$ emissions; the remaining third emanates from oceans, natural vegetation, humans, wild animals and biomass burning. On land, $\mathrm{NH}_{3}$ emitted from the various sources eventually returns to the biosphere by dry deposition to sink areas, predominantly semi-natural vegetation, and by wet and dry deposition as ammonium $\left(\mathrm{NH}_{4}^{+}\right)$ to all surfaces. However, the land/atmosphere exchange of gaseous $\mathrm{NH}_{3}$ is in fact bi-directional over unfertilized as well as fertilized ecosystems, with periods and areas of emission and deposition alternating in time (diurnal, seasonal) and space (patchwork landscapes). The exchange is controlled by a range of environmental factors, including meteorology, surface layer turbulence, thermodynamics, air and surface heterogeneous-phase chemistry, canopy geometry, plant development stage, leaf age, organic matter decomposition, soil microbial turnover, and, in agricultural systems, by fertilizer application rate, fertilizer type, soil type, crop type, and agricultural management practices. We review the range of processes controlling $\mathrm{NH}_{3}$ emission and uptake in the different parts of the soil-canopy-atmosphere continuum, with $\mathrm{NH}_{3}$ emission potentials defined at the substrate and leaf levels by different $\left[\mathrm{NH}_{4}^{+}\right] /\left[\mathrm{H}^{+}\right]$ratios $(\Gamma)$.
\end{abstract}

Surface/atmosphere exchange models for $\mathrm{NH}_{3}$ are necessary to compute the temporal and spatial patterns of emissions and deposition at the soil, plant, field, landscape, regional and global scales, in order to assess the multiple environmental impacts of airborne and deposited $\mathrm{NH}_{3}$ and $\mathrm{NH}_{4}^{+}$. Models of soil/vegetation/atmosphere $\mathrm{NH}_{3}$ exchange are reviewed from the substrate and leaf scales to the global scale. They range from simple steady-state, "big leaf" canopy resistance models, to dynamic, multi-layer, multi-process, multichemical species schemes. Their level of complexity depends on their purpose, the spatial scale at which they are applied, the current level of parameterization, and the availability of the input data they require. State-of-the-art solutions for determining the emission/sink $\Gamma$ potentials through the soil/canopy system include coupled, interactive chemical transport models (CTM) and soil/ecosystem modelling at the regional scale. However, it remains a matter for debate to what extent realistic options for future regional and global models should be based on process-based mechanistic versus empirical and regression-type models. Further discussion is needed on the extent and timescale by which new approaches can be used, such as integration with ecosystem models and satellite observations. 


\section{Introduction}

\subsection{Ammonia in the environment}

Ammonia $\left(\mathrm{NH}_{3}\right)$ emission from the biosphere to the atmosphere is one of the many unintended consequences of reactive nitrogen $\left(\mathrm{N}_{\mathrm{r}}\right)$ creation from inert dinitrogen gas $\left(\mathrm{N}_{2}\right)$ through symbiotic biological nitrogen fixation (BNF) and the Haber-Bosch process, and of the agricultural usage of the fixed $\mathrm{N}_{\mathrm{r}}$ for crop and meat production (Sutton et al., 2011). Conversely, $\mathrm{NH}_{3}$ emission is also one of the main precursors of the nitrogen cascade (Galloway et al., 2003), whereby the $\mathrm{N}$ atom of the $\mathrm{NH}_{3}$ molecule may potentially participate in a number of environmental impacts through a series of pathways and chemical and (micro-) biological transformations in the biosphere. As airborne $\mathrm{NH}_{3}$ is transported downwind from sources, chemically processed in the atmosphere, and dry- and wet-deposited to the Earth's surface, it may be converted in air, vegetation, soils and water successively to $\mathrm{NH}_{4}^{+}, \mathrm{NO}_{3}^{-}, \mathrm{NO}, \mathrm{N}_{2} \mathrm{O}$, many organic $\mathrm{N}$ forms, threatening in terms of air quality, water quality, soil quality, the greenhouse gas balance, ecosystems and biodiversity -5 key threats identified by Sutton et al. (2011).

Quantitatively, $\mathrm{NH}_{3}$ is currently believed to account for approximately half of all global biospheric, anthropogenic and natural atmospheric $\mathrm{N}_{\mathrm{r}}$ emissions, with $\mathrm{N}_{\mathrm{r}}$ defined and inventoried as the sum of $\mathrm{NH}_{3}-\mathrm{N}$ and oxidized nitrogen $\mathrm{NO}_{\mathrm{x}}-\mathrm{N}$. Global estimates of $\mathrm{NH}_{3}$ and $\mathrm{NO}_{\mathrm{x}}$ emissions provided by the Emissions Database for Global Atmospheric Research (EDGAR, 2011) were 40.6 and 37.2 $\mathrm{Tg} \mathrm{N} \mathrm{yr}^{-1}$ for the year 2008, respectively. Agricultural $\mathrm{NH}_{3}$ emissions dominate and are of the order of $27-38 \mathrm{Tg} \mathrm{NH}_{3}-\mathrm{N} \mathrm{yr}^{-1}$ (Beusen et al., 2008). Uncertainties in global $\mathrm{NH}_{3}$ emissions are large, possibly up to $30-40 \%$, as shown by the variability in other published global figures (e.g. calculated estimates of 75 (50-128), by Schlesinger and Hartley, 1992; $45 \mathrm{Tg} \mathrm{NH}_{3}-$ $\mathrm{N} \mathrm{yr}^{-1}$ by Dentener and Crutzen, 1994; $54 \mathrm{Tg} \mathrm{NH}_{3}-\mathrm{N} \mathrm{yr}^{-1}$ by Bouwman et al., 1997; $43 \mathrm{Tg} \mathrm{NH}_{3}-\mathrm{N} \mathrm{yr}^{-1}$ by van Aardenne et al., 2001). By comparison, the global biological and industrial $\mathrm{N}_{2}$ fixation is of the order of $140 \mathrm{Tg} \mathrm{N} \mathrm{yr}^{-1}$ (Galloway et al., 2003), of which $\mathrm{NH}_{3}$ emissions represent a loss of approximately one-third. The environmental impacts of $\mathrm{NH}_{3}$ are expected to become more pronounced in many regions of the world where increases in $\mathrm{NH}_{3}$ emissions are expected to occur during the 21 st century, as a result of agricultural intensification and the manifold effects of climatic change on $\mathrm{N}$ cycling.

Within the European Union (EU-27), total $\mathrm{NH}_{3}$ and $\mathrm{NO}_{\mathrm{x}}$ emission estimates are also of the same order, at 3.0 and $2.8 \mathrm{Tg} \mathrm{N} \mathrm{yr}^{-1}$, respectively (European Environment Agency, 2012; Sutton et al., 2011), contributing around $7.5 \%$ of global emissions. Although EU-27 $\mathrm{NH}_{3}$ emissions declined by $28 \%$ from 1990 to 2010 , the share of $\mathrm{NH}_{3}$ in total European $\mathrm{N}_{\mathrm{r}}$ emissions increased from $44 \%$ to reach the current level of $51 \%$, because $\mathrm{NO}_{\mathrm{x}}$ emissions almost halved
$(-47 \%)$ over the same $20 \mathrm{yr}$ period (European Environment Agency, 2012), due to very significant $\mathrm{NO}_{\mathrm{x}}$ emission abatements in the transport, industry and energy sectors. A range of $\mathrm{NH}_{3}$ emission projections in Europe tend to indicate either a small increase, or possibly a slow linear decline of the order of $\sim 25 \%$ by the year 2100 , while $\mathrm{NO}_{\mathrm{x}}$ emissions are projected to decline exponentially by $\sim 75 \%$ over the same time horizon (Winiwarter et al., 2011).

As oxidised $\mathrm{N}_{\mathrm{r}}$ eventually takes a backseat to reduced $\mathrm{N}_{\mathrm{r}}$ emissions in Europe and N. America, the degree to which $\mathrm{NH}_{3}$ will control atmospheric chemistry and $\mathrm{N}$ deposition to sensitive ecosystems is set to increase over the next few decades. In addition, because $\mathrm{NH}_{3}$ emissions largely originate in agriculture and are predominantly the result of biological processes (with the notable exception of biomass burning and forest fires - e.g. R'Honi et al., 2012), they are much more weather/climate sensitive than are $\mathrm{NO}_{\mathrm{x}}$ emissions, which are dominated by industrial, domestic and traffic combustion processes. With global temperatures expected to rise by a few $\mathrm{K}$, and based on thermodynamic considerations (a volatilisation $\mathrm{Q}_{10}$ of 3-4), agricultural $\mathrm{NH}_{3}$ emissions could increase substantially over the 21 st century, although water availability is also a critical factor, favouring mineralisation of organic $\mathrm{N}$ sources while suppressing $\mathrm{NH}_{3}$ emissions by allowing dilution and infiltration (Sutton et al., 2013). The net impact of rising temperatures and altered spatial/seasonal precipitation patterns on regional and global $\mathrm{NH}_{3}$ budgets is as yet uncertain, with the uncertainty being compounded by land-use and land-cover changes and evolving agricultural practices (e.g. fertilization rates, spreading techniques, grazing density). Such an assessment will require the development of fully mechanistic, climate-dependent models for the quantification of surface/atmosphere $\mathrm{NH}_{3}$ exchange under global environmental change (Sutton et al., 2013).

\subsection{Requirements for different ammonia exchange models}

Predicting global-change-induced alterations of $\mathrm{NH}_{3}$ emissions and dry deposition is just one out of a range of environmental issues and ecological applications requiring biosphere/atmosphere $\mathrm{NH}_{3}$ exchange modelling, along with e.g. local $\mathrm{N}$ deposition impacts assessments (Hertel et al., 2011; Theobald et al., 2004, 2009; Sutton et al., 1998b; Loubet et al., 2009a), air quality studies (Pinder et al., 2007; Wu et al., 2008), and transboundary air pollution flux estimation (Simpson et al., 2012; Berge et al., 1999). Models of surface/atmosphere $\mathrm{NH}_{3}$ exchange have been both developed and applied for a number of purposes and at a large range of spatial scales ranging from the leaf or plant (Massad et al., 2010a), the canopy or ecosystem (Sutton et al., 1998a; Nemitz et al., 2001a; Riedo et al., 2002; Personne et al., 2009), the landscape (Loubet et al., 2009a; Hertel et al., 2006), to the national/regional level (van Pul et al., 2009; 
Bash et al., 2012) and to the globe (Dentener and Crutzen, 1994).

The objectives of the modelling depend on the spatial and temporal scales at which models are ultimately applied. At the field/ecosystem scale, surface exchange models often come as an aid to the interpretation of measured flux data and to further process understanding (e.g. Sutton et al., 1995b; Flechard et al., 1999; Nemitz et al., 2000b; Spindler et al., 2001; Neirynck and Ceulemans, 2008; Burkhardt et al., 2009), as the unexplained variability (residuals) points to potential model weaknesses and areas for further improvements. Models may also be used to fill gaps in measured flux time series in order to provide seasonal or annual $\mathrm{NH}_{3}$ exchange budgets (Flechard et al., 2010). In the absence of measured fluxes, but based on local meteorology and measured ambient concentrations at given sites, inferential modelling provides $\mathrm{NH}_{3}$ flux estimates for individual ecosystems (Smith et al., 2000; Zimmermann et al., 2006; Walker et al., 2008; Zhang et al., 2009; Flechard et al., 2011). At larger (landscape, regional, global) scales, surface/atmosphere schemes are parameterized for different land uses and embedded within modelling contexts that encompass the whole cycle (from an Earth-Atmosphere-Earth perspective) of emission, dispersion, transport, chemistry and deposition (van Pul et al., 2009; Asman et al., 1998).

The process understanding gained over the years from controlled environment studies and field-scale measurements is eventually formalized into soil-vegetation-atmosphere transfer (SVAT) models, which then feed - in simplified, generalized forms - into landscape-scale models (LSMs), regional or global chemistry and transport models (CTMs), and dynamic global vegetation models (DGVMs).

\subsection{Ammonia measurement and modelling approaches}

The development, parameterization and validation of models over the years has been, to a large extent, underpinned by the ever-increasing availability of $\mathrm{NH}_{3}$ concentration and/or flux datasets across all scales.

At sub-landscape scales (cuvette, chamber, plot, field), this has stemmed from technological advances in $\mathrm{NH}_{3}$ flux measurement instrumentation, capable of adequate lower detection limits, continuous online analysis for extended periods of time, selective quantification of gaseous $\mathrm{NH}_{3}$ from aerosol $\mathrm{NH}_{4}^{+}$, together with tolerable troubleshooting and maintenance workloads. In particular, at the field scale, wet denuder systems with automated online detection (Wyers et al., 1993; Blatter et al., 1994; Erisman et al., 2001; Thomas et al., 2009) have helped produce many exchange flux datasets by aerodynamic gradient methods (AGM) or Bowen ratio techniques, both at remote background locations with low (sub-ppb) concentration levels (Flechard and Fowler, 1998b; Milford et al., 2001a), and over polluted semi-natural ecosystems and fertilized agricultural systems (Wyers and Erisman, 1998; Ne- mitz et al., 2000a, b; Neirynck and Ceulemans, 2008; Sutton et al., 2009b; Flechard et al., 2010; Wolff et al., 2010a; Loubet et al., 2012; Walker et al., 2013). Relaxed eddy accumulation systems have allowed $\mathrm{NH}_{3}$ flux measurements at one single height (Nemitz et al., 2001b; Meyers et al., 2006; Hensen et al., 2009a). In parallel, a range of new generation, fast-response optical and mass spectrometry instruments have emerged over the last $15 \mathrm{yr}$ (see von Bobrutzki et al., 2009, for a review and intercomparison), which have proved suitable for eddy covariance (EC) measurements of large (emission) fluxes such as those occurring after the land spreading of manures (Whitehead et al., 2008; Sintermann et al., 2011). However, many of these instruments have yet to realize their full potential for the smaller exchange fluxes typical of unfertilized background situations (Famulari et al., 2004), not least due to aerosol $\mathrm{NH}_{4}^{+}$interference and to highfrequency damping losses of $\mathrm{NH}_{3}$ fluctuations from adsorption/desorption within the measurement system, especially air inlet lines and online filters (Ellis et al., 2010; Whitehead et al., 2008).

At landscape/regional/global scales, it is much harder to make flux measurements, and modelled surface/atmosphere exchange cannot easily be directly validated. At the landscape scale, limited use has been made of plume measurements and inverse modelling of strong sources (Hensen et al., 2009b; Flesch et al., 2007; Blackall et al., 2007; Loubet et al., 2009b; Carozzi et al., 2013). However, model evaluation, especially at the regional scale, typically relies on the indirect indicators provided by measured wet deposition of $\mathrm{NH}_{\mathrm{x}}\left(\mathrm{NH}_{3}+\mathrm{NH}_{4}^{+}\right)$and, wherever available, ambient $\mathrm{NH}_{3}$. Ammonia concentration measurements as part of spatial networks of atmospheric pollution monitoring using low-cost, long-term sampling, are available in few places worldwide (Tang et al., 2009; Adon et al., 2010). Encouragingly, recent developments in satellite-based infrared spectroscopy to map $\mathrm{NH}_{3}$ concentrations (Clarisse et al., 2009; Shephard et al., 2011; R'Honi et al., 2012) suggest that the monitoring of $\mathrm{NH}_{3}$ from space will help validate large-scale atmospheric models and refine current modelled estimates of regional and global $\mathrm{NH}_{3}$ emissions.

Advances in instrumentation, flux measurements and process understanding since the early 1980s have allowed the atmospheric pollution modelling community to move from a unidirectional paradigm for $\mathrm{NH}_{3}$ (fixed discrete point sources versus diffuse dry deposition everywhere else), to a dynamic bi-directional view, in which sources and sinks alternate in space and time depending on weather, pollution climate and agricultural management (Sutton et al., 2013). The major mechanisms and controls of $\mathrm{NH}_{3}$ exchange have been identified at the substrate, plant, and ecosystem scales, even if there remain substantial gaps in knowledge, but the methodologies and models currently used to estimate emissions and deposition at landscape and regional scales have not all reached comparable levels of complexity. This is only partly due to computational limits (CPU time), as the very 
detailed processes operating at very short timescales might become prohibitive when run over regional and multi-annual scales. More likely, however, it is often a consequence of the lack of fine resolution, detailed input data required to run the schemes, compounded by the difficulty of turning largely heterogeneous measurement (flux) datasets into a generalised, unified and self-consistent modelling theory.

\subsection{Scope of the review}

The state of the art of $\mathrm{NH}_{3}$ surface/atmosphere exchange (measurement and modelling) has been examined in a number of reviews, e.g. Sutton et al. (1993c, 1995b), Asman et al. (1998), Nemitz et al. (2001a), Hertel et al. (2006, 2012), Loubet et al. (2009a), van Pul et al. (2009), Sutton et al. (2007), Fowler et al. (2009), Wu et al. (2009), Massad et al. (2010b), Zhang et al. (2010), Sutton et al. (2013). The present contribution seeks to bring together the most recent advances in measurements, understanding and modelling of surface/atmosphere $\mathrm{NH}_{3}$ exchange over the vegetated land area, including the application of fertilizers, manures and slurry to farmland. Note that although $\mathrm{NH}_{3}$ emissions from farmstead livestock housing and manure storage facilities represent around $20 \%$ (and biomass burning an additional $15 \%$ ) of total emissions globally (EDGAR, 2011), these will not be considered specifically. Similarly, sea/air exchange is not treated here, even though marine $\mathrm{NH}_{3}$ emissions can be substantial, e.g. $30 \mathrm{Gg} \mathrm{NH}_{3}-\mathrm{N} \mathrm{yr}^{-1}$ over the EMEP grid area (Barrett, 1998).

The present paper focuses on bi-directional $\mathrm{NH}_{3}$ exchange over vegetation and soils in both (semi)-natural vegetation and agricultural systems, as well as uni-directional exchange (emission) fluxes from land-applied mineral $\mathrm{N}$ fertilizers and manures. A brief overview is first given of the meteorological, thermodynamic, chemical and biological processes controlling $\mathrm{NH}_{3}$ emission and uptake at the substrate, plant and ecosystem levels. Existing models of surface exchange are examined at the different scales from the leaf to the globe, with an emphasis on the development of canopy-scale models and their implementation at larger scales (landscape, regional). Although the conceptualization of a model and its parameterization (the calibration of its parameters based on observations) are quite different things, in the surface exchange literature the two terms have sometimes been used interchangeably. The ultimate objective of this work is to integrate current knowledge into a common modelling framework adapted for local, regional and global scale models, and to examine the degree to which measurement and input data are available, or missing, in order to parameterize, and ultimately run, surface/atmosphere exchange models at the different scales.

\section{Processes controlling $\mathrm{NH}_{3}$ emission and uptake in the soil/plant/atmosphere continuum}

\subsection{Thermodynamic and chemical controls}

At the level of each potential $\mathrm{NH}_{3}$ source or sink in the soil/vegetation system (apoplast, leaf cuticle, surface water films, leaf litter, soil solution, fertilizer pellets, applied manure), the gaseous $\mathrm{NH}_{3}$ concentration $\left(\mathrm{NH}_{3, \mathrm{~g}}\right)$ in equilibrium with dissolved $\left[\mathrm{NH}_{3, \text { aq }}\right]$ and $\left[\mathrm{NH}_{4}^{+}\right]$is governed by Henry's law $\left(K_{\mathrm{h}}\right)$ and the $\mathrm{NH}_{3}$ protonation constant $\left(K_{\mathrm{a}}\right)$ (Seinfeld and Pandis, 2006; see Montes et al., 2009, for a review of $K_{\mathrm{a}}$ and $\mathrm{K}_{\mathrm{h}}$ parameterizations, and Fig. 1a, b). In the context of the atmospheric exchange through stomata with the leaf apoplast, this equilibrium concentration has been called the compensation point, here denoted $\chi_{\mathrm{cp}}$; the net gaseous $\mathrm{NH}_{3}$ flux to or from the air surrounding the substrate then depends on the concentration difference $\chi_{\mathrm{cp}}-\chi_{\mathrm{a}}$, where $\chi_{\mathrm{a}}$ is the ambient $\mathrm{NH}_{3}$ concentration (Farquhar et al., 1980). This differential between surface and air concentrations can be applied for many substrates: if the concentration gradient is zero then there is no net exchange flux; if $\chi_{\mathrm{cp}}>\chi_{\mathrm{a}}$ then $\mathrm{NH}_{3}$ emission from the substrate occurs, while with $\chi_{\mathrm{cp}}<\chi_{\mathrm{a}}$ there is a net uptake by the substrate. By convention, a positive flux denotes $\mathrm{NH}_{3}$ emission, negative indicates deposition or uptake.

\subsubsection{Temperature effects and the $\Gamma$ ratio $\left(\left[\mathrm{NH}_{4}^{+}\right] /\left[\mathrm{H}^{+}\right]\right)$}

Thermodynamics dictate that any warming of the substrate, at constant substrate $\mathrm{pH}$, theoretically results in a displacement of dissolved $\mathrm{NH}_{3}$ to the gas phase, promoting $\mathrm{NH}_{3}$ emission or at least opposing uptake by the substrate from the air. The relationship of $\chi_{\mathrm{cp}}$ to temperature is exponential (Seinfeld and Pandis, 2006), with a warming of 4$5 \mathrm{~K}$ roughly translating into a doubling of the compensation point (Fig. 1c) for a given $\left[\mathrm{NH}_{4}^{+}\right] /\left[\mathrm{H}^{+}\right]$ratio in the liquid phase (Flechard and Fowler, 2008). The $\left[\mathrm{NH}_{4}^{+}\right] /\left[\mathrm{H}^{+}\right]$ratio is henceforth termed $\Gamma$ and characterises the $\mathrm{NH}_{3}$ emission potential, normalised for temperature. Measured values of $\Gamma$ have been shown to be vastly variable (up to 5 orders of magnitude difference) between various parts of plant canopies, e.g. leaf surface water, soil, litter, bulk leaf tissue and the apoplast, e.g. in grassland (Sutton et al., 2009b; Burkhardt et al, 2009) and in maize (Walker et al., 2013), but the different $\chi_{\mathrm{cp}}$ values all respond in the same way to temporal temperature changes as long as $\Gamma$ is constant.

In practice, it is clear that ecosystem $\mathrm{N}$ and $\mathrm{NH}_{4}^{+}$pools are ever changing and that $\Gamma$ values may undergo diurnal, seasonal and annual cycles in response to weather, phenology, senescence, etc, such that the theoretical temperature response with respect to $\mathrm{NH}_{3}$ fluxes is not necessarily verified in the long term. Modelling approaches based on the temperature response of a $\Gamma$ emission potential should therefore 

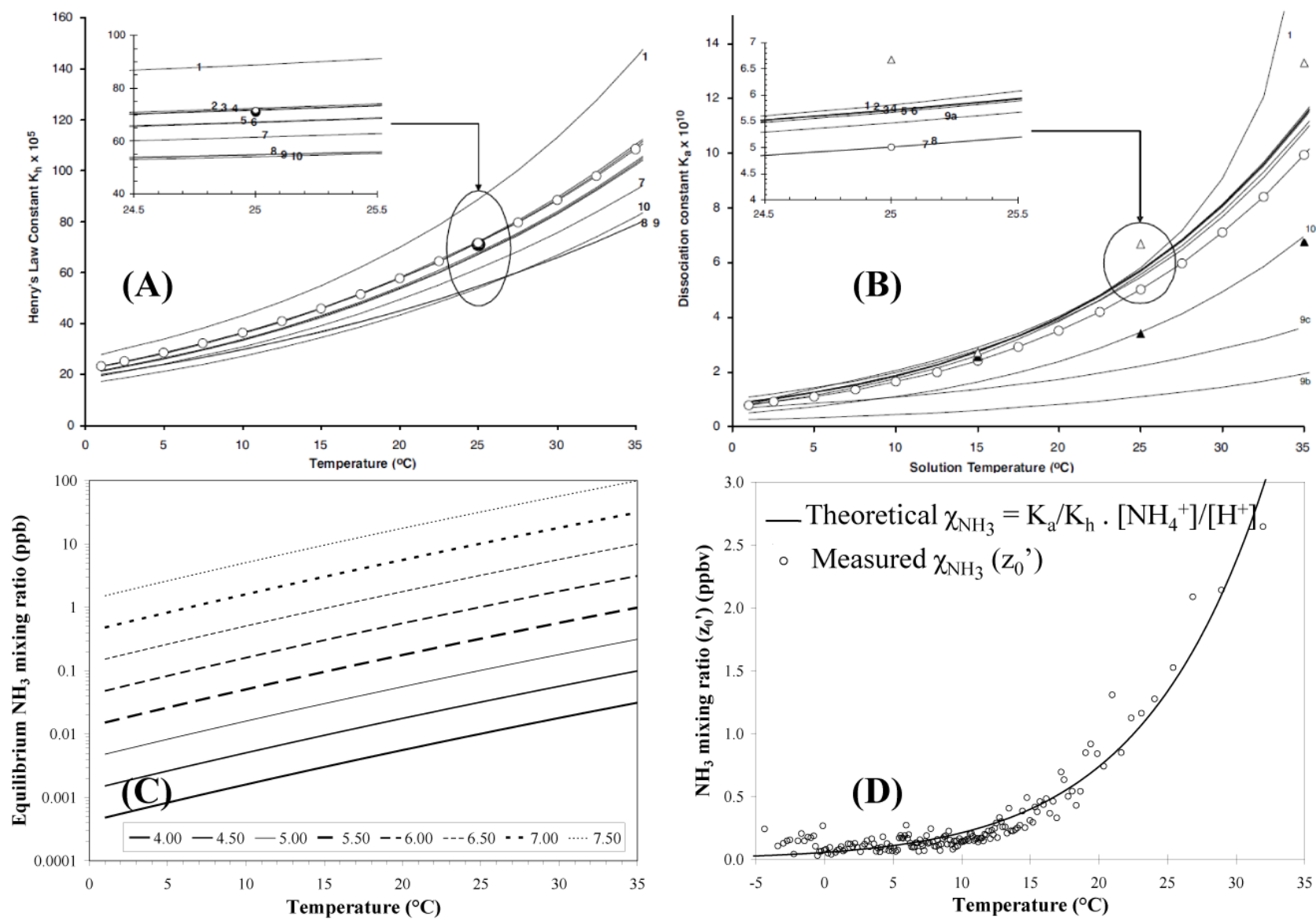

Fig. 1. Thermodynamic controls of the air/solution $\mathrm{NH}_{3} / \mathrm{NH}_{4}^{+}$partitioning. (A) and (B): compilation by Montes et al. (2009) of published values, parameterizations and temperature dependencies of Henry's law coefficients $\left(K_{\mathrm{h}}\right)$ and dissociation constants $\left(K_{\mathrm{a}}\right)$; the curve numbers refer to specific experiments cited in Montes et al. (2009), for solutions ranging from pure water to slurries and high activity solutions; (C): theoretical equilibrium air $\mathrm{NH}_{3}$ concentration of a $100 \mu \mathrm{M} \mathrm{NH}+$ solution as a function of temperature and showing the effect of $\mathrm{pH}$ in the range 4 to 7.5, calculated according to Sutton et al. (1994); (D): fitting of a theoretical thermodynamic curve to micrometeorologically measured surface $\mathrm{NH}_{3}\left(z_{0}{ }^{\circ}\right)$ concentrations over Scottish peatland, resulting in a best fit for the $\left[\mathrm{NH}_{4}^{+}\right] /\left[\mathrm{H}^{+}\right]$ratio $(\Gamma)$ of 132 for the moorland ecosystem (Flechard and Fowler, 1998b).

theoretically also deal with temporal $\Gamma$ dynamics in the various parts of an ecosystem.

In the atmosphere, the reversible equilibrium of the gas/aerosol $\mathrm{NH}_{3} / \mathrm{HNO}_{3} / \mathrm{NH}_{4} \mathrm{NO}_{3}$ triad is also temperature (and relative humidity, RH) sensitive (Mozurkewich, 1993), with likewise a displacement of aerosol-phase $\mathrm{NH}_{4}^{+}$and $\mathrm{NO}_{3}^{-}$towards gaseous $\mathrm{NH}_{3}$ and $\mathrm{HNO}_{3}$ in warmer (and drier) conditions. Depending on the relative mixing ratios of $\mathrm{NH}_{3}$, $\mathrm{HNO}_{3}$ and $\mathrm{NH}_{4} \mathrm{NO}_{3}$, and on temperature and $\mathrm{RH}$ in the air column within and just above vegetation, gas/particle interconversion may alter the net $\mathrm{NH}_{3}$ flux, as exchange velocities for gas-phase $\mathrm{NH}_{3}$ and aerosol-phase $\mathrm{NH}_{4}^{+}$are different (Brost et al., 1988; Nemitz et al., 2004; see Sect. 2.5).

\subsubsection{Surface/substrate $\mathrm{pH}$ and $\mathrm{acid} / \mathrm{base}$ ratio}

Substrate $\mathrm{pH}$ is also a major chemical control of $\mathrm{NH}_{3}$ fluxes; for a constant $\left[\mathrm{NH}_{4}^{+}\right]$in solution the compensation point increases by a factor of 3.2 for every additional $0.5 \mathrm{pH}$ unit, and by 10 for every $\mathrm{pH}$ unit (Fig. 1). Thus the wide range of $\mathrm{pH}$ values, and their temporal variations, typically encountered in plants and on other environmental surfaces, clearly show the importance of using accurate values in models of both emission from fertilizers and background bi-directional exchange. Apoplastic $\mathrm{pH}$ typically varies in the range 5-7 (Farquhar et al., 1980; Schjoerring et al., 1998; Hill et al., 2002; Massad et al., 2008), and a range of stress factors can induce temporal variations (Felle and Hanstein, 2002). The $\mathrm{pH}$ of the apoplast can increase by a few tenths of a unit in drought-stressed plants (Sharp and Davies, 2009), while both $\mathrm{NH}_{3}$ and $\mathrm{CO}_{2}$ can also alkalinize the apoplast (Hanstein and 
Felle, 1999; Felle and Hanstein, 2002). In grassland, Loubet et al. (2002) reported a sharp rise in apoplastic $\mathrm{pH}$ (from $\sim 6.5$ to $\sim 7.5$ ) as grazing animals were introduced to the pasture. Leaf age can be a factor; in perennial Luzula sylvat$i c a$, young leaves were found to have much higher apoplastic $\mathrm{pH}$ than old leaves, leading to 4 to 10 -fold higher $\mathrm{NH}_{3}$ compensation points (Hill et al., 2002).

On external leaf surfaces, the $\mathrm{pH}$ of rain and dew is typically acidic, in the range 3.5-6 (Burkhardt et al., 2009; Flechard et al, 1999), but alkaline conditions may also occur in plant surface wetness, resulting from the presence of soil particles (Sutton et al., 1993a; Walker et al., 2013). Also, instantaneous or chronic exposure to elevated $\mathrm{NH}_{3}$ levels is likely to raise surface $\mathrm{pH}$ and affect the magnitude of the surface exchange flux (Wu et al., 2009).

Jones et al. (2007) showed that the non-stomatal resistance $\left(R_{\mathrm{ns}}\right)$ of moorland plants to the uptake of atmospheric $\mathrm{NH}_{3}$ increased linearly with ambient $\mathrm{NH}_{3}$ concentration in the range $0-100 \mu \mathrm{g} \mathrm{m}^{-3}$. This indicates that at high ambient $\mathrm{NH}_{3}$ levels, the non-stomatal dry deposition process is self-limiting as the cuticle and other canopy surfaces may become $\mathrm{NH}_{3}$-saturated and a high $\mathrm{pH}$ strongly suppresses the effective $\mathrm{NH}_{3}$ solubility. Such situations occur typically in the vicinity of point sources such as animal production facilities (Loubet et al., 2009a), where ambient concentrations decrease exponentially with distance, from typically $>100 \mu \mathrm{g} \mathrm{m}^{-3}$ within the nearest $50 \mathrm{~m}$ of animal buildings and manure storage areas down to less than $10 \mu \mathrm{g} \mathrm{m}^{-3}$ within a kilometer (Walker et al., 2008).

The concurrent dry and wet deposition of acidic atmospheric gases and aerosols contributes to the regulation of plant surface $\mathrm{pH}$, and much depends on the prevailing pollution climate, the occurrence and duration of surface wetness, and the relative abundancies of $\mathrm{NH}_{3}$ (the major atmospheric base) and of atmospheric acids (Erisman and Wyers, 1993; Flechard et al., 1999). Thus plant surface (cuticle, wetness) $\mathrm{pH}$ is the main (if implicit) underlying mechanism that accounts for some parameterizations for non-stomatal resistance to $\mathrm{NH}_{3}$ deposition, developed in a range of publications (Erisman et al., 1994; Nemitz et al., 2001a; Massad et al., 2010b; Wichink Kruit et al., 2010), and based on the atmospheric molar ratios of $\mathrm{NH}_{3}$ to $\mathrm{SO}_{2}$ or $\mathrm{NH}_{3}$ to total acids $\left(\mathrm{SO}_{2}, \mathrm{HNO}_{3}, \mathrm{HCl}\right)$, as proxies of surface alkalinity/acidity.

For field applied manures, the $\mathrm{pH}$ of cattle and pig slurries is typically in the range 7.5-8, but values down to 6.3 and up to 9.0 have been reported (Sintermann et al., 2012). This, combined with the natural variability of soil $\mathrm{pH}$ across agricultural landscapes in which manures are applied to land, contributes to the large variability in fluxes and $\mathrm{NH}_{3}$ emission factors (EF) (Génermont and Cellier, 1997; Søgaard et al., 2002; Sommer et al., 2003; Sintermann et al., 2012). It should be noted that farmers typically monitor and manage soil $\mathrm{pH}$ to insure it is in an optimal range for the crop being produced and models should take this into account when estimating $\mathrm{NH}_{3}$ fluxes for agricultural crops.

\subsection{Meteorological controls}

Weather affects ecosystem/atmosphere $\mathrm{NH}_{3}$ exchange directly through the physical effects of wind speed, turbulence, global radiation, atmospheric stability and water (rainfall, dewfall, snowfall, evapotranspiration). The enhancement by wind speed and surface friction of $\mathrm{NH}_{3}$ volatilisation rates after slurry spreading or inorganic fertilizer application is well documented, with the effect being quantified by the aerodynamic resistance $\left(\mathrm{R}_{a}\right)$ to heat and trace gas transfer (Génermont and Cellier, 1997; Søgaard et al., 2002; Sommer et al., 2003). After slurry spreading, the radiative heating of the surface drives the evaporation of water from deposited manure and possibly the formation of a crust, which adds an additional surface resistance $\left(R_{\mathrm{c}}\right)$ to the aerodynamic $\left(R_{\mathrm{a}}\right)$ and the laminar boundary layer $\left(R_{\mathrm{b}}\right)$ resistances to emission (Sommer et al., 2003).

Unstable atmospheric conditions favour convective mixing and $\mathrm{NH}_{3}$ volatilisation, although they tend to co-occur with warm days with strong evaporation and high vapour pressure deficit (VPD), during which a slurry crust may form. Rainfall at the time of spreading tends to suppress $\mathrm{NH}_{3}$ emission by diluting thick slurry and facilitating infiltration into the soil, where $\mathrm{NH}_{4}^{+}$ions adsorb to sites of cation exchange; however, after a dry period rainfall may dissolve the dry slurry crust and solubilise $\mathrm{NH}_{4}^{+}$, which then becomes available for volatilisation. Similarly, short-lived $\mathrm{NH}_{3}$ emission pulses may be triggered by rainfall after dry weather spells, for example in agricultural soils amended with mineral fertilizer and up to several weeks following fertilization (Walker et al., 2013), or in natural alkaline soils in arid environments, such as, e.g. the Mojave Desert (McCalley and Sparks, 2008).

The same meteorological drivers similarly impact patterns of background and bi-directional exchange. Large wind speeds and unstable conditions reduce $\mathrm{R}_{a}$ and thus tend to increase emissions from the canopy (upward fluxes) as well as dry deposition (downward fluxes). However, large wind speeds also increase $\mathrm{NH}_{3}$ dispersion (Loubet et al., 2009a) and thus tend to reduce ambient $\mathrm{NH}_{3}$ concentration levels close to point sources (Flechard and Fowler, 1998a), such that, although the exchange velocity is higher (higher turbulence, lower $\mathrm{R}_{a}$ ), the dry deposition flux may not be greater (Flechard and Fowler, 1998b).

\section{Leaf surface wetness}

The control by rainfall and dewfall is more straightforward, with leaf-surface water generally acting as a more efficient sink for highly water-soluble $\mathrm{NH}_{3}$ than does a dry cuticle, and water droplets also physically blocking stomatal apertures (Zhang et al., 2003), all favouring dry deposition and limiting emission by the ecosystem. Water droplets, and also thin water films formed by deliquescent particles on leaf surfaces (Burkhardt and Eiden, 1994), are often acidic and increase the affinity and sink potential of the canopy for 
atmospheric $\mathrm{NH}_{3}$ (Flechard and Fowler, 1998b), as well as for $\mathrm{NH}_{3}$ emitted by the underlying soil and leaf litter (Nemitz et al., 2000a). Burkhardt and Eiden (1994) also describe a "wick" effect of microscopic water films, by which the migration of $\mathrm{NH}_{4}^{+}$ions between the apoplast and the external cuticle, along stomatal guard cell walls, is controlled by $\mathrm{pH}$ and $\mathrm{NH}_{4}^{+}$concentration gradients. Similarly, Sutton et al. (1995a) describe trans-cuticular fluxes of $\mathrm{NH}_{4}^{+}$between apoplast and leaf surface. Contrary to direct gaseous $\mathrm{NH}_{3}$ transfer through stomates, such liquid-phase mediated transfers are controlled by the presence of free water and are controlled by relative humidity and/or the hygroscopicity of particles at the surface, but they do contribute to the net canopyscale $\mathrm{NH}_{3}$ flux.

The succession of wet and dry meteorological phases, such as nocturnal/diurnal cycles of dew formation and evaporation, and brief showers followed by sunny spells, may lead to alternating patterns of $\mathrm{NH}_{3}$ uptake and re-emission from plant leaf surfaces. Cases of $\mathrm{NH}_{3}$ desorption from cuticles following leaf surface water evaporation have been reported (Sutton et al., 1995c, 1998a; Flechard et al., 1999; Neirynck and Ceulemans, 2008), demonstrating the reversibility of the non-stomatal uptake process. Further, recent $\mathrm{NH}_{3}$ flux measurements over maize, coupled with surface water $\mathrm{pH}$ observations and controlled experiments, suggest that wet leaf surfaces may actually occasionally provide a less efficient sink for $\mathrm{NH}_{3}$ than dry cuticles, as a result of trans-cuticular base cation leaching and the presence of alkaline soil particles, both raising the $\mathrm{pH}$ of surface wetness (Walker et al., 2013).

All the processes described above are dependent on prevailing meteorological conditions, with surface wetness being controlled by the ratio of rainfall to evapotranspiration (driven by atmospheric VPD, wind speed and net radiation), while soil particle emission (erosion) is governed by wind speed, soil dryness, as well as agricultural activities, e.g. tillage. Air, vegetation and soil temperatures control a host of plant physiological (Section 2.3), soil and microbiological processes (Sect. 2.4). Plant growth and root $\mathrm{NH}_{4}^{+}$ intake, microbial activity, ammonification (microbiological $\mathrm{NH}_{4}^{+}$fixation from $\mathrm{N}_{2}$ ), nitrification (microbiological oxidation of $\mathrm{NH}_{4}^{+}$into $\mathrm{NO}_{3}^{-}$), soil respiration (mineralisation of soil organic matter) and leaf litter decay, all generally increase with temperature (given adequate water and nutrient supply) and regulate the dynamics of ecosystem $\mathrm{NH}_{4}^{+}$pools and $\mathrm{NH}_{3}$ exchange fluxes.

\subsection{Plant physiological controls}

Vegetation may be a net source or a net sink for $\mathrm{NH}_{3}$, depending on the nitrogen status of plants and thus (indirectly) on the influx of nitrogen into the ecosystem, whether by fertilization of through atmospheric deposition (Massad et al., $2010 b$ ), providing a negative feedback where long-term $\mathrm{NH}_{3}$ deposition tends toward ecosystem saturation (Sutton et al., 1993c). The present section focuses on the physiological pa- rameters controlling the $\mathrm{NH}_{\mathrm{x}}$ status of the apoplast of green leaves (defined as the intercellular space where water and solutes can move freely), stems and inflorescences, and to some extent of senescing attached leaves.

\subsubsection{The stomatal compensation point}

Meyer (1973) was the first to recognize that $\mathrm{NH}_{3}$ is present (as $\mathrm{NH}_{3 \text {,aq }}$ and $\mathrm{NH}_{4}^{+}$) in intercellular fluids on the cell walls of the mesophyll cells of leaves (the apoplast), so that a compensation point air concentration of $\mathrm{NH}_{3}$ exists. This was later shown in measurements by Lemon and Van Houtte (1980) and most famously by Farquhar et al. (1980). Prior studies using dynamic chamber measurements had typically shown consistent uptake by plant leaves and a direct control by stomatal conductance (e.g. Hutchinson et al., 1972), but the $\mathrm{NH}_{3}$ concentrations applied to the chamber inlet were often much greater than typical ambient levels encountered in the field $\left(0.1-10 \mu \mathrm{g} \mathrm{m}^{-3}\right)$, and above the stomatal compensation point $\left(\chi_{\mathrm{s}}\right)$, precluding emissions from the apoplast. Since then, many controlled environment studies have shown linear relationships between ambient $\mathrm{NH}_{3}\left(\chi_{\mathrm{a}}\right)$ concentration and the $\mathrm{NH}_{3}$ flux, with a bi-directional exchange switching from an emission at low $\chi_{\mathrm{a}}$ levels to an uptake at higher $\chi_{\mathrm{a}}$ levels, the switch occurring at $\chi_{\mathrm{s}}$ (Sutton et al., 1995b; Husted et al., 1996; Schjoerring et al., 1998; Hill et al., 2001).

The stomatal compensation point is the equilibrium $\mathrm{NH}_{3}$ concentration associated with the $\left[\mathrm{NH}_{\mathrm{x}}\right]$ concentration in the apoplast, which results from the balance in healthy leaves of several production and consumption processes. These include: $\mathrm{NH}_{4}^{+}$import via the xylem; active (unidirectional) $\mathrm{NH}_{4}^{+}$transport into leaf cell cytoplasm and vacuole; passive (bi-directional) $\mathrm{NH}_{3}$ transport between apoplast and cells; $\mathrm{NH}_{4}^{+}$assimilation within the cytoplasm into amino acids via the glutamine synthetase/glutamate synthetase (GS/GOGAT) cycle; and $\mathrm{NH}_{4}^{+}$generation by, e.g. photorespiration, nitrate reduction, protein turnover and lignin biosynthesis (Joy, 1988; Schjoerring et al., 1998, 2002; Massad et al., 2008, 2010a). The experimental inhibition of GS by methionine sulfoximine in barley in the laboratory (Schjoerring et al., 1998), or the use of barley mutants with a reduced GS activity (Mattsson and Schjoerring, 1996), both lead to $\mathrm{NH}_{4}^{+}$accumulation in the apoplast and dramatic increases in stomatal $\mathrm{NH}_{3}$ emissions, demonstrating the critical role of GS (and GOGAT) in avoiding $\mathrm{NH}_{4}^{+}$accumulation in leaf tissues and regulating $\mathrm{NH}_{3}$ emission.

\subsubsection{Apoplastic pH}

It is worth noting that, as the stomatal compensation point is not simply a function of $\left[\mathrm{NH}_{4}^{+}\right]$in the apoplast, but rather a direct function of the $\left[\mathrm{NH}_{4}^{+}\right] /\left[\mathrm{H}^{+}\right]$ratio (or $\Gamma$ ) in the apoplast $\left(\Gamma_{\mathrm{s}}\right)$ (Sect. 2.1), $\chi_{\mathrm{s}}$ increases exponentially with $\mathrm{pH}$. Any internal physiological regulation of apoplastic $\left[\mathrm{H}^{+}\right]$ 
that does not have a commensurate effect on $\left[\mathrm{NH}_{4}^{+}\right]$therefore systematically affects $\chi_{\mathrm{s}}$ and the stomatal $\mathrm{NH}_{3}$ flux. Unlike intracellular $\mathrm{pH}$, which must be maintained within a narrow range (7.2-7.5) to allow all plant metabolic functions to proceed, apoplastic $\mathrm{pH}$ is rather variable due to a fairly low passive buffer capacity (Felle and Hanstein, 2002). The necessary regulation of intracellular $\mathrm{pH}$ is responsible for proton transfers across the cytoplasmic membrane, leading to apoplastic $\mathrm{pH}$ changes (Massad et al., 2008). In addition, plant responses to environmental stress factors such as drought have also been shown to affect apoplastic pH (Felle and Hanstein, 2002; Sharp and Davies, 2009), as do variations in ambient soluble trace gas $\left(\mathrm{NH}_{3}, \mathrm{CO}_{2}\right)$ concentrations (Hanstein and Felle 1999). Thus small fluctuations in membrane transport, gas exchange (stomatal conductance) and intercellular mass exchange impact apoplastic $\mathrm{pH}$ (Felle and Hanstein, 2002). Apoplastic $\mathrm{pH}$ is also believed to be influenced by $\mathrm{N}$ nutrition (Raven, 1988), even if the effect is unclear (Massad et al., 2008). Plant species relying on $\mathrm{NO}_{3}^{-}$ nutrition and assumed to assimilate $\mathrm{NO}_{3}^{-}$in the shoots tend to have higher apoplastic $\mathrm{pH}$, while vegetation relying on mixed $\mathrm{N}$ sources $\left(\mathrm{NH}_{4}^{+}, \mathrm{NO}_{3}^{-}\right.$, organic $\left.\mathrm{N}\right)$ and more likely to favour root assimilation tend to exhibit lower apoplastic $\mathrm{pH}$ values (Hoffmann et al., 1992).

\subsubsection{Plant nitrogen nutrition}

Plant nitrogen uptake and status, development stage and species all affect $\Gamma_{\mathrm{s}}$, resulting in diurnal and seasonal fluctuations at the ecosystem scale (Schjoerring et al., 1998; Massad et al., 2008, 2010b). The form of inorganic nitrogen (either $\mathrm{NH}_{4}^{+}$or $\mathrm{NO}_{3}^{-}$) being taken up by roots has been shown to impact stomatal $\mathrm{NH}_{3}$ emission significantly, with emissions from $\mathrm{NH}_{4}^{+}$-fed barley being a factor 10 higher than those from $\mathrm{NO}_{3}^{-}$-fed plants, consistent with higher leaf tissue $\left[\mathrm{NH}_{4}^{+}\right]$and higher xylem $\mathrm{NH}_{4}^{+}$concentration, given equivalent $\mathrm{N}$ contents of the nutrient solution (Mattsson and Schjoerring, 1996).

Such effects of $\mathrm{N}$ form may have consequences for spatial distributions of $\Gamma_{\mathrm{s}}$ values across landscapes, since wellaerated agricultural soils are generally $\mathrm{NO}_{3}^{-}$-rich and $\mathrm{NH}_{4}^{+}$poor, while in permanent grasslands, heathlands and mature forests the opposite situation prevails (Schjoerring et al., 1998). Even though it is often assumed that all $\mathrm{NH}_{4}^{+}$is assimilated in the roots prior to transport to the shoots as amino acids, some studies have shown that at least a fraction of $\mathrm{NH}_{4}^{+}$might be transported prior to assimilation (Massad et al., 2008). By contrast, upon absorption by roots, $\mathrm{NO}_{3}^{-}$ can either be reduced to $\mathrm{NH}_{4}^{+}$in root cells, stored in root cell vacuoles, exported via the xylem to the leaves or expelled to the outside of the root. Thus the $\mathrm{NH}_{4}^{+}$abundance in xylem and in the apoplast of leaves depends both on the soil $\left[\mathrm{NH}_{4}^{+}\right] /\left[\mathrm{NO}_{3}^{-}\right]$ratio and on the balance of root assimilation, transport and storage in roots. Further, although $\Gamma_{\mathrm{s}}$ generally increases with increasing $\mathrm{N}$ supply (Mattsson and Schjoerring, 1996), and preferentially with $\mathrm{NH}_{4}^{+}$supply to the roots for several plant species, the relationship between the amount of $\mathrm{N}$ absorbed by the roots and the compensation point is not straightforward because of a possible masking effect due to apoplastic $\mathrm{pH}$ change (Mattsson and Schjoerring, 2002; Massad et al., 2008).

High concentrations of $\mathrm{N}$ and $\mathrm{NH}_{4}^{+}$in bulk leaf tissues are expected to result in high $\Gamma_{\mathrm{s}}$ values (Schjoerring et al., 1998). Mattson et al. (2009a) measured apoplastic $\mathrm{pH}$ and $\mathrm{NH}_{4}^{+}$ concentrations of the eight most abundant graminae species of a fertilized grass sward in N. Germany, using the apoplastic extraction by vaccuum infiltration technique (Husted and Schjoerring, 1995). This direct method for the determination of $\Gamma_{\mathrm{S}}$ is based on the measurement of the leaf apoplastic $\mathrm{NH}_{4}^{+}$ concentration and $\mathrm{pH}$ by means of extraction with successive infiltration and centrifugation of leaf segments (Husted and Schjoerring, 1995). The measured apoplastic $\mathrm{NH}_{4}^{+}$concentrations differed by almost one order of magnitude between species, while apoplastic $\mathrm{pH}$ values also varied from 6.0 to 6.9. The resulting $\Gamma_{\mathrm{s}}$ values ranged from about 30 to over 700 and correlated very strongly (linearly) to bulk leaf $\left[\mathrm{NH}_{4}^{+}\right]$, with the consequence that three out of eight grass species with the highest stomatal compensation points could behave as $\mathrm{NH}_{3}$ sources, while the remaining five species were consistent sinks throughout the 3 week measurement campaign. Such variations in stomatal $\mathrm{NH}_{3}$ emission potentials among species within the same habitat demonstrate the challenge of modelling the exchange at the ecosystem scale.

Massad et al. (2010b) compiled 60 published values of $\Gamma_{\mathrm{s}}$ for non-managed (non-fertilized) ecosystem types including forests, heathlands and moorlands (average 502, range 3-5604), and 96 published $\Gamma_{\mathrm{s}}$ values for managed systems including croplands, and fertilized and/or grazed grasslands (average 782, range 16-5233). In addition to data obtained using the vaccuum infiltration technique, the data included estimates by cuvette-based controlled experiments and by field-scale micrometeorological flux measurements. Massad et al. (2010b) concluded that the key driver of $\Gamma_{\mathrm{s}}$ appears to be the total $\mathrm{N}$ input to the ecosystem (whether by fertilization, atmospheric deposition, or both), and that $\Gamma_{\mathrm{s}}$ values were positively and exponentially related to bulk tissue $\left[\mathrm{NH}_{4}^{+}\right]$. Fertilized agricultural ecosystems generally show higher $\Gamma_{\mathrm{s}}$ values than semi-natural vegetation, although very large $\Gamma_{\mathrm{s}}$ values were also reported for example over polluted forest sites in the Netherlands and Belgium, which have been subjected to high nitrogen deposition loads for decades (Neirynck and Ceulemans, 2008; Wyers and Erisman, 1998).

\subsubsection{Temporal variations}

The apoplastic $\Gamma_{\mathrm{s}}$ ratio undergoes temporal variations on seasonal (Fig. 2) and diurnal timescales. Seasonal variations are expected to occur since the assimilation, transport and turnover of nitrogen change dramatically with plant 

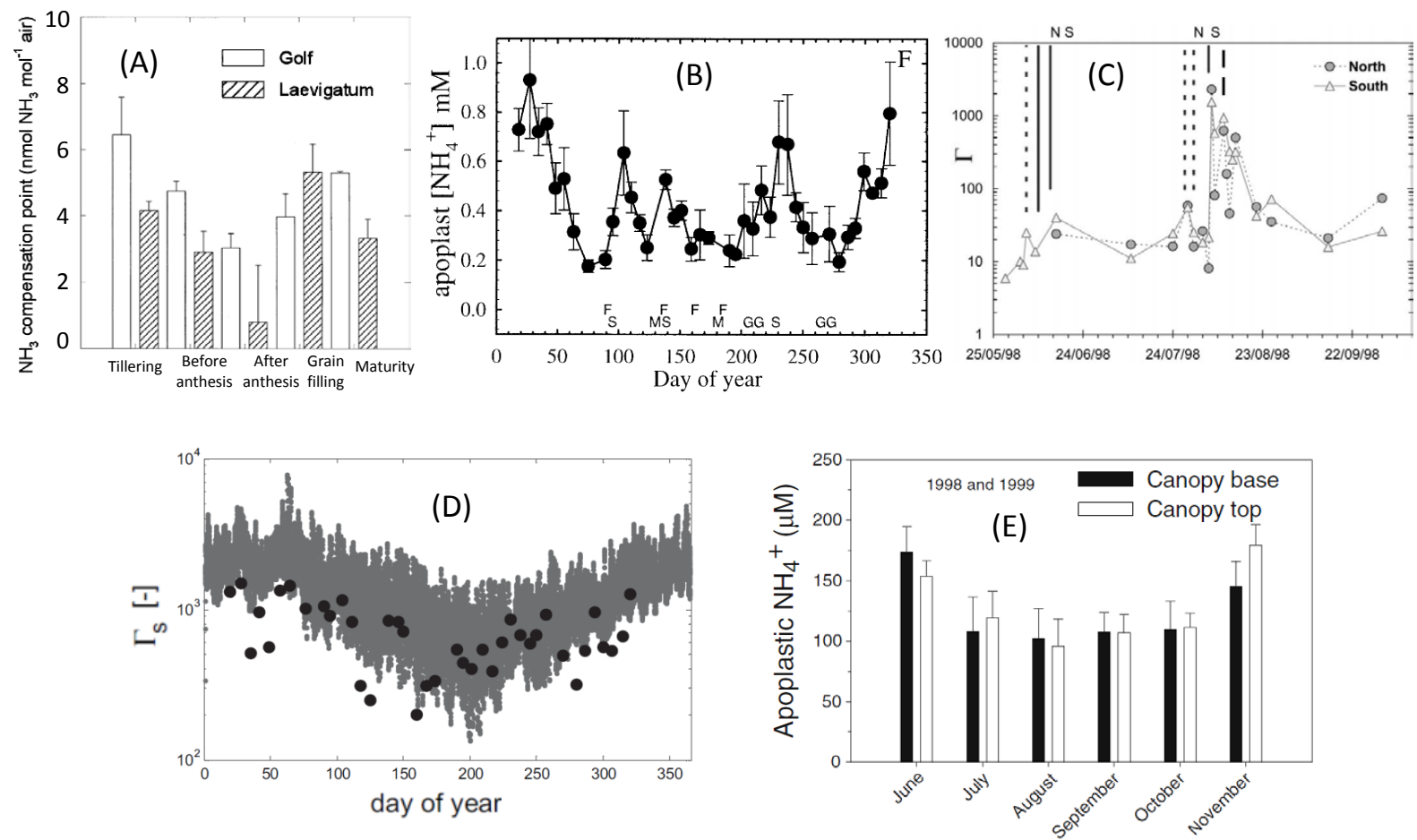

Fig. 2. Seasonal variations of: (A) stomatal compensation point in Hordeum vulgare (Husted et al., 1996); (B) apoplastic [NH $\left.{ }_{4}^{+}\right]$in fertilized and grazed Lolium perenne grassland (van Hove et al., 2002); (C) apoplastic $\Gamma_{\mathrm{s}}$ in fertilized and grazed Lolium perenne grassland in two adjacent fields (North and South) (Loubet et al., 2002); (D) apoplastic $\Gamma_{\mathrm{s}}$ in Lolium perenne / Poa trivialis grassland (Wichink Kruit et al., 2010); and (E) apoplastic $\left[\mathrm{NH}_{4}^{+}\right]$in Fagus sylvatica (Wang et al., 2011). In (B), F and S indicate application of artificial fertilizer (calcium nitrate) and slurry, respectively; $\mathrm{M}$ mowing and $\mathrm{G}$ grazing by cows. In (C), vertical lines indicate management events: dotted lines = cut; bold line $=$ fertilization; bold dashed lines $=$ grazing. The $\Gamma$ symbol represents the ratio $\left[\mathrm{NH}_{4}^{+}\right] /\left[\mathrm{H}^{+}\right]$.

developmental stage, and the seasonal $\mathrm{NH}_{3}$ exchange pattern may vary for different types of vegetation depending on which processes dominate the actual $\mathrm{N}$ utilization (Schjoerring et al., 1998).

In two barley (Hordeum vulgare) cultivars grown in hydroponics, Husted et al. (1996) showed a marked decrease in the $\mathrm{NH}_{3}$ stomatal compensation point in the period from tillering to anthesis, followed by an increase during senescence. In a fertilized ryegrass (Lolium perenne) pasture, van Hove et al. (2002) found that mean spring and summer apoplastic $\left[\mathrm{NH}_{4}^{+}\right]$were a factor $2-3$ lower than in autumn and winter, but no distinct trend for apoplastic pH. Similarly, in a beech (Fagus sylvatica) forest, Wang et al. (2011) measured a gradual decrease of $\Gamma_{\mathrm{s}}$ from leaf expansion (June) $\left(\Gamma_{\mathrm{s}}>150\right)$ until the mid-season (August) $\left(\Gamma_{\mathrm{s}}<100\right)$, followed by an increase during late season and approaching senescence $\left(\Gamma_{\mathrm{s}}>170\right)$. Consequently, during the two (early season and late season) $\Gamma_{\mathrm{s}}$ peaks, the leaves could act as an $\mathrm{NH}_{3}$ source, while during the mid-season stomatal uptake prevailed. The authors concluded that a low glutamine synthetase activity in young, emerging beech leaves as well as in senescent leaves and hence, a low capacity for $\mathrm{NH}_{4}^{+}$ assimilation, resulted in increased concentrations of tissue and apoplastic $\mathrm{NH}_{4}^{+}$. Cellular breakdown during senescence and the associated catabolism of proteins, amino acids and chlorophyll liberates large amounts of $\mathrm{NH}_{4}^{+}$, which is no longer assimilated and raises the $\mathrm{NH}_{3}$ emission potential of plants, even before leaves drop to the litter on the ground surface (Mattsson and Schjoerring, 2003). Age-related differences in the $\mathrm{NH}_{3}$ compensation point of Luzula sylvatica were also found to be considerable (Hill et al., 2002), with both apoplastic $\mathrm{pH}$ and $\mathrm{NH}_{4}^{+}$concentrations increasing during leaf expansion and declining prior to senescence.

Diurnal patterns of $\Gamma_{\mathrm{s}}$ are generally less systematic than seasonal ones, even if there can be a large degree of hour-tohour variability (Sutton et al., 2000; Herrmann et al., 2009; Flechard et al., 2010). Although diurnal cyles of $\mathrm{NH}_{3}$ exchange fluxes have been observed in e.g. Brassica napus (Husted et al., 2000), Hordeum vulgare (Schjoerring et al., 1993) and tropical grassland (Trebs et al. 2006), with highest $\mathrm{NH}_{3}$ emission rates typically occurring during the daytime and low rates at night, much of the observed diurnal variability in fluxes may be attributed to the temperature effect rather than to $\Gamma_{\mathrm{s}}$ (Sutton et al., 2000; Personne et al., 2009). Reported diurnal variations in apoplastic $\mathrm{NH}_{4}^{+}$and $\mathrm{H}^{+}$concentrations often do not follow any particular trend (Husted 
et al., 2000; van Hove et al., 2002), even if some observations in a mixed graminae sward did tend to indicate higher $\Gamma_{\mathrm{s}}$ values during the day than at night (Herrmann et al., 2009), especially after the grass was cut and fertilized.

\subsubsection{Fertilization effects on the apoplastic emission potential}

Agricultural management (fertilization, animal grazing, grass cutting) is another source of temporal variability for $\Gamma_{\mathrm{s}}$. A number of studies have shown that, in managed agricultural systems, field fertilizer application results in a $\Gamma_{\mathrm{s}}$ peak during the days following the application and usually a return to the pre-fertilization value within one to two weeks. Mattsson and Schjoerring (2002) demonstrate that leaf apoplastic $\mathrm{NH}_{4}^{+}$is a highly dynamic pool, closely reflecting changes in the external (e.g. root) $\mathrm{N}$ supply. In fertilized Lolium perenne grassland, Loubet et al. (2002) measured an increase in both apoplastic $\left[\mathrm{NH}_{4}^{+}\right]$and $\Gamma_{\mathrm{S}}$ by up to two orders of magnitude immediately following the application of ammonium nitrate fertilizer, but the effect was short-lived, lasting only two weeks (Fig. 2). Mattsson et al. (2009b) also observed a sharp (factor 10) increase in the apoplastic $\mathrm{NH}_{4}^{+}$concentration of newly emerging leaves after cutting and fertilization of mixed grassland, whereby the $\mathrm{NH}_{3}$ compensation point peaked the day after the fertilizer was applied and thereafter decreased over the following 10 days until reaching the same level as before fertilization. Smaller increases in $\Gamma_{\mathrm{s}}$ associated with grass cuts and grazing have also been reported (Milford et al., 2001b; van Hove et al., 2002; Loubet et al., 2002; Wang and Schjoerring, 2012).

\subsubsection{Stomatal conductance}

Another major physiological control of $\mathrm{NH}_{3}$ exchange fluxes at the leaf and plant level is the regulation of stomatal opening and conductance, through which the gaseous exchange between the sub-stomatal cavity and the atmosphere is mediated. Stomatal conductance $\left(G_{\mathrm{s}}\right)$ has long been known to be controlled by global radiation $\left(R_{\mathrm{g}}\right)$ or photosynthetically active radiation (PAR), air temperature $\left(T_{\mathrm{a}}\right)$, vapour pressure deficit (VPD), and soil water content (SWC) (Jarvis et al., 1976; Emberson et al., 2000a, b). Heat and drought stress cause stomata to close during the daytime, reducing $G_{\mathrm{s}}$, evapotranspiration, $\mathrm{CO}_{2}$ assimilation and the stomata/atmosphere transfer of trace gases including $\mathrm{NH}_{3}$. For example, $\mathrm{NH}_{3}$ flux measurements over soybean during dry summer conditions showed much suppressed stomatal exchange fluxes, and the bulk of the exchange dominated by non-stomatal fluxes, due to limited soil water availability and drought affecting stomatal opening during the afternoon (Walker et al., 2006). Those authors pondered whether their results were representative of soybean within their study area, but it should be stressed that such measurements are extremely valuable to characterize $\mathrm{NH}_{3}$ exchange in dry con- ditions and regions of the world, since a large majority of existing field $\mathrm{NH}_{3}$ flux datasets are representative of reasonably well-watered conditions in temperate climates.

Further, research over the past 20-30 yr has shown the impact of rising $\mathrm{CO}_{2}$ (Ainsworth and Rogers, 2007) and $\mathrm{O}_{3}$ (Wittig et al., 2007) concentrations on stomatal conductance, with expected reductions of $G_{\mathrm{S}}$ of the order of $-20 \%$ to $-30 \%$ for elevated $\mathrm{CO}_{2}$ and $-10 \%$ to $-20 \%$ for elevated $\mathrm{O}_{3}$. Within the context of global change, such impacts on $G_{\mathrm{s}}$ should be accounted for when considering present and future scenarios of $\mathrm{NH}_{3}$ exchange.

\subsection{Soil and microbial processes}

Many processes within the soil profile and on the soil surface lead to an $\mathrm{NH}_{4}^{+}$pool being present and available for exchange with the air column above the ground. Within the topsoil and particularly the root zone of any land ecosystem, the $\mathrm{NH}_{4}^{+}$pool is depleted by root absorption, by nitrification, by microbial immobilization, and by emission to the atmosphere; it is replenished by atmospheric deposition, by symbiotic $\mathrm{N}_{2}$ fixation (BNF) and ammonification, by microbial turnover, by mineralization of soil organic matter (SOM) and of $\mathrm{N}$-containing root exudates, and by the decay of leaf litter on the ground surface. Adsorption and binding to negatively charged clay mineral and organic colloids represent a transient pool, while dilution and infiltration through the deeper soil layers decrease the emission potential. In addition, in fertilized agricultural systems, the large and sporadic inputs of mineral and organic forms of $\mathrm{N}$ lead to sudden increases in available $\mathrm{N}$ and particularly $\mathrm{NH}_{4}^{+}$, often well in excess of the instantaneous plant and microbial demand. In keeping with the $\Gamma_{\mathrm{s}}$ terminology adopted for the apoplastic $\left[\mathrm{NH}_{4}^{+}\right] /\left[\mathrm{H}^{+}\right]$ratio, corresponding terms may be defined for the topsoil layer $\left(\Gamma_{\text {soil }}\right)$, for the leaf litter $\left(\Gamma_{\text {litter }}\right)$, or collectively a ground layer term $\left(\Gamma_{\mathrm{g}}\right)$. Figure 3 illustrates how typical values measured for $\Gamma_{\text {soil }}$ and $\Gamma_{\text {litter }}$ far outweigh (by 2-3 orders of magnitude) $\Gamma_{\mathrm{s}}$ values in fertilized cut grassland, especially during the days following the application of fertilizer.

\subsubsection{Soil background emission potential}

Ammonium and ammonia are naturally present in soils as a product of microbial turnover and soil organic matter mineralisation, while fertilization (mineral and organic) as well as grazing in grasslands both supply large quantities of reduced $\mathrm{N}$ to agricultural soils. However, soil $\mathrm{NH}_{4}^{+}$is depleted by root uptake during the growing season, and by nitrification in well-aerated soils, while the soil $\mathrm{NH}_{3}$ emission potential $\left(\Gamma_{\text {soil }}\right)$ also largely depends on soil $\mathrm{pH}$. One of the earliest studies on this effect made regional scale estimates of ammonia emission from soils based on mineralization rates, although at that time field verification of the modelled fluxes were missing (Dawson, 1977). 


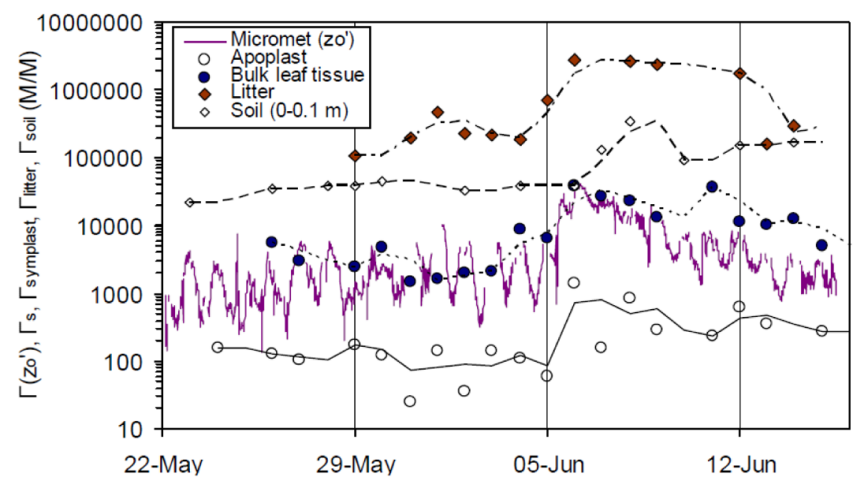

Fig. 3. Time course of estimated $\Gamma$ values (ratio of $\left[\mathrm{NH}_{4}^{+}\right] /\left[\mathrm{H}^{+}\right]$) in different compartments of a mixed grassland ecosystem (from Sutton et al., 2009b). The grass was cut on 29 May and lifted for silage on 31 May. Fertilizer $\left(100 \mathrm{~kg} \mathrm{~N} \mathrm{ha}^{-1}\right.$ as calcium ammonium nitrate) was applied on 5 June.

In a more recent study over grassland, David et al. (2009) also identified the underlying soil as a strong potential source, but only after the grass was cut and for a short period of time ( $\sim 1$ day), and even then the soil potential emission was a factor of 3 lower than that of the leaf litter. However, few publications have ever shown soil below vegetation to be an ammonia source, be it below a grassland canopy in summer (Sutton et al., 1993b), under barley (Schjoerring et al., 1993), or oilseed rape (Nemitz et al., 2000a).

Neftel et al. (1998) actually suggested that soil must be a sink for $\mathrm{NH}_{3}$ in a triticale field, since their semi-permeable membrane setup for direct measurements of $\mathrm{NH}_{3}$ concentration in the soil showed consistently low $\left(<0.1 \mu \mathrm{g} \mathrm{m}^{-3}\right)$ concentrations. This was despite large measured $\left[\mathrm{NH}_{4}^{+}\right]$values in soil $\mathrm{KCl}$ extracts, which, accounting for the soil $\mathrm{pH}$ of 6.5 , should have resulted in soil pore space $\mathrm{NH}_{3}$ concentrations 2 orders of magnitude higher than those measured. They concluded from this discrepancy that the largest part of the estimated ammonium content in the soil was not in the liquid phase, but was instead adsorbed to solid soil particles, and thus not available for gas exchange with open porosity and the atmosphere. Similarly, Nemitz et al. (2000a) measured much lower $\mathrm{NH}_{3}$ concentrations at a depth of $-0.1 \mathrm{~m}$ within the soil than just above the leaf litter of oilseed rape, ruling out the possibility that the underlying soil may have been an $\mathrm{NH}_{3}$ source in that study, and pointing to the importance of substantial $\mathrm{NH}_{3}$ gradients at the air-soil-litter interface. There are altogether few reports of soil emission potentials for vegetated canopies in the literature that clearly distinguish the soil emission potential and flux from those associated with the leaf litter or the whole canopy (see Massad et al., 2010b for a review).

\subsubsection{Soil emissions after fertilizer and manure application}

Ammonia emission from the soil layer is most important after fertilization, especially if the fertilizer is urea-based or organic manure (Génermont et al., 1998; Søgaard et al., 2002; Meyers et al., 2006; Sintermann et al., 2012). At the European scale, the land-spreading of organic manures is believed to contribute around $30-40 \%$ of total $\mathrm{NH}_{3}$ emissions (Sintermann et al., 2012, and references therein). Values of $\Gamma_{\text {soil }}$ typically increase by one or several orders of magnitude after slurry spreading (Flechard et al., 2010). Although Fig. 3 indicates that $\Gamma_{\text {litter }}$ was a factor of 10 higher than $\Gamma_{\text {soil }}$ in the grassland system in Sutton et al. (2009b), even after fertilization, this study dealt with mineral fertilizer, and the situation is quite different for organic manures. A dominant mechanism of $\mathrm{NH}_{3}$ loss to the atmosphere is the hydrolysis of urea and/or uric acid present in large quantities in animal wastes i.e. urine, slurries and farm yard manures, by the urease enzyme present in the excreted faeces and also in the soil. This leads to large concentrations of dissolved $\mathrm{NH}_{\mathrm{x}}$ and thus a high $\mathrm{pH}$, promoting $\mathrm{NH}_{3}$ volatilisation from the liquid phase. Urea hydrolysis also produces dissolved inorganic carbon, and the subsequent volatilisation of $\mathrm{CO}_{2}$ increases $\mathrm{pH}$, while $\mathrm{NH}_{3}$ volatilisation decreases $\mathrm{pH}$ and is in principle self-limiting.

Apart from meteorological effects (Sect. 2.2), the most important processes controlling $\mathrm{NH}_{3}$ volatilisation are the ion production and buffering processes controlling the $\mathrm{pH}$ of the slurry/soil liquid, the solid chemistry that determines precipitation of $\mathrm{NH}_{4}^{+}$to slurry dry matter, the physical processes controlling the movement of slurry liquid into and within the soil, the interaction of slurry liquid with soil cation exchange capacity (CEC) (Sommer et al., 2003; Genermont and Cellier, 1997). Note that the method of field application (splash plate, trailing hose, trailing shoe, soil injection) is also expected to make a difference, with "low emission" application techniques being promoted in a number of countries to abate field losses (Sintermann et al., 2012; Carozzi et al., 2013).

Soil $\mathrm{pH}$ is expected to be a critical parameter controlling the magnitude of the percentage loss of volatilised $\mathrm{NH}_{3}$ to the total $\mathrm{NH}_{\mathrm{x}}$ content of land-spread slurry, with emissions being effectively suppressed ( $<5 \%$ loss) at soil $\mathrm{pH} 5$ and potentially reaching over $50 \%$ at $\mathrm{pH} 7$ (Génermont and Cellier, 1997; Loubet et al., 2009a). However, in practice there remain questions regarding the extent to which soil $\mathrm{pH}$ influences $\mathrm{NH}_{3}$ losses from surface applied fertilizer and manures, as incomplete mixing may typically occur. Thus when and where soil $\mathrm{pH}$ affects the flux is a very complex question.

Soil microbial nitrification of the applied manure or fertilizer $\mathrm{NH}_{4}^{+}$depletes the $\mathrm{NH}_{\mathrm{x}}$ pool and thus may potentially limit the $\mathrm{NH}_{3}$ emission potential in the days following field spreading. Whether nitrification significantly reduces $\mathrm{NH}_{3}$ emission factors depends on nitrification rates, which have 
been shown to be extremely variable. For example Felber et al. (2012) measured very fast conversion of applied $\mathrm{NH}_{4}^{+}$ from cattle slurry to $\mathrm{NO}_{3}^{-}$in top soil $(0-10 \mathrm{~cm})$ of grassland, with most of the $\mathrm{NH}_{4}^{+}$being nitrified within 2 days. By contrast, Laubach et al. (2012) found that nitrification proceeded more slowly in grassland fertilized with cattle urine, as soil $\left[\mathrm{NH}_{4}^{+}\right]$only decreased by half over a week, although here soil $\left[\mathrm{NH}_{4}^{+}\right]$was roughly a factor of 50 higher than in the study by Felber et al. (2012). Such variability highlights the need to give nitrification proper consideration in models of $\mathrm{NH}_{3}$ volatilisation.

Emissions from synthetic fertilizers depend on the form of inorganic $\mathrm{N}$ applied but are typically smaller per unit added $\mathrm{N}$ than from manures. Emission from urea-based compounds are larger than from ammonium nitrate fertilizers, which do not raise soil solution $\mathrm{pH}$. The use of urease inhibitors has been shown to reduce and delay $\mathrm{NH}_{3}$ volatilisation from urea in a number of field trials, including in a fertilized maize field, in which Walker et al. (2013) detected two distinct emission pulses spread over one month.

Despite extensive trials with a large literature over the last $25 \mathrm{yr}$ and good fundamental understanding of $\mathrm{NH}_{3}$ losses from field-applied manures and fertilizers (e.g. Søgaard et al., 2002, and the Ammonia Loss from Field-applied Animal Manure (ALFAM) database), there remain substantial uncertainties in field-scale $\mathrm{NH}_{3}$ fluxes and the associated emission factors (EF). Sintermann et al. (2012) compiled and reviewed over $350 \mathrm{EF}$ measurements published between 1991 and 2011 and raised questions about the representativeness, and possible overestimation, of $\mathrm{NH}_{3}$ fluxes measured in mediumsized ( $20 \mathrm{~m}$ diameter) plots by mass balance methods such as the integrated horizontal flux (IHF) approach. The authors point out that emerging $\mathrm{NH}_{3}$ volatilisation flux measurements at the field ( $>1 \mathrm{ha}$ ) scale over the last 5-10 yr generally indicate much lower ( factor 2$) \mathrm{NH}_{3}$ losses, typically below $30 \%$ of slurry $\mathrm{NH}_{\mathrm{x}}$ content, than did many mediumsized plot measurements carried out in the early 1990s (typically $50-80 \%$ losses), with serious implications for local and regional scale $\mathrm{NH}_{3}$ budgets. A recent re-assessment by Neftel et al. (2013) of EF measurements made in Switzerland in the early 1990s, using the $z_{\text {inst }}$ (simplified IHF) method (Wilson et al., 1982), hinted that these early EF values may have been significantly overestimated due to a combination of at least three factors, all leading to a systematic overestimation: over-speeding of the cup anemometers near the ground, cross-interference of plots located at distances of $70 \mathrm{~m}$, and inadequate values of the $z_{\text {inst }}$ scaling factor. Such careful reanalyses of historical EF datasets from other countries might provide clues for the apparent discrepancies, or inconsistencies, reported in Sintermann et al. (2012).

\subsubsection{Emission potential of the leaf litter and influence of plant and ecosystem $\mathrm{N}$ cycling}

Apart from fertilizer-induced $\mathrm{NH}_{3}$ volatilisation, significant emissions may also occur from soil in barren land and in senescent plant canopies where leaf litter on the soil surface contributes to emissions (Sutton et al., 2009b; Massad et al., 2010b). Ammonia emissions from the leaf litter, even if understood in principle, remain very uncertain due to the limited number of studies (e.g. Denmead et al., 1976; Harper et al., 1987; Nemitz et al, 2000a; Mattsson and Schjoerring, 2003; David et al., 2009; Wang and Schjoerring, 2012). The literature generally indicates very large $\Gamma_{\text {litter values but }}$ their temporal dynamics are poorly understood. By contrast to mineralization rates of plant litter incorporated into soils (e.g. Nicolardot et al., 1995), little is known about processes within detached leaves lying on the ground surface. Schjoerring et al. (1998) argued that $\mathrm{NH}_{4}^{+}$production by mineralization and liberation in the leaf tissue are coupled to degradation of chlorophyll and of soluble proteins in detached senescent leaves; this is by contrast to senescing leaves that are still attached to the plant, which still have a relatively efficient $\mathrm{N}$ remobilisation and are able to avoid accumulation of correspondingly high $\mathrm{NH}_{4}^{+}$levels by transfer to other parts of the plant.

For the ground leaf litter, it has been assumed that $\left[\mathrm{NH}_{4}^{+}\right]$ is controlled by the litter water content, by mineralization and nitrification rates as well as the amount of $\left[\mathrm{NH}_{4}^{+}\right]$released to the atmosphere as $\mathrm{NH}_{3}$ (Nemitz et al, 2000a). The $\mathrm{NH}_{3}$ emission potential of the leaf litter $\left(\Gamma_{\text {litter }}\right)$ is first and foremost dependent on the initial bulk $\mathrm{N}$ content of senescent leaves as they become detached from the plant; N-rich leaves are obviouly more likely than $\mathrm{N}$-poor leaves to liberate large amounts of $\mathrm{NH}_{4}^{+}$via mineralisation on the ground. The nitrogen content of plant residues is controlled by contrasting processes in perennial woody species and in annual or biennial non-woody plants, as detailed hereafter.

\section{Role of translocation on the leaf litter nitrogen content of trees}

In trees, the litter $\mathrm{N}$ content is controlled by the ratio of ecosystem-internal $\mathrm{N}$ cycling (litter production, mineralisation, root uptake) to tree internal $\mathrm{N}$ cycling (assimilation, translocation, storage). These processes ensure that large amounts of $\mathrm{N}$ remain available to the plant and are moderately protected against immobilisation in stable soil organic compounds or losses via leaching and gaseous emission (Wang et al., 2013). The $\mathrm{N}$ status of attached senescing leaves is controlled by the degree to which $\mathrm{N}$ is retranslocated from such leaves into the rest of the tree before leaf fall. The re-translocation is directed either into woody roots and/or the trunks in deciduous species, or from previous years leaves into the youngest age class needles in conifers. The resulting reduction in foliar $\mathrm{N}$ content may be expressed 
as the fraction of $\mathrm{N}$ re-translocation relative to the initial $\mathrm{N}$ content in the green leaves.

Comparing three European forests subject to contrasting atmospheric $\mathrm{N}$ deposition loads, Wang et al. (2013) found that this $\mathrm{N}$ re-translocation efficiency was lowest in a Douglas fir stand (37\%) subject to very large $\left(45 \mathrm{~kg} \mathrm{~N} \mathrm{ha}^{-1} \mathrm{yr}^{-1}\right)$ $\mathrm{N}$ deposition, compared to a temperate beech forest (70\%) and a boreal pine stand (62\%) exposed to much lower $\mathrm{N}$ deposition (ca. 20 and $5 \mathrm{~kg} \mathrm{~N}$ ha- $1 \mathrm{yr}^{-1}$, respectively). The boreal pine site thus returned the lowest amount of $\mathrm{N}$ via foliage litter to the soil, while the temperate Douglas fir stand returned the highest amount of litter $\mathrm{N}$ to the ground. The authors concluded that forests activate very different mechanisms to reduce $\mathrm{N}$ losses in foliage litter production: (i) increased $\mathrm{N}$ re-translocation efficiency, (ii) increased leaf longevity, (iii) decreased foliage $\mathrm{N}$ content and and (iv) decreased foliage mass. Despite the lowest leaf longevity and highest leaf $\mathrm{N}$ contents, the beech canopy reduced the $\mathrm{N}$ losses via leaf litter production by having very efficient $\mathrm{N}$ re-translocation prior to leaf fall.

\section{Nitrogen content in leaf litter and other residues in crops and grassland}

Nitrogen re-allocation from ageing leaves to younger leaves, to growing seeds and to storage for the next growing season may also occur in annual and biennial non-woody plants, such as many agricultural crops, and in perennial grasslands (Wang and Schjoerring, 2012). However, in many cases all the non-harvested above-ground biomass eventually returns to soil, either as litterfall during the growing season, or after harvest. Thus the soil layer is the ultimate resting place for the non-harvested stem and foliar N, both from bottomcanopy senescent leaves dropping to litter during the growing season, as well as litterfall following complete senescence or harvest. In a ryegrass (Lolium perenne) grassland, Wang and Schjoerring (2012) found that green photosynthesizing leaves generally had the largest total $\mathrm{N}$ concentration, followed by stems and inflorescences. By contrast, the lowest total $\mathrm{N}$ content occurred in senescent leaves, indicative of $\mathrm{N}$ re-allocation. The situation was reversed for the bulk $\Gamma$ ratio (total leaf tissue $\left[\mathrm{NH}_{4}^{+}\right] /\left[\mathrm{H}^{+}\right]$), with green leaves and stems generally showing substantially lower $\Gamma$ values than senescent leaves and litter. Thus, although remobilization had reduced total $\mathrm{N}$ concentrations in senescent leaves and litter, mineralization of organic $\mathrm{N}$ compounds still lead to much higher bulk $\left[\mathrm{NH}_{4}^{+}\right]$values than in green leaves.

Many studies have observed large $\mathrm{NH}_{3}$ concentrations near the ground surface and litter in closed canopies (e.g. Denmead et al., 1976; Nemitz et al., 2000a), resulting from the production and accumulation of $\mathrm{NH}_{4}^{+}$by mineralisation of litter organic compounds. In mixed grassland, David et al. (2009) defined the litter as the sum of both senescing attached leaves and dead/decomposing detached leaves. By means of dynamic chamber measurements (cuvette), they found that emissions from the litter were the largest source in the canopy and that emissions were higher from wet than from dry litter. They also found that peak $\mathrm{NH}_{3}$ emissions from litter leaves occurred both after a step decrease and a step increase of air relative humidity, due to a change in either increased evaporation or increased mineralization. This was consistent with the findings within an oilseed rape canopy by Nemitz et al. (2000a), who demonstrated with a simple dynamic litter model that shrinking liquid pools within the leaf litter lead to more concentrated $\mathrm{NH}_{4}^{+}$pools and increased emissions. Here, measurements of withincanopy vertical $\mathrm{NH}_{3}$ concentration profiles, from a depth of $-0.1 \mathrm{~m}$ in the soil up to the top of the oilseed rape canopy $(1.4 \mathrm{~m})$, showed mean in-soil and top-canopy concentrations of the same order $\left(1-2 \mu \mathrm{g} \mathrm{m}^{-3}\right)$, but much higher concentrations $\left(\sim 9 \mu \mathrm{g} \mathrm{m}^{-3}\right)$ just above the leaf litter. This information, coupled with the inverse Lagrangian modelling technique (ILT) (Raupach, 1989) to determine the vertical distribution of $\mathrm{NH}_{3}$ concentration, sources and sinks within the canopy, demonstrated the existence of a large emission potential within decomposing litter leaves on the soil surface, which was consistent with previous studies (e.g. Denmead et al., 1976). However, in order to simulate diurnal variations of the measured $\mathrm{NH}_{3}$ concentration at the surface of the leaf litter $\left(\chi_{\text {litter }}\right)$, Nemitz et al. (2000a) needed to adopt a dynamic approach for $\Gamma_{\text {litter }}$. By contrast, using a constant $\Gamma_{\text {litter }}$ resulted in an overestimation of $\chi_{\text {litter }}$ at the start and an underestimation of $\chi_{\text {litter }}$ towards the end of the modelled period. This reflected the dynamics of the litter $\mathrm{NH}_{4}^{+}$pool, which could be shown in a simple dynamic model to be controlled by (a) mineralization and nitrification rates according to Dawson (1977) and (b) the response of the leaf water content to relative humidity $(\mathrm{RH})$, as proposed by van Hove and Adema (1996).

\subsection{Vertical distribution of sources and sinks within and above ecosystems}

The magnitude and direction (or sign) of the net vegetation/atmosphere $\mathrm{NH}_{3}$ flux are controlled by the difference between the ambient $\mathrm{NH}_{3}$ concentration $\left(\chi_{\mathrm{a}}\right)$ and the canopy compensation point, denoted $\chi_{\mathrm{c}}$ and introduced by Sutton et al. (1995b). The $\chi_{c}$ modelling concept (further developed in Sect. 3) reflects the fact that both $\mathrm{NH}_{3}$ emission and deposition may co-occur at different levels within a canopy or plant-soil system, with for example emissions by a leaf litter on the soil surface and by sunlit stomates in the upper part of the canopy, concurrent with deposition to wet nonstomatal leaf surfaces and also possibly uptake by cooler, shaded stomates in the lower part of the canopy (Sutton et al., 1995a; Nemitz et al., 2000a, b, 2001a; Personne et al., 2009). Given this multi-layered vertical distribution of sources and sinks and internal canopy cycling of $\mathrm{NH}_{3}, \chi_{\mathrm{c}}$ defines the net bulk, canopy-scale potential for emission or deposition when 
set against the atmospheric $\mathrm{NH}_{3}$ concentration $\chi_{\mathrm{a}}$ occurring overhead.

Micrometeorological $\mathrm{NH}_{3}$ flux measurements made above ecosystems provide estimates of the net exchange between the whole soil/litter/canopy system (including the withincanopy air space) and the free atmosphere. Such ecosystemscale measurements by themselves do not provide the sink and source contributions of the different canopy components (soil, litter, stomates, green leaves, senescing leaves, stems, inflorescences, non-stomatal (cuticular) surfaces, etc.) to the net exchange. Measurements using dynamic chamber may be used to isolate certain terms, such as individual leaves, soil or litter, but other terms such as the partitioning between stomatal and non-stomatal fluxes (Sutton et al., 1995a), or the air column sink/source term from gas-particle interconversion (GPIC) (Brost et al., 1988; Nemitz et al., 1996), can only be apprehended by using models. The ability to model the different canopy component flux terms quantitatively is crucial to determine the net canopy-scale flux (for e.g. regional-scale modelling), but it also provides insights into the $\mathrm{NH}_{3}$ canopy cycling and reveals potential feedbacks between total $\mathrm{N}$ inputs and the net $\mathrm{NH}_{3}$ flux (Sutton et al., 1995a).

The $\mathrm{NH}_{3}$ exchange literature shows many examples of vertical stratification of sources and sinks within soil-plants systems, and of widely varying $\mathrm{NH}_{3}$ emission potentials for canopy components. This is exemplified by the different $\Gamma$ ratios (Fig. 3) in grassland, ranging over 4-5 orders of magnitude (Sutton et al., 2009b), and by a similar picture in maize (Walker et al., 2013), which also included a $\Gamma$ term for leaf surface wetness (dew, guttation).

\subsubsection{Within-canopy vertical $\mathrm{NH}_{3}$ concentration profiles}

The vertical distribution of - and relationships between the various $\mathrm{NH}_{3}$ sources and sinks are influenced by canopy structure, leaf area index (LAI) and leaf area density profile, which control within-canopy turbulence as well as vertical profiles of wind speed, $\mathrm{NH}_{3}$, temperature and $\mathrm{RH}$. Ammonia profiles within cereal canopies have often shown the largest concentration at mid-canopy, at the height of the greatest leaf density (e.g. Meixner et al., 1996), which was consistent with the widely held assumption that, above cereal crops, $\mathrm{NH}_{3}$ emissions mostly originate from stomata (e.g. Farquhar et al., 1980). By contrast, in canopies of grass-clover pasture as well as soybeans, oilseed rape and quackgrass, withincanopy profiles showed the highest concentrations at ground level (Denmead et al., 1976; Lemon and van Houtte, 1980; Sutton et al., 1993b; Nemitz et al., 2000a, 2009a; Bash et al., 2010), which is generally attributed to leaf litter decomposition and $\mathrm{NH}_{3}$ emission from the soil. In the light of the latter studies, and especially given the much larger emission potentials associated with the soil and leaf litter than with the apoplast (Fig. 3), the role of stomatal emissions as a major control of the net canopy-scale flux must be re-examined.
Although the apoplast may, under certain circumstances, act as an $\mathrm{NH}_{3}$ source, this very much depends on the vertical position of leaves, which is correlated with their age, temperature, and their proximity to the free atmosphere or to the soil/litter layer.

\subsubsection{Recapture of soil/litter-emitted $\mathrm{NH}_{3}$ by the overlying canopy}

For agricultural crops during the growing season, soil emissions might be expected to be largely recaptured by the overlying canopy, either by stomatal absorption or by surface wetness uptake (Nemitz et al., 2000a; Meyers et al., 2006). In practice, the fraction of $\mathrm{NH}_{3}$ estimated to be recaptured is very variable between studies.

The ability of plant canopies to recapture substantial amounts of $\mathrm{NH}_{3}$ released from fertilizer or plant residues at the ground is an important issue in agricultural air quality that is still a matter of debate (Denmead et al., 2008). For example, management options to reduce $\mathrm{NH}_{3}$ volatilization losses from urea include to delay its field application (Denmead et al., 2008), or to use urease inhibitors (Walker et al., 2013). In the second of these, it is envisaged that a developed canopy would attenuate canopy wind speeds, leading to lower transport rates in the canopy air space, increased $\mathrm{NH}_{3}$ concentrations, and greater uptake by the canopy foliage (Denmead et al., 2008).

By combining vertical in-canopy $\mathrm{NH}_{3}$ profile measurements with ILT modelling, Nemitz et al. (2000a) calculated that all $\mathrm{NH}_{3}$ emitted from the ground level was recaptured within the lowest half of an oilseed rape canopy, except during windy nighttime conditions, and that the net ecosystem daytime emission (measured by the flux gradient technique above the canopy) originated from the top half of the canopy. The $\mathrm{N}$ loss from the plant's top leaves and siliques (seed cases) to the atmosphere as gaseous $\mathrm{NH}_{3}$ was more than balanced by the lower leaves uptake from $\mathrm{NH}_{3}$ emitted by decomposing leaf litter. Similarly, in a fully developed grassland canopy (before cutting), Nemitz et al. (2009a) measured in-canopy profiles of $\mathrm{NH}_{3}$, which again were consistent with a large ground-level source, presumably from senescent plant parts, which was entirely recaptured by the overlying canopy. This ground-level source was believed to be responsible for the sustained $\mathrm{NH}_{3}$ emissions observed after grass cutting, as indicated by independent bioassay and chamber measurements (David et al., 2009). The GRassland AMmonia Interactions Across Europe (GRAMINAE) grassland experiment, summarised by Sutton et al. (2009a, b), demonstrated that overall, net above-canopy fluxes were mostly determined by stomatal and cuticular uptake before the cut, by leaf litter emissions after the cut, and by fertilizer and litter emissions after fertilization.

A range of other experiments in crops have shown only partial canopy recapture of soil emissions. In maize, Bash et al. (2010) calculated, using an analytical first-order closure 
inverse source/sink model, that the fraction of soil-emitted $\mathrm{NH}_{3}$ that was recaptured by the overlying canopy was $73 \%$ for fertilizer applied to the soil surface (see also Walker et al., 2013). In another maize canopy, over which dairy waste effluent was spread, Harper et al. (2000) found that $17 \%$ of the soil $\mathrm{NH}_{3}$ emission was recaptured by the canopy during one ILT modelling run in mid-afternoon. However, overall only $21 \%$ of the net emissions came from the soil, while $79 \%$ came from the foliage. This occurred because the fertilizer was sprayed from above the canopy, so that much of the $\mathrm{NH}_{3}$ was emitted from leaf surfaces even before the fertilizer hit the ground. This shows that the fertilizer application method alters the soil-canopy source and sink relationship and should be accounted for in CTMs as a way to more accurately simulate the impact of agricultural management practices on fertilizer $\mathrm{NH}_{3}$ emissions.

In a sugarcane crop, Denmead et al. (2008) estimated that the percentage of canopy recapture of $\mathrm{NH}_{3}$ volatilized from urea fertilizer applied to the ground was of the order of $20 \%$ for a LAI of 2, but they indicated that this fraction would increase with LAI, and that the efficiency of $\mathrm{NH}_{3}$ recapture would be different in denser canopies or crops with different canopy structure. By extension, in dry climates, and for young and/or sparse or recently cut vegetation (grassland), the soil source strength potential is likely to be more fully expressed (as net emission to the atmosphere), since the canopy recapture fraction is likely to be small. In such systems, if the soil layer $\Gamma$ ratio is large, then the net canopy-scale flux is likely to be largely independent of stomatal and leaf surface exchange if LAI is small (Nemitz et al., 2001a).

\subsubsection{Gas-particle interconversion (GPIC) within and above the canopy}

Air column chemistry within and above the canopy, and particularly the reversible thermodynamic equilibria of the $\mathrm{NH}_{3}-\mathrm{HNO}_{3}-\mathrm{NH}_{4} \mathrm{NO}_{3}$ and $\mathrm{NH}_{3}-\mathrm{HCl}-\mathrm{NH}_{4} \mathrm{Cl}$ gas-aerosol triads, is known to affect $\mathrm{NH}_{3}$ surface-atmosphere exchange rates (Brost et al., 1988). There are three ways in which gasparticle conversion and aerosol evaporation affect $\mathrm{NH}_{3}$ fluxes and local $\mathrm{N}_{\mathrm{r}}$ budgets (Nemitz et al., 2009b):

1. Vertical flux divergence and error in flux measurement. The presence of additional sources or sinks in the air below the flux measurement height means that the measured flux differs from the true surface exchange. Thus, fluxes measured by micrometeorological techniques that operate at a single measurement height $\left(z_{\mathrm{m}}\right)$, such as EC and relaxed eddy accumulation (REA), may need to be corrected for this effect. While these single height approaches still derive the correct local flux at the measurement height, the situation is more complex for gradient flux measurements. In that case, the vertical $\mathrm{NH}_{3}$ gradient is modified by the chemistry, so that the aerodynamic gradient technique (AGM) may need to be modified to derive the correct $\mathrm{NH}_{3}$ flux, includ- ing the chemical production or depletion term within the canopy space in addition to foliar exchange (Nemitz et al., 2004; van Oss et al., 1998).

2. Error in inferential estimates and deposition modelling. Deposition and emission are often derived from the air concentration in an inferential approach, using resistance models of a range of complexity. This approach does not usually consider chemical conversion within the resistance analogue (Kramm and Dlugi, 1994). In addition, changes in the gas/particle partitioning modify air concentrations compared with the simulation of an atmospheric transport model that ignores chemical reactions. For example, the $\mathrm{NH}_{3}$ air concentration is lowered by transfer to the particle phase, further stimulating stomatal emission, which is governed by the difference between stomatal compensation point and atmospheric concentration. A multi-layer modelling framework that simulates the coupled exchange, transport and chemistry inside the canopy is needed to resolve this effect (Nemitz et al., 2012; Ellis et al., 2011).

3. Modification of the local $\mathrm{N}_{\mathrm{r}}$ budget. Gas-to-particle conversion usually occurs in situations of strong $\mathrm{NH}_{3}$ emission. In this case a fraction of the emitted $\mathrm{NH}_{3}$ is converted into slowly depositing $\mathrm{NH}_{4} \mathrm{NO}_{3}$ aerosol, "increasing" the potential for local $\mathrm{N}$ deposition and lowering the air concentration of $\mathrm{NH}_{3}$ near the surface, thus stimulating further emissions from $\mathrm{NH}_{3}$ compensation points. At the same time, fast depositing $\mathrm{HNO}_{3}$ is converted into slowly depositing $\mathrm{NH}_{4} \mathrm{NO}_{3}$ aerosol, "decreasing" net $\mathrm{N}$ deposition. Similarly, $\mathrm{NH}_{4} \mathrm{NO}_{3}$ evaporation may occur near the surface, due to elevated canopy temperatures and reduced concentration of $\mathrm{NH}_{3}$ and $\mathrm{HNO}_{3}$ (driven by deposition), usually over seminatural vegetation, which provides an efficient sink for $\mathrm{NH}_{3}$. This process converts slowly depositing aerosol $\mathrm{NH}_{4} \mathrm{NO}_{3}$ into fast depositing $\mathrm{HNO}_{3}$ and $\mathrm{NH}_{3}$ gas, thus increasing total $\mathrm{N}$ deposition. The net effect of gas-toparticle conversion on the local $\mathrm{N}$ budget will depend on the relative magnitudes and exchange rates of the different compounds involved.

The potential degree of vertical flux divergence depends on the comparative chemical timescales for the evaporation or formation of $\mathrm{NH}_{4} \mathrm{NO}_{3}$ and $\mathrm{NH}_{4} \mathrm{Cl}$ and the timescales for turbulent transport, which are different within and above the canopy; it also depends on the relative mixing ratios of $\mathrm{NH}_{3}$ compared with the other chemically interactive species (gaseous $\mathrm{HNO}_{3}$ and $\mathrm{HCl}$ and aerosol-phase $\mathrm{NH}_{4}^{+}, \mathrm{NO}_{3}^{-}$and $\mathrm{Cl}^{-}$). Thus Nemitz et al. (2000c), for example, found ample evidence that there was the potential for $\mathrm{NH}_{4} \mathrm{Cl}$ formation (i.e. an $\mathrm{NH}_{3}$ sink) within an oilseed rape canopy in $\mathrm{S}$. Scotland, where the in-canopy turbulence was low and residence times long. By contrast, above the canopy they predicted that there was potential for $\mathrm{NH}_{4} \mathrm{Cl}$ evaporation (i.e. 


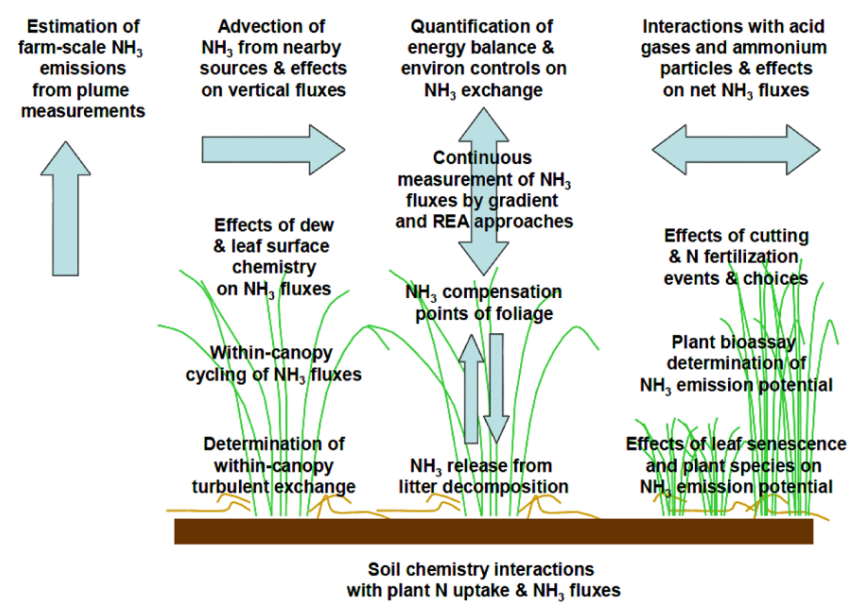

Fig. 4. Overview of processes controlling surface/atmosphere $\mathrm{NH}_{3}$ exchange in the soil-vegetation-atmosphere continuum, summarising the scientific objectives of the GRAMINAE integrated experiment (from Sutton et al., 2009a), but relevant for $\mathrm{NH}_{3}$ exchange studies in any ecosystem.

an $\mathrm{NH}_{3}$ source). The small aerosol concentrations measured at their site resulted in chemical timescales for the evaporation or formation of $\mathrm{NH}_{4} \mathrm{NO}_{3}$ and $\mathrm{NH}_{4} \mathrm{Cl}$ that were much longer than those for diffusive transport above the canopy. This meant that gas-particle interactions were unlikely to have affected above-canopy flux-gradient measurements of $\mathrm{NH}_{3}$, and indicated that the aerodynamic gradient method is applicable to $\mathrm{NH}_{3}$ flux measurements in environments with low particle concentrations (relative to $\mathrm{NH}_{3}$ ) without the need to correct for the effects of GPIC. However, the relative effect of these interactions on the fluxes of $\mathrm{HNO}_{3}$ and $\mathrm{NH}_{4} \mathrm{NO}_{3}$ may be considerable (cf. Nemitz et al., 2012). During the GRAMINAE Braunschweig experiment, gas-particle interactions were also believed to have had a minor effect on measured ammonia fluxes, though the relative effect on calculated aerosol deposition rates was significant (Sutton et al., 2009b; Nemitz et al., 2009b).

In more polluted environments, the impact of GPIC on $\mathrm{NH}_{3}$ exchange can be significant. Over heathland in warm conditions in the Netherlands, Nemitz et al. (2004) established that there was near-surface evaporation of volatile $\mathrm{NH}_{4}^{+}$(i.e. an apparent $\mathrm{NH}_{3}$ source) during the aerosol deposition process, which led to a substantial overestimation of the $\mathrm{NH}_{3}$ flux (by the gradient method) of $+20 \mathrm{ng} \mathrm{m}^{-2} \mathrm{~s}^{-1}$ during the day. They concluded that $\mathrm{NH}_{4}^{+}$evaporation may lead to a significant underestimation of $\mathrm{NH}_{3}$ deposition to semi-natural vegetation during daytime by current measurements and models, in which such processes are not explicitly accounted for. This is particularly true if flux measurements are carried out in areas where large aerosol concentrations lead to short chemical timescales and where large concentration of volatile $\mathrm{NH}_{4} \mathrm{NO}_{3}$ or (less likely) $\mathrm{NH}_{4} \mathrm{Cl}$ are present. These conditions are fulfilled above semi-natural vegetation in the vicinity of high $\mathrm{NH}_{3}$ emission densities, common in the Netherlands and other areas with high livestock densities.

Model simulations by van Oss et al. (1998) successfully simulated observations of $\mathrm{NO}_{3}^{-}$-aerosol deposition faster than permitted by turbulence above the Dutch forest Speulderbos. They showed that $\mathrm{NH}_{3}$ emission fluxes obtained at Speulderbos may not originate from the foliage but could at least partly be explained by the evaporation of $\mathrm{NH}_{4} \mathrm{NO}_{3}$ close to or within the canopy. However, evaporation of $\mathrm{NH}_{4} \mathrm{NO}_{3}$ from leaf surfaces may have a similar effect. The complex topic of air column chemistry and gas-particle interconversion and its relevance to $\mathrm{NH}_{3}$ exchange is addressed more fully by Nemitz et al. (2012).

The stratification and interactions of processes controlling surface/atmosphere $\mathrm{NH}_{3}$ exchange reviewed in this section are illustrated in Fig. 4, which was originally drawn to summarise the scientific objectives and tasks within the GRAMINAE Braunschweig experiment (Sutton et al., 2009a). This project focused on processes in fertilized and cut grassland, but Fig. 4 can essentially serve as a blueprint for any integrated project aiming at a full understanding of component-scale and canopy-scale $\mathrm{NH}_{3}$ fluxes in other vegetation types (for semi-natural ecosystems, the management and fertilization issues can simply be ignored). The figure illustrates intuitively that $\mathrm{NH}_{\mathrm{x}}$ pools exist, expand or shrink over time, and interact at all levels of the ecosystem: soil (agregates, cation exchange sites, water-filled porosity, open porosity); soil surface, fertilizer residues and litter; plant (xylem, phloem, apoplast, cytoplasm, vacuole, organelles); plant surfaces (water films, cuticle, deliquescent aerosols); and even in the air space within and above the canopy. Surface/exchange models should therefore, in theory, seek to simulate the temporal as well as the vertical variability in these pools, in order to simulate the dynamics of canopyscale fluxes.

\section{Ammonia exchange models and parameterizations from the leaf to the globe: state-of-the-art}

A large number of models have been developed to simulate $\mathrm{NH}_{3}$ exchange fluxes for the different ecosystem components or processes (soil, litter, leaf, plant, heterogeneousphase chemistry), either separately or integrated into canopyscale 1-dimensional (1-D) soil-vegation-atmosphere (SVAT) frameworks. Landscape-scale, regional-scale and globalscale models are 2-D or 3-D, and they typically include simplified versions of canopy-scale models to simulate the 1-D surface exchange as part of the wider modelling context of emission, dispersion, transport, chemistry and deposition. The level of complexity of 1-D $\mathrm{NH}_{3}$ exchange models depends on the different purposes and temporal scales as well as spatial scales, at which they are put to use. Modelling approaches range from the fully empirical to the primarily mechanistic. This section provides an overview of existing 
models, and their current parameterizations, ranging from the component (or substrate) scale to the global scale. The review is by no means exhaustive, but instead focuses on state-ofthe-art models, and those models which represent potential options for implementation into integrated canopy, or larger scale, models. At each level, the model's scope, advances, challenges, and degree of validation are discussed. Model names are highlighted in bold characters on first mention, and a summary of models is provided in Table 1.

\subsection{Process/component scale models: soil, manure, fertilizer, leaf litter, leaf, cuticle, air column chemistry}

\subsubsection{Ammonia emissions from slurry and fertilizer applied to soils $\left(\Gamma_{\text {soil }}\right.$ emission potential $)$}

Various modelling concepts have been developed to account for the physico-chemical processes controlling $\mathrm{NH}_{3}$ emission from mineral or organic manures upon field application to bare soil, and to simulate the peak emissions and diurnal trends of $\mathrm{NH}_{3}$ emissions following slurry application (e.g. van der Molen, 1990; Sommer et al., 2003; Montes et al., 2009). Génermont and Cellier (1997) developed a mechanistic model (Volt'Air) that simulates the controls by soil, meteorology and slurry characteristics on $\mathrm{NH}_{3}$ volatilisation from field-applied slurry, accounting for the transfers and equilibria in the topsoil and between the soil and the atmosphere. The model included energy balance and advection submodels, which made it suitable for field scale applications using simple meteorological data. Sensitivity analysis showed that soil $\mathrm{pH}$ has a large influence on volatilization. The model is also sensitive to soil adsorption capacity and some hydraulic characteristics (saturation water conductivity, water content at field capacity) (Garcia et al., 2011). Volt'Air has also been extended to simulate emissions by mineral fertilizers (Laguel-Hamaoui, 2012).

The process-based AGRIN model, developed by Beuning et al. (2008), combined model theory of soil biological processes such as SOM decomposition, nitrification and denitrification (DNDC, Li et al., 1992; Li, 2000), with Volt'Air-type models of $\mathrm{NH}_{3}$ volatilization (Génermont and Cellier, 1997; Van der Molen et al., 1990). New processes were also introduced to improve model performance, such as a separate slurry layer. In such models a key challenge is to simulate the $\mathrm{pH}$ of the emitting layer, which may be rather different from, or independent of, the background $\mathrm{pH}$ value for the underlying topsoil, e.g. in cases where infiltration is limited. Also, for implementation in CTMs, regional soil $\mathrm{pH}$ maps need to account for the effects of liming practices.

Empirical/statistical regression approaches for slurry emissions include the Ammonia Loss from Field-applied Animal Manure (ALFAM) model (Søgaard et al., 2002), whereby volatilisation is described mathematically by a Michaelis-Menten-type equation, with the loss rates as the response variable, and soil water content, air temperature, wind speed, slurry type, dry matter content of slurry, total ammoniacal nitrogen content of slurry $\left(\mathrm{TAN}=\left[\mathrm{NH}_{\mathrm{x}}\right]=\left[\mathrm{NH}_{3}\right]+\left[\mathrm{NH}_{4}^{+}\right]\right)$, application method and rate, mode of slurry incorporation and measuring technique are the explanatory variables. Similarly, using regression analysis, Menzi et al. (1998) used the results of field and wind tunnel experiments to derive a simple empirical model to estimate ammonia emissions after the application of liquid cattle manure on grassland. Their model takes into account the mean saturation deficit of the air, the TAN content of the manure and the application rate. Lim et al. (2007) proposed an artificial neural network (ANN) approach for predicting ammonia emission from field-applied manure, which combined principal component analysis (PCA)-based preprocessing and weight partitioning method (WPM)-based post-processing. Their so-called PWA (standing for PCAWPM-ANN) approach is expected to account for the complex nonlinear effects between the $\mathrm{NH}_{3}$ emission variables such as soil and manure states, climate and agronomic factors.

For soils amended with commercial fertilizers, such as anhydrous $\mathrm{NH}_{3}$, urea, ammonium nitrate, or mixtures of these forms, soil $\mathrm{NH}_{3}$ emission is modelled in the Community Multiscale Air Quality (CMAQ) model (Foley et al., 2010) by a simplified version of the US Department of Agriculture's Environmental Policy Integrated Climate (EPIC) model (Williams et al., 2008; Cooter et al., 2010), which includes simulation of nitrification through a combination of a first-order kinetic rate equation (Reddy et al., 1979) and elements of the Crop Environment REsource Synthesis (CERES) crop model (Godwin et al., 1984). The rate of $\mathrm{N}$ transformation is computed as a function of soil $\mathrm{pH}$, temperature, and soil moisture effects on nitrification and subsequent volatilization. In EPIC, volatilization is simply a fixed fraction of nitrification, while the CMAQ-EPIC coupling application makes use of the bi-directional flux paradigm to characterize the emission. One basic hypothesis of the simplified EPIC processes included in CMAQ is that characterization of the nitrification process alone will adequately simulate the concentration of $\mathrm{NH}_{4}^{+}$and $\mathrm{H}^{+}$in agricultural soils. The upper 15 to $45 \mathrm{~cm}$ of the soil layer reflects the impact of specific tillage practices on biogeochemical process rates. The EPIC/CMAQ method requires knowledge of physical properties of the ambient soil profile, meteorology, and regional crop management practices and uses a crop growth model to estimate tillage and fertilizer application timing and amount. This information is provided to CMAQ by a full EPIC management simulation. The EPIC model also can perform detailed dynamic slurry or solid form manure simulations, but this information is not yet implemented in the current coupling with CMAQ. For $\mathrm{NH}_{3}$ transfer to the surface, the EPIC/CMAQ model formally develops and evaluates refinements to the Nemitz et al. (2001a) model for $\mathrm{NH}_{3}$ flux over a managed agricultural soil, that includes a 
Table 1. A selection of soil, plant, ecosystem, atmosphere models, dealing with $\mathrm{NH}_{3}$ emission, dry deposition, bi-directional exchange, dispersion, chemistry, transport, from the process scale to the global scale.

\begin{tabular}{|c|c|c|}
\hline Full Model Name & Acronym/Short name & Reference \\
\hline \multicolumn{3}{|l|}{ Process-based soil, manure, fertilizer, or agro/ecosystem emission } \\
\hline AGRIN & AGRIN & Beuning et al. (2008) \\
\hline Ammonia Loss from Field-applied Animal Manure & ALFAM & Søgaard et al. (2002) \\
\hline Crop Environment REsource Synthesis & CERES & Godwin et al. (1984) \\
\hline Crop Environment REsource Synthesis - EGC (INRA) & CERES-EGC & Gabrielle et al. (1995) \\
\hline DeNitrification DeComposition & DNDC & Li et al. (1992); Li (2000) \\
\hline Environmental Policy Integrated Climate & EPIC & Williams et al. (2008) \\
\hline Generation of emissions from Uric Acid Nitrogen Outputs & GUANO & Blackall et al. (2007); Riddick (2012) \\
\hline Volt'Air & Volt'Air & Genermont and Cellier (1997) \\
\hline \multicolumn{3}{|l|}{ Leaf/plant-scale stomatal exchange } \\
\hline Multi-Layer BioChemical & MLBC & Wu et al. (2003) \\
\hline Pasture Simulation & PaSim & Riedo et al. $(1998,2002)$ \\
\hline STomatal AMmonia compensation Point & STAMP & Massad et al. (2010a) \\
\hline \multicolumn{3}{|l|}{ Canopy/ecosystem-scale dry deposition/exchange } \\
\hline DEPosition of Acidifying Compounds & DEPAC & Erisman et al. (1994) \\
\hline DEPosition of Acidifying Compounds v.3.11 & DEPAC 3.11 & $\begin{array}{l}\text { Wichink Kruit et al. (2010); } \\
\text { van Zanten et al. (2010) }\end{array}$ \\
\hline Dynamic pollutant Exchange with Water films on vegetation Surfaces & DEWS & Flechard et al. (1999) \\
\hline Multi-Layer Model & MLM & Meyers et al. (1998) \\
\hline PLant ATmosphere INteraction & PLATIN & Grünhage and Haenel $(1997,2008)$ \\
\hline SPRUCE forest DEPosition & SPRUCEDEP & Zimmermann et al. (2006) \\
\hline SURFace ATMosphere $\mathrm{NH}_{3}$ & SURFATM-NH 3 & Personne et al. (2009) \\
\hline \multicolumn{3}{|l|}{ Landscape-scale dispersion and deposition } \\
\hline $\begin{array}{l}\text { American Meteorological Society/Environmental } \\
\text { Protection Agency Regulatory Model }\end{array}$ & AERMOD & Perry et al. (2004) \\
\hline Atmospheric Dispersion Modelling System & ADMS & Carruthers et al. (1999) \\
\hline DDR & DDR & Asman et al. (1989) \\
\hline DEPO1 & DEPO1 & Asman (1998) \\
\hline Flux Interpretation by Dispersion and Exchange over Short range & FIDES-2D & Loubet et al. (2001) \\
\hline Local Atmospheric Dispersion and Deposition & LADD & Hill (1998) \\
\hline MOdel of Dispersion and Deposition of Ammonia over the Short-range & MODDAAS-2D & Loubet et al. (2006) \\
\hline Operational Priority Substances (Pro 4.1) & OPS-Pro 4.1 & van Jaarsveld (2004) \\
\hline Operational Priority Substances (Short Term) & OPS-st & van Jaarsveld (2004), van Pul et al. (2008) \\
\hline Operationelle Meteorologiske Luftkvalitetsmodeller DEPosition & OML-DEP & Olesen et al. (2007); Sommer et al. (2009) \\
\hline TREND/OPS & TREND/OPS & Asman and van Jaarsveld (1992) \\
\hline \multicolumn{3}{|l|}{ Regional-scale chemical transport models } \\
\hline A Unified Regional Air-quality Modelling System & AURAMS & Zhang et al. (2003) \\
\hline CHIMERE & CHIMERE & Vautard et al. (2001) \\
\hline Community Multiscale Air Quality & CMAQ & Byun and Schere (2006) \\
\hline Danish Ammonia MOdelling System & DAMOS & Geels et al. (2012) \\
\hline European Monitoring and Evaluation Programme & EMEP & Simpson et al. (2012) \\
\hline Fine Resolution AMmonia Exchange & FRAME & Singles et al. (1998) \\
\hline LOng Term Ozone Simulation EURopean Operational Smog & LOTOS-EUROS & Wichink Kruit et al. (2012) \\
\hline Multi-scale Atmospheric Transport and CHemistry & MATCH & Klein et al. (2002) \\
\hline \multicolumn{3}{|l|}{ Global-scale chemical transport models } \\
\hline Goddard Earth Observing System Chemical transport model & GEOS-Chem & Bey et al. (2001); Wang et al. (1998) \\
\hline MOdel of the Global UNiversal Tracer transport In The Atmosphere & MOGUNTIA & Dentener and Crutzen (1994) \\
\hline Tracer Model version 5 & TM5 & Huijnen et al. (2010) \\
\hline UK Met. Office Global Three-Dimensional Lagrangian Model & STOCHEM & Collins et al. (1997); Bouwman et al. (2002) \\
\hline
\end{tabular}


soil resistance term (see Sect. 3.2). A similar approach was also developed using the Volt'Air $\mathrm{NH}_{3}$ emission module and the CERES-EGC crop growth model (Gabrielle et al., 1995; Theobald et al., 2005).

Although strictly speaking not pertaining to the manure or fertilizer categories, $\mathrm{NH}_{3}$ emissions from seabird excreta (guano) on the ground of land-based colonies present similarities and their study and modelling proves relevant in this context. Agricultural sources of $\mathrm{NH}_{3}$ are complicated by different management practices across the globe, whereas seabird emissions represent a model system for studying climate dependence (Riddick et al., 2012). Seabird colonies are the largest point sources of ammonia globally (up to $\sim 6 \mathrm{Gg}$ $\mathrm{NH}_{3}$ colony ${ }^{-1} \mathrm{yr}^{-1}$, on average; Blackall et al., 2007). Riddick et al. (2012) present an $\mathrm{NH}_{3}$ emission mid estimate with an overall uncertainty range of 270 [97-442] Gg $\mathrm{NH}_{3}$ per year for seabird colonies globally. In the Generation of emissions from Uric Acid Nitrogen Outputs (GUANO) model (Blackall et al., 2007; Riddick, 2012), the emission of $\mathrm{NH}_{3}$ from seabird excreted $\mathrm{N}$ is described in four steps: (i) Excretion of nitrogen rich guano, in the form of uric acid based on a seabird energetics model (Wilson et al., 2004); (ii) conversion of uric acid total ammoniacal nitrogen (TAN), with a climate- and surface $\mathrm{pH}$-dependent rate; (iii) TAN partition between $\mathrm{NH}_{4}^{+}$and $\mathrm{NH}_{3}$ on the surface; and (iv) $\mathrm{NH}_{3}$ volatilization to the atmosphere, controlled by the wind speed, aerodynamic resistance $\left(R_{\mathrm{a}}\right.$ and $\left.R_{\mathrm{b}}\right)$ and the fraction of $\mathrm{NH}_{3}$ re-absorbed by the substrate and re-captured by any overlying vegetation.

The review by Sintermann et al. (2012) of published $\mathrm{NH}_{3}$ emission factors for field applied slurry showed that (i) very substantial differences between EF estimates from field-scale (both AGM and EC) measurements and the ALFAM and Menzi et al. (1998) simple empirical models, for Swiss datasets (e.g. Spirig et al., 2010; Sintermann et al., 2011), with estimates TAN losses in the range $5-30 \%$ by measurements vs. $20-70 \%$ by these two models; and (ii) that EF estimates by measurements depended on the spatial scale at which they were carried out (chamber, small or medium plot, field), suggesting strong potential methodological biases. This provides a very clear indication that the current level of validation for models of $\mathrm{NH}_{3}$ volatilisation from field applied manures is rather poor. The authors concluded that new series of measurements are urgently needed in order to (i) provide systematic comparisons of measurements from medium-scale plots and field-scale measurements under identical conditions, and using a range of different measurement techniques, and (ii) pursue the characterisation of $\mathrm{NH}_{3} \mathrm{EFs}$ in terms of the influence of slurry composition and application method, soil properties and meteorology. Such future experiments should ideally cover the detailed temporal dynamics (hourly or better over the full course of emission) to help understand the environmental interactions, and must report on the parameters required to perform a plausibility check and to apply and develop process-oriented models.

\subsubsection{Litter emissions $\left(\Gamma_{\text {litter }}\right.$ emission potential $)$}

The model developed by Nemitz et al. (2000a) to simulate the dynamics of the litter $\mathrm{NH}_{3}$ emission potential, based on measurements of $\left[\mathrm{NH}_{4}^{+}\right] /\left[\mathrm{H}^{+}\right]$ratio in bulk tissue extracts and on mineralization and nitrification rates, is one of very few available methods at present and appears to be relatively easy to implement. A more detailed mechanistic treatment is provided by EPICv.0509 (see Appendix A in Cooter et al., 2012; Williams et al., 2008), in which soil organic $\mathrm{C}$ and $\mathrm{N}$ are split into three compartments: microbial biomass, slow humus and passive humus, and organic residues added to the soil surface or belowground are split into metabolic and structural litter compartments as a function of $\mathrm{C}$ and $\mathrm{N}$ content. Following the CENTURY (Parton et al., 1994) approach, EPIC includes linear partition coefficients and soil water content to calculate movement as modified by sorption, which are used to move organic materials from surface litter to subsurface layers; temperature and water controls affecting transformation rates are calculated internally in EPIC; the surface litter fraction in EPIC has a slow compartment in addition to metabolic and structural litter components; while lignin concentration is simulated as an empirical sigmoidal function of plant age.

Although the $\mathrm{NH}_{3}$ emission potential of the litter $\left(\Gamma_{\text {litter }}\right)$ is very high, especially in fertilized agricultural systems (Fig. 3), this component has been very much understudied compared with, say, apoplastic $\Gamma_{\mathrm{s}}$. Within the European Union-funded collaborative project ECLAIRE ("Effects of Climate Change on Air Pollution and Response Strategies for European Ecosystems"; http://www.eclaire-fp7.eu), work is on-going to characterise $\mathrm{NH}_{3}$ emission potentials in a range of litter samples from selected ECLAIRE monitoring sites across Europe. The incubation of litter samples in a twofactorial design of different soil moistures (20-80\% waterfilled pore space) and temperatures $\left(5-20^{\circ} \mathrm{C}\right)$ should provide a better understanding of litter emission dynamics.

\subsubsection{Leaf/plant-scale stomatal exchange $\left(\Gamma_{\mathrm{s}}\right.$ emission potential)}

Substantial progress has been achieved over the last 10 years in modelling the cell and plant physiological mechanisms that determine the apoplastic $\Gamma_{\mathrm{s}}$ ratio and its temporal variations. In particular, the Pasture Simulation (PaSim) ecosystem model for the simulation of dry matter production and $\mathrm{C}, \mathrm{N}, \mathrm{H}_{2} \mathrm{O}$ and energy fluxes (Riedo et al., 1998), accounts for the effects of nitrification, denitrification and grazing, and was extended by Riedo et al. (2002) to couple $\mathrm{NH}_{3}$ exchange with ecosystem functioning. For this purpose, the aboveground plant substrate $\mathrm{N}$ pool in previous versions of PaSim was sub-divided into apoplastic and symplastic components. The apoplastic substrate $\mathrm{N}$ pool was linked to the stomatal $\mathrm{NH}_{3}$ exchange, while soil ammoniacal $\mathrm{N}\left(\mathrm{NH}_{\mathrm{x}}\right)$ was partitioned between the soil surface and several soil layers, with 
the soil surface $\mathrm{NH}_{3}$ exchange being driven by the $\mathrm{NH}_{4}^{+}$content in a soil surface layer (set at $0-3 \mathrm{~mm}$ depth). This was the first attempt by any model to account for plant $\mathrm{N}$ nutrition and development stage in predicting $\Gamma_{\mathrm{s}}$. One significant drawback identified by the authors was that PaSim did not consider the form of $\mathrm{N}$ taken up by the roots (reduced or oxidised), which may be significant since plants absorbing $\mathrm{NH}_{4}^{+}$have higher $\mathrm{NH}_{3}$ emissions compared with plants absorbing $\mathrm{NO}_{3}^{-}$(see Sect. 2.3). Riedo et al. (2002) offered this as an explanation for the lack of late summer emissions in their simulations, in contrast to observed fluxes in a Scottish pasture.

Another significant development is the stomatal ammonia compensation point (STAMP) leaf-scale model for C3 plants by Massad et al. (2010a), in which $\Gamma_{\mathrm{s}}$ is likewise related to plant $\mathrm{N}$ and $\mathrm{C}$ metabolism. Here, five compartments are considered explicitly: xylem, cytoplasm, apoplasm, vacuole and sub-stomatal cavity, while the main processes accounted for are (i) transport of $\mathrm{NH}_{4}^{+}, \mathrm{NH}_{3}$ and $\mathrm{NO}_{3}^{-}$between the five compartments; (ii) $\mathrm{NH}_{4}^{+}$production through photorespiration and $\mathrm{NO}_{3}^{-}$reduction; (iii) $\mathrm{NH}_{4}^{+}$assimilation by the GS/GOGAT cycle; (iv) chemical and thermodynamic equilibriums in all the compartments; and (v) and stomatal transfer of $\mathrm{NH}_{3}$ (Fig. 5). In contrast to PaSim, STAMP accounts for either $\mathrm{NH}_{4}^{+}$-based nutrition, $\mathrm{NO}_{3}^{-}$-based nutrition, or a combination of both. However, STAMP only represents a leaf (single-layer canopy) in a vegetative stage of growth, in which apoplast and cytoplasm are relatively uncoupled with respect to $\mathrm{NH}_{\mathrm{x}}$; STAMP does not account for the effects of senescence on $\mathrm{NH}_{3}$ metabolism, restricting model applicability in the case of plants having senescent leaves and in multilayered canopies. STAMP was validated against measured $\chi_{\mathrm{s}}$ values and both apoplastic and intra-cellular $\mathrm{NH}_{\mathrm{x}}$ concentrations, using flux chamber measurements with 7-9 oilseed rape plants at 5 weeks of age (Massad et al., 2009). The model has yet to be scaled up to the crop canopy level, integrating soil and plant processes, which will also require the model to be thoroughly tested against field data.

Unlike PaSim and STAMP, the stomatal compensation point model integrated by $\mathrm{Wu}$ et al. (2009) in the MultiLayer BioChemical (MLBC) dry deposition model of Wu et al. (2003) is not driven by ecosystem, plant and leaf biochemistry and metabolism, but it does explore from a theoretical viewpoint the issue of potential feedbacks between emission, deposition and leaf temperature on the dynamics of apoplastic $\Gamma_{\mathrm{s}}$. Simulations show that modeled apoplastic $\left[\mathrm{NH}_{4}^{+}\right]$and $\left[\mathrm{H}^{+}\right]$display significant diurnal variation when the buffer effect of the underlying metabolic processes generating or consuming $\mathrm{NH}_{4}^{+}$are ignored, and that the model predictive capability for canopy-scale exchange fluxes over fertilized soybean (measurements by Walker et al., 2006) is slightly improved by incorporating the feedback of $\mathrm{NH}_{3}$ flux on apoplastic $\left[\mathrm{NH}_{4}^{+}\right]$(vs. a constant $\Gamma_{\mathrm{s}}$ approach). Ignoring entirely the apoplastic buffer effects associated with xylem

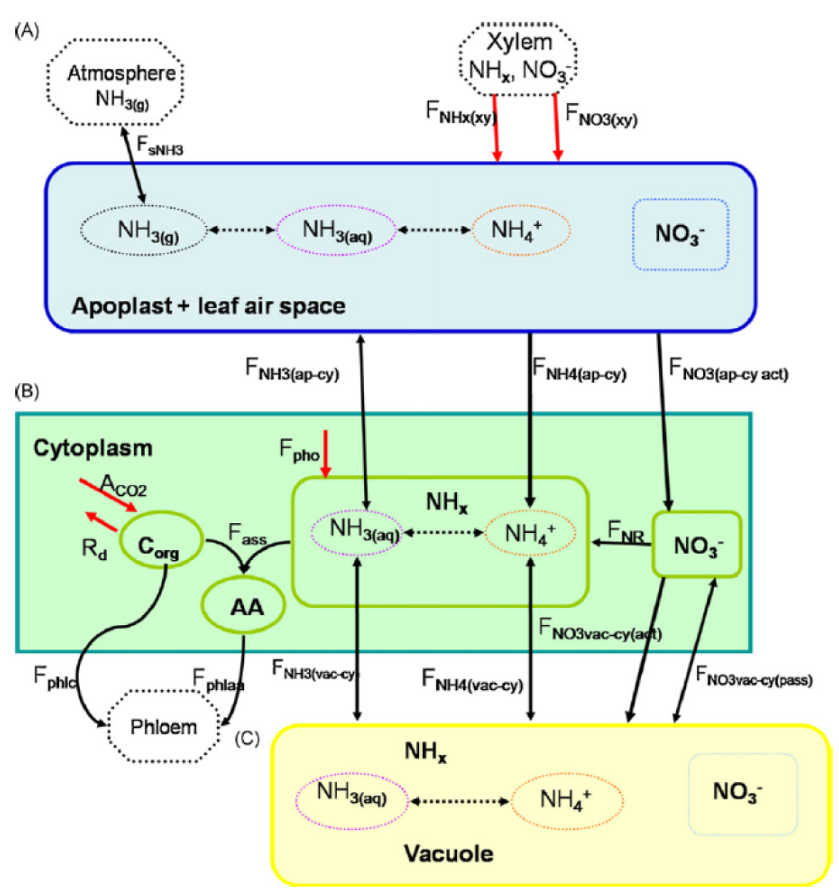

Fig. 5. Components and flow diagram of the STAMP (stomatal ammonia compensation point) model by Massad et al. (2010a). Oneway arrows represent active transport, two-way arrows represent passive diffusion, dotted arrows represent equilibria and red arrows represent forcing variables.

supply and cytoplasmic exchange appears to be an unrealistic oversimplification, but the dynamic stomatal compensation point MLBC runs by Wu et al. (2009) do raise the issue of the significance for modelling of diurnal $\Gamma_{\mathrm{s}}$ variations, which have been observed elsewhere (e.g. Herrmann et al., 2009), albeit of a smaller magnitude.

\subsubsection{Leaf surface aqueous chemistry $\left(\Gamma_{d}\right.$ emission potential)}

Water droplets resting on leaf surfaces have long been known to act as sinks for soluble atmospheric trace gases including $\mathrm{SO}_{2}$ (Brimblecombe, 1978; Fowler and Unsworth, 1979) and $\mathrm{NH}_{3}$ (Sutton et al., 1992). Although leaf wetness is usually assumed to increase surface affinity (i.e. reduce surface resistance) for $\mathrm{NH}_{3}$ uptake, Sutton et al. (1995c, 1998a) recognized that exchange with leaf surface water could be reversible and they developed the first capacitance-based model to simulate $\mathrm{NH}_{3}$ desorption from the drying out cuticle of a wheat canopy. One underlying assumption was that part of the previously deposited $\mathrm{NH}_{3}$ was not fixed by reaction to form low vapour pressure salts (e.g. $\left.\left(\mathrm{NH}_{4}\right)_{2} \mathrm{SO}_{4}\right)$ and thus may be released back to the atmosphere upon evaporation of surface wetness, with this leading to an increase in $\left[\mathrm{NH}_{4}^{+}\right]$in the leaf surface water pool, and the associated values termed $\Gamma_{\mathrm{d}}$ and $\chi_{\mathrm{d}}$. The water film thickness $\left(M_{\mathrm{H}_{2} \mathrm{O}}\right)$, 


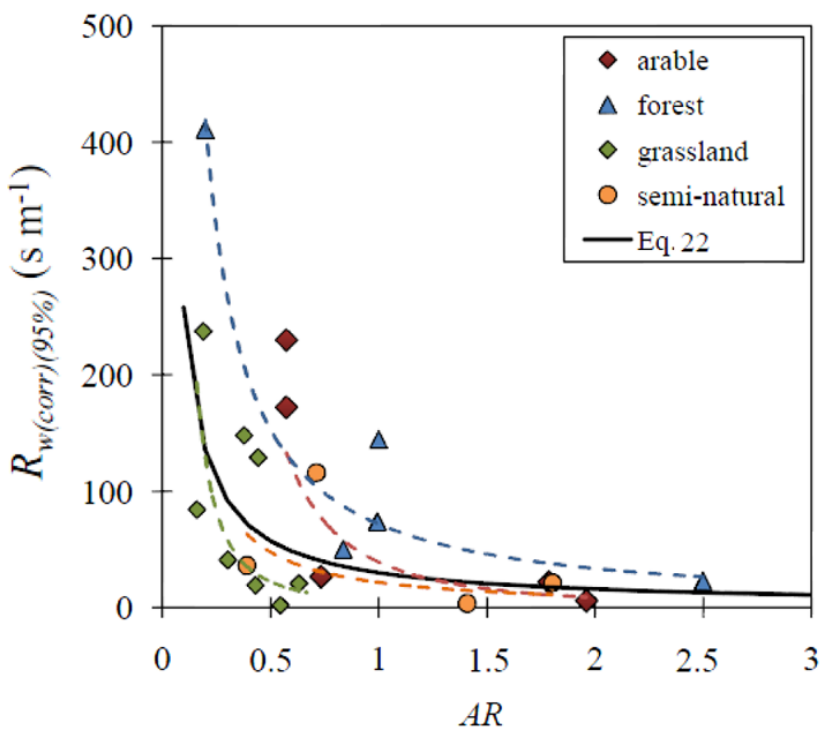

Fig. 6. External leaf surface resistance at $95 \%$ relative humidity $\left(R_{\mathrm{W}(\operatorname{corr})(95 \%)}\right)$ as a function of the ratio of Total Acids $/ \mathrm{NH}_{3}$ $\left(\mathrm{AR}=\left(2 \mathrm{SO}_{2}+\mathrm{HNO}_{3}-+\mathrm{HCl}\right) / \mathrm{NH}_{3}\right)$ in the atmosphere separated

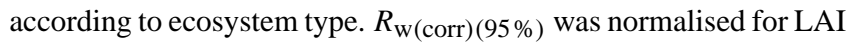
and temperature. From Massad et al. (2010b).

which scaled by LAI determines the bulk canopy leaf surface water storage $\left(M_{\mathrm{H}_{2} \mathrm{O}}^{\mathrm{c}}\right)$, was estimated on the basis of relative humidity at the surface (Sutton et al., 1998a; van Hove et al., 1989; Burkhardt and Eiden, 1994). The treatment of leaf surface wetness as a dynamic pool of $\mathrm{NH}_{4}^{+}$, with periods of pool contraction (evaporation) followed by periods of expansion (dewfall, rainfall), meant that the bi-directional cuticular $\mathrm{NH}_{3}$ flux (into or out of the adsorption capacitor $C_{\mathrm{d}}$ ) was dependent on previous fluxes (hysteresis). The charging resistance $\left(R_{\mathrm{d}}\right)$ was calculated as $R_{\mathrm{d}}\left(\mathrm{s} \mathrm{m}^{-1}\right)=5000 / C_{\mathrm{d}}$, equivalent to an 83 min time constant, and the $\mathrm{NH}_{3}$ surface reaction rate $\left(K_{\mathrm{r}}\right)$ and surface solution $\mathrm{pH}$ (needed to calculate $\Gamma_{\mathrm{d}}$ ) were both prescribed.

The Sutton et al. (1998) $C_{\mathrm{d}} / R_{\mathrm{d}}$ simple dynamic approach was subsequently adopted by Neirynck and Ceulemans (2008) for Scots Pine forest; here, however, water film thickness was calculated as a function of the normalized output of a leaf wetness sensor (LW), while parameterizations of both $K_{\mathrm{r}}$ and surface $\mathrm{pH}$ were obtained by optimizing the model results to minimize bias and maximize the $R^{2}$ between observed and modelled fluxes.

A significant development of the capacitance model was provided by Flechard et al. (1999), here termed DEWS (Dynamic pollutant Exchange with Water films on vegetation Surfaces), originally developed in moorland vegetation. This model has since been applied for managed grassland to the Braunschweig flux dataset (Burkhardt et al., 2009). By contrast to the Sutton et al. (1998a) and Neirynck and Ceulemans (2008) implementations of the $C_{\mathrm{d}} / R_{\mathrm{d}}$ model, in which leaf surface solution $\mathrm{pH}$ was prescribed or statisti- cally optimized, the dynamic chemistry model of Flechard et al. (1999) simulated solution chemistry, $\mathrm{pH}$ and $\Gamma_{\mathrm{d}}$ mechanistically, where Henry and dissociation equilibria were forced by measured ambient concentrations of the trace gases $\mathrm{NH}_{3}, \mathrm{SO}_{2}, \mathrm{CO}_{2}, \mathrm{HNO}_{2}, \mathrm{HNO}_{3}$ and $\mathrm{HCl}$. The oxidation of $\mathrm{SO}_{2}$ to $\mathrm{SO}_{4}^{2-}$ by $\mathrm{O}_{3}, \mathrm{O}_{2}$ and $\mathrm{H}_{2} \mathrm{O}_{2}$ and the exchange of base cations and $\mathrm{NH}_{4}^{+}$between the leaf surface and plant interior were also accounted for. The cuticular adsorption resistance $\left(R_{\mathrm{d}}\right)$ was parameterized as an exponential function of the ionic strength of the solution. Activity coefficients were included in the numerical calculations of the equilibrium $\mathrm{pH}$ and solute concentrations for solutions with ionic strengths up to $0.3 \mathrm{M}$.

Although mechanistically satisfying, and successful in field-scale studies, these dynamic chemistry models to simulate surface-wetness-related $\mathrm{NH}_{3}$ fluxes are computationally intensive, requiring short time steps (seconds to minutes), and thus they have not been implemented until now in large-scale models such as CTMs. Most models use unidirectional, steady-state cuticular resistance approaches for leaf surface wetness, in which no $\Gamma_{d}$ is assumed. Instead, the non-stomatal resistance to deposition, associated with the epifoliar $\mathrm{NH}_{3}$ sink and termed $R_{\mathrm{W}}$ here (or $R_{\text {ext }}$, or $R_{\mathrm{ns}}$, or $R_{\text {cut }}$, in different models; e.g. Flechard et al., 2011), typically decreases with increasing RH (or increases with VPD), to reflect the larger sink strength of wet surfaces. The effect of $\mathrm{pH}$ on $\mathrm{NH}_{3}$ uptake rates is reflected, in some models or parameterizations, in the dependence of $R_{\mathrm{W}}$ on the atmospheric molar ratio of $\mathrm{SO}_{2} / \mathrm{NH}_{3}$ or Total Acids $/ \mathrm{NH}_{3}$ (e.g. Erisman et al., 1994; Nemitz et al., 2001a; Massad et al., 2010b; Simpson et al., 2012), or simply on the $\mathrm{NH}_{3}$ concentration itself (Jones et al., 2007). Figure 6 shows the exponential decay curve fitted to a compilation of published $R_{\mathrm{W}}$ values (at $95 \%$ $\mathrm{RH}$ ) as a function of the Total Acids/ $\mathrm{NH}_{3}$ ratio, at a range of $\mathrm{NH}_{3}$ flux measurement sites, for four major ecosystem types (Massad et al., 2010b). Despite a substantial scatter, there is no question that, at sites where the pollution climate is dominated by $\mathrm{NH}_{3}$, non-stomatal uptake is severely restricted by a high $\mathrm{pH}$ and high surface $\left[\mathrm{NH}_{4}^{+}\right]$(e.g. high $\Gamma_{\mathrm{d}}$ ).

A "hybrid" non-stomatal $\mathrm{NH}_{3}$ exchange modelling concept, half-way between capacitance $\left(\Gamma_{\mathrm{d}}>0\right.$, bi-directional) and resistance $\left(\Gamma_{d}=0\right.$, deposition-only) models, was developed within the DEPosition of Acidifying Compounds (DEPAC 3.11) model by Wichink Kruit et al. (2010) and van Zanten et al. (2010). Their model recognized the existence of a non-zero $\Gamma_{\mathrm{d}}$ emission potential (which they termed $\Gamma_{\mathrm{w}}$ ), which increased with ambient $\mathrm{NH}_{3}$ concentration at a given site. However, the parameterization of the external leaf surface pathway was not truly bi-directional, since the equivalent $\chi_{\mathrm{d}}\left(\right.$ or $\chi_{\mathrm{w}}$ ) was approximately parameterized as a fraction of the ambient air concentration $\left(\chi_{\mathrm{a}}\right)$, and thus $\chi_{\mathrm{d}}$ never exceeded $\chi_{\mathrm{a}}$. Nonetheless, the parameterization accounted for saturation effects at high air concentrations, in a similar fashion to e.g. the $\mathrm{NH}_{3}$-dependent $R_{\mathrm{w}}$ of Jones et al. (2007), 
with the difference that non-zero values of $\Gamma_{\mathrm{d}}$ and $\chi_{\mathrm{d}}$ were mechanistically more realistic. In making this modification, much of the uncertainty in the dependence of the cuticular exchange on the pollution climate and ecosystem was transferred from $R_{\mathrm{W}}$ to $\chi_{\mathrm{w}}$. While the exact partitioning between the two terms remained uncertain, the hybrid approach had the advantage of accounting, in theory, for the bi-directional and concentration-dependent exchange with the leaf cuticle, while avoiding the requirement for more complex timedependent dynamic modelling solutions.

\subsubsection{Air column chemistry}

Nemitz et al. (2012) present a comprehensive review of models dealing with acid gases, aerosols and their interactions with $\mathrm{NH}_{3}$, and thus only a brief overview is given here. Several numerical models have been developed for the implementation of modified gradient techniques to infer the surface flux of $\mathrm{NH}_{3}$ and chemically reactive species from profile measurements and accounting for GPIC effects on vertical flux divergence (Brost et al., 1988; Kramm and Dlugi, 1994; Nemitz et al., 1996; van Oss et al., 1998; Nemitz and Sutton, 2004; Ryder, 2010). Modelling results showed that reactions could theoretically change $\mathrm{NH}_{3}$ fluxes by as much as $40 \%$ (Kramm and Dlugi, 1994) or even lead to flux reversal (van Oss et al., 1998).

For the chemical source/sink term associated with the $\mathrm{NH}_{3}-\mathrm{HNO}_{3}-\mathrm{NH}_{4} \mathrm{NO}_{3}$ triad, the kinetics of the chemical inter-conversion can either be described by the use of chemical timescales, reaction rate coefficients, or by using a full model of size-resolved chemistry and microphysics. Brost et al. (1988) were the first to model the effect of the $\mathrm{NH}_{3}$ $\mathrm{HNO}_{3}-\mathrm{NH}_{4} \mathrm{NO}_{3}$ equilibrium on surface exchange fluxes of $\mathrm{NH}_{3}$, and described the reaction as a first-order relaxation towards equilibrium with a characteristic time $\tau_{\mathrm{c}}$. The later model by van Oss et al. (1998) also described the shift towards equilibrium by a relaxation-type equation for the flux divergence. The first-order relaxation approach received criticism from Kramm and Dlugi (1994), who proposed an alternative model, favouring a reaction rate formulation using rate coefficients for condensation $\left(k_{1}\right)$ and evaporation $\left(k_{2}\right)$, and coupled with an inferential resistance model for the estimation of surface exchange fluxes from single-point concentration data. Nemitz (1998) argued that both firstorder relaxation and reaction rate approaches were actually equally valid, but there are large uncertainties in the reaction rate coefficients (Kramm and Dlugi, 1994) and in chemical timescales (Wexler and Seinfeld, 1990).

For the calculation of the concentration and flux profiles modified by chemical reactions, additional information linking the flux $\left(F_{\chi}\right)$ to atmospheric turbulence is required to solve the vertical flux divergence, i.e. the $\delta F_{\chi} / \delta z$ differential, which constitutes a so-called closure problem (Nemitz, 1998). Second-order closure (SOC) approaches use information from the budget equations of the turbulent fluxes, which include second-moment terms. By contrast, first-order closure (FOC), also called K-closure models, use information provided by the concentrations themselves, implying that $\mathrm{K}$ theory is used for the flux-gradient relationship. SOC tends to be regarded as a reference and should be accurate, but there are difficulties in applying the method to all atmospheric stabilities. By contrast, FOC is much easier to apply in all stabilities, but there are limitations of the applicability of inert $\mathrm{K}$-theory to reactive species. Thus efforts have been made to estimate the magnitude of the error induced by FOC compared with SOC, and to develop modified K-theories and correction procedures (Nemitz, 1998).

The effects of ground $\mathrm{NH}_{3}$ emissions on $\mathrm{NH}_{4} \mathrm{NO}_{3}$ formation, the extension of existing FOC approaches by the $\mathrm{NH}_{3}-$ $\mathrm{HCl}-\mathrm{NH}_{4} \mathrm{Cl}$ triad, and the inclusion of vertical gradients of temperature, relative humidity and aerosol composition were innovative aspects developed by Nemitz et al. (1996) and Nemitz (1998). The numerical model presented by Nemitz and Sutton (2004) took the approach further and developed a modified gradient technique, which explicitly calculated the particle size distribution of the $\mathrm{NH}_{4}^{+}$aerosol as a function of height, in addition to the concentration and flux profiles of the bulk aerosol species. From the change of the size distribution with height $(z)$, apparent aerosol deposition velocities could be inferred, which may be compared with values derived from eddy-covariance (EC) measurements, e.g. using optical particle counters. With the knowledge of the size distribution it became also possible to calculate the chemical timescale $\left(\tau_{\mathrm{c}}\right)$ of the equilibration process (Wexler and Seinfeld, 1990) as a function of the size distribution at each height. Ryder (2010) took this approach another major step forward, by modeling the evolution of a mixed, sizedistributed aerosol in a fully coupled model treating transport, emission/deposition, chemistry, phase transition and aerosol microphysics in a multi-layer approach, which also resolved chemical interactions within the canopy. All previous approaches were based on single-layer (big-leaf) exchange models.

The advances in GPIC/flux interaction modelling over the last $15 \mathrm{yr}$ have therefore been very substantial, but models have not yet been applied on a routine basis at spatial scales larger than the field. Also, despite the increasing availability of multiple gas and aerosol species concentrations and fluxes over a range of ecosystems (e.g. Douglas fir forest, van Oss et al., 1998; oilseed rape, Nemitz et al. 2000b; heathland, Nemitz et al., 2004, Nemitz and Sutton, 2004; tropical pasture, Trebs et al., 2004; grassland, Nemitz, 1998, Nemitz et al., 2009b, Wolff et al., 2010a, Thomas et al., 2009; spruce forest, Wolff et al., 2010a, b), model results have only rarely been compared with measurements. Significant future model improvements could be anticipated from a systematic processing of all existing datasets and from conducting model sensitivity analyses of the minimum complexity required to reproduce measurements adequately. It should be noted that, 
in general, the relative effect of GPIC on fluxes of acids and aerosols is larger than that on $\mathrm{NH}_{3}$ (Nemitz et al., 2012).

\subsection{Canopy/ecosystem scale models}

Canopy-scale models integrate component processes and their interactions within SVAT frameworks, with the objective of predicting the net ecosystem $\mathrm{NH}_{3}$ flux from the inputs of: (i) ambient $\mathrm{NH}_{3}$ and other concentrations $\left(\chi_{\mathrm{a}}\right)$; (ii) meteorology (global and net radiation, temperature, relative humidity or VPD, wind speed, and friction velocity, sensible, latent and ground heat fluxes if available); and (iii) ecosystem characteristics such as LAI, canopy height $\left(h_{\mathrm{c}}\right)$. Model concepts range from simple, steady-state, "Big-Leaf" canopy resistance $\left(R_{\mathrm{c}}\right) /$ deposition velocity $\left(V_{\mathrm{d}}\right)$ approaches, to complex, dynamic, multiple-layer canopy compensation point schemes. Most models are based on the resistance analogy, in which the flux $\left(F_{\chi}\right)$ between two potentials $\mathrm{A}$ and $\mathrm{B}$ is equal to the potential difference $\left(\chi_{\mathrm{A}}-\chi_{\mathrm{B}}\right)$ divided by the resistance $\left(R_{\mathrm{A}, \mathrm{B}}\right)$, with the soil-canopy-atmosphere system being represented as a network of potentials connected by resistances in series (for different layers) and in parallel (for different pathways) (e.g. Monteith and Unsworth, 1990).

\subsubsection{Canopy resistance $\left(R_{\mathrm{c}}\right)$ models}

Canopy resistance/deposition velocity $\left(R_{\mathrm{c}} / V_{\mathrm{d}}\right)$ models (e.g. Baldocchi et al., 1987; Wesely, 1989; Erisman et al., 1994; see review by Wesely and Hicks, 2000) simulate $\mathrm{NH}_{3}$ dry deposition to the surface, whereby $R_{\mathrm{c}}$ is the total resistance to deposition resulting from component terms such as stomatal $\left(R_{\mathrm{S}}\right)$, mesophyll $\left(R_{\mathrm{m}}\right)$, non-stomatal/external/cuticular ( $R_{\mathrm{w}}$ or $R_{\mathrm{ns}}$ or $R_{\mathrm{ext}}$ or $\left.R_{\mathrm{cut}}\right)$, or soil ( $R_{\text {soil }}$ or $\left.R_{\mathrm{g}}\right)$ resistances (Fig. 7a). $R_{\mathrm{c}} / V_{\mathrm{d}}$ models assume a zero $\mathrm{NH}_{3}$ emission potential in the canopy, and thus the exchange is uni-directional (deposition-only). The deposition velocity is calculated as the inverse sum of $R_{\mathrm{c}}$ in series with the aerodynamic $\left(R_{\mathrm{a}}\right)$ and viscous sub-layer $\left(R_{\mathrm{b}}\right)$ resistances above the canopy, and the flux $F_{\chi}$ as the product of $\mathrm{NH}_{3}$ concentration $\left(\chi_{\mathrm{a}}\right)$ and $V_{\mathrm{d}}$ :

$V_{\mathrm{d}}\{z\}=\left(R_{\mathrm{a}}\{z\}+R_{\mathrm{b}}+R_{\mathrm{c}}\right)^{-1}$

$F_{\chi}=-V_{\mathrm{d}}\{z\} \times \chi_{\mathrm{a}}\{z\}$,

where $V_{\mathrm{d}}, R_{\mathrm{a}}$ and $\chi_{\mathrm{a}}$ are all expressed at the same reference height $(z)$ above d, the displacement height. The resistances $R_{\mathrm{a}}$ and $R_{\mathrm{b}}$ are relatively well characterised and readily calculated from micrometeorological measurements (e.g. Monteith and Unsworth, 1990; Garland, 1977). Stomatal resistance to gaseous transfer is typically derived in the different models using a generic light-response function within a multiplicative algorithm also accounting for T, VPD and SWC stress factors (Jarvis, 1976; Emberson et al., 2000a, b).
Some models split PAR into its direct and diffuse fractions and compute the sunlit and shaded components of LAI, such that total (or bulk) stomatal resistance is calculated from sunlit and shaded resistances weighted by their respective LAI fractions (Baldocchi et al., 1987). By contrast the much simpler $R_{\mathrm{S}}$ routine by Wesely (1989) only requires global radiation and surface temperature as input, and may be used when land use and vegetation characteristics are not well known.

Canopy resistance models often use a Big-Leaf approach, i.e. they do not distinguish several layers vertically in the canopy, nor do they simulate in-canopy turbulent transfer, and vegetation is thus assumed to behave as one single leaf. Such models can nonetheless include an in-canopy aerodynamic resistance term $\left(R_{\mathrm{ac}}\right)$ in series with $R_{\text {soil }}$ (e.g. Wesely, 1989; DEPAC, Erisman et al., 1994; European Monitoring and Evaluation Programme (EMEP), Simpson et al., 2012; A Unified Regional Air-quality Modelling System (AURAMS), Zhang et al., 2003). Most of the existing $R_{\mathrm{c}}$ model variants, alongside specific innovations, actually borrowed model parts and parameterizations from other models, e.g. PLant ATmosphere INteractions (PLATIN, Grünhage and Haenel, 1997), drawing on Wesely (1989), Sutton et al. (1995b) and DEPAC; or SPRUCE forest DEPosition (SPRUCEDEP, Zimmermann et al., 2006), drawing on PLATIN, Wesely (1989), DEPAC, EMEP and AURAMS.

In contrast to big leaf $R_{\mathrm{c}}$ models, the MLBC dry deposition model proposed by $\mathrm{Wu}$ et al. (2003), based on the Multi-Layer Model (MLM) by Meyers et al. (1998), described gaseous exchange between the soil, plants, and the atmosphere. A biochemical stomatal resistance model based on the Berry-Farquhar approach (Berry and Farquhar, 1978) described photosynthesis and respiration and their coupling with stomatal resistance for sunlit and shaded leaves separately. Various aspects of the photosynthetic process in both $\mathrm{C} 3$ and $\mathrm{C} 4$ plants were considered in the model. The source/sink term $\mathrm{S}(z)$ was parameterized using terms to account for fluxes through the stomata of sun-lit and shaded leaves, and for fluxes through the cuticles of the leaves. The canopy was divided into $N=20$ equally spaced levels, and $\mathrm{S}(z)$ was evaluated at each height, and summed with appropriate normalization. Vertical leaf area density $\operatorname{LAI}(z)$ was assumed to be described by a beta distribution (Massman, 1982), which was chosen for compatibility with the roughness length and displacement height model of Massman (1997). Plant canopy structures were fit by one of six typical vertical profiles.

\subsubsection{Canopy compensation $\left(\chi_{c}\right)$ point models}

The recognition that there is a non-zero $\mathrm{NH}_{3}$ emission potential $(\Gamma)$ in most vegetation types, as well as in different parts of the canopy (Sect. 2), has led to the development of a range of canopy compensation point $\left(\chi_{c}\right)$ models, in which the net bi-directional flux to or from the atmosphere is provided generically from the difference between $\chi_{c}$ and 


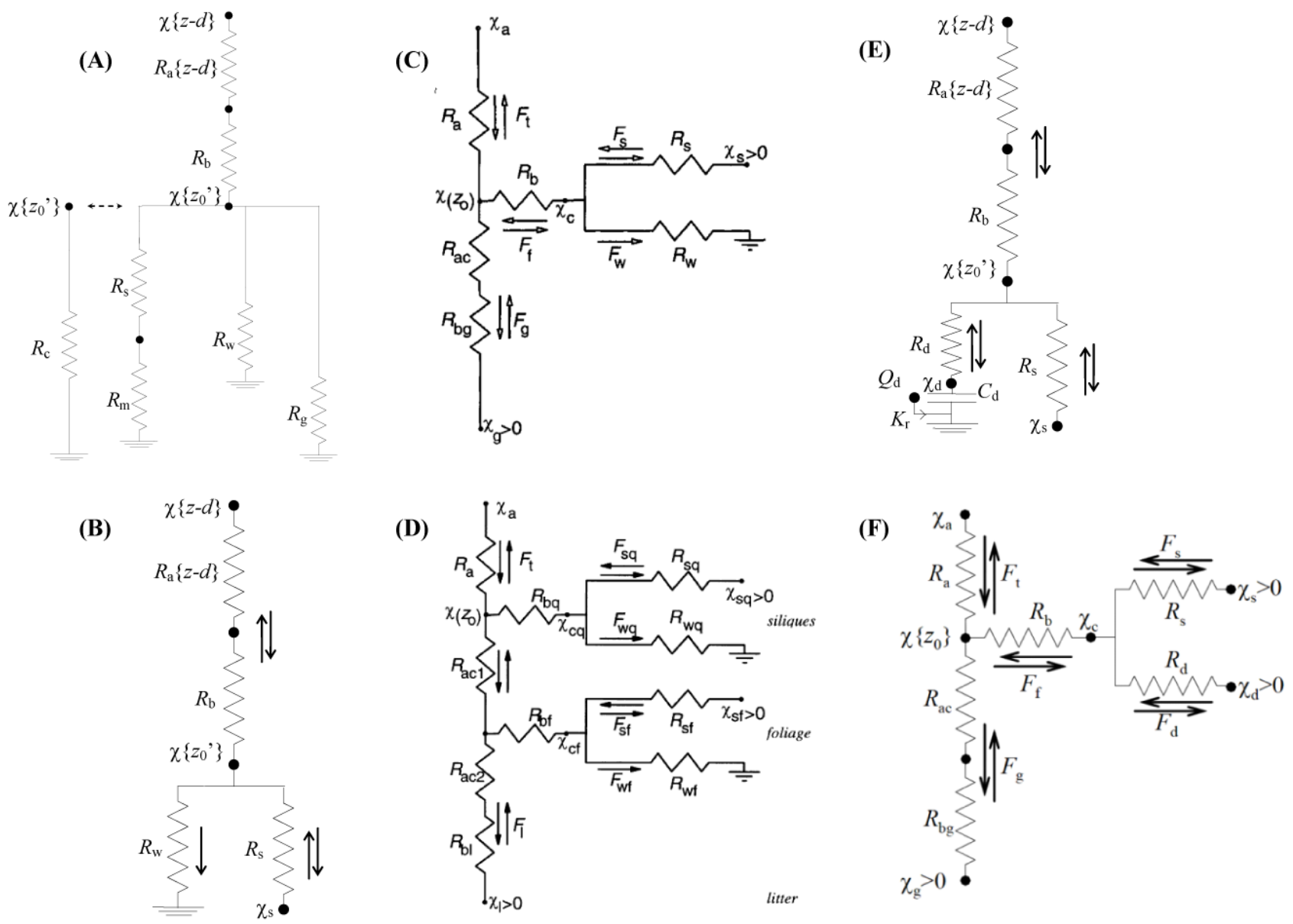

Fig. 7. Typical surface/atmosphere schemes for the modelling of net canopy-scale $\mathrm{NH}_{3}$ fluxes. (A) Generic example of canopy resistance $\left(R_{\mathrm{C}}\right)$ model; (B) the 1-layer $\chi_{\mathrm{s}} / R_{\mathrm{W}}$ canopy compensation point model by Sutton et al. (1995b); (C) the 2-layer $\chi_{\mathrm{s}} / \chi_{\mathrm{g}} / R_{\mathrm{W}}$ canopy compensation point model by Nemitz et al. (2001a); (D) the 3-layer (soil, foliage, silique/inflorescence) canopy compensation point model by Nemitz et al. (2000b); (E) the 1-layer $\chi_{\mathrm{s}} / \chi_{\mathrm{d}} / R_{\mathrm{d}}$ capacitance canopy compensation point model by Sutton et al. (1998a); and (F) the 2-layer $\chi_{\mathrm{s}} / \chi_{\mathrm{g}} / \chi_{\mathrm{d}} / R_{\mathrm{d}}$ dynamic chemistry canopy compensation point model by Burkhardt et al. (2009).

$\chi_{\mathrm{a}}$ :

$F_{\chi}=\frac{\chi_{\mathrm{c}}-\chi_{\mathrm{a}}\{z\}}{R_{\mathrm{a}}\{z\}+R_{\mathrm{b}}}$

For the formulation of $\chi_{c}$ itself, various canopy architectures have been put forward. The first $\chi_{\mathrm{c}}$ model was developed by Sutton et al. (1995b, 1998a) and is often referred to as the "two-leg" $\chi_{\mathrm{s}} / R_{\mathrm{w}}$ model (Fig. $7 \mathrm{~b}$ ), featuring bidirectional exchange with stomata and deposition to nonstomatal surfaces. Here the $R_{\mathrm{W}}$ term accounted for all nonstomatal canopy sink terms, including leaf cuticle waxes and water, and allowed both deposition from the atmosphere as well as re-capture of $\mathrm{NH}_{3}$ emitted by stomata. The canopy compensation point was calculated as (Sutton et al., 1995b):

$\chi_{\mathrm{c}}=\frac{\frac{\chi_{\mathrm{a}}\{z\}}{R_{\mathrm{a}}\{z\}+R_{\mathrm{b}}}+\frac{\chi_{\mathrm{s}}}{R_{\mathrm{s}}}}{\left(R_{\mathrm{a}}\{z\}+R_{\mathrm{b}}\right)^{-1}+R_{\mathrm{s}}^{-1}+R_{\mathrm{w}}^{-1}}$
This 1-layer framework has been successfully applied for situations in which the canopy was closed and/or where soil $\mathrm{NH}_{3}$ emission was negligible. However, where soil or litter $\mathrm{NH}_{3}$ emission took place and dominated the canopy-scale flux, very large and unrealistic apoplastic $\Gamma_{\mathrm{s}}$ ratios (compared with independent estimates by apoplastic bioassays) were required to simulate the observed net emissions (Milford, 2004). The 2-layer model by Nemitz et al. (2001a) was thus the logical extension of the 1-layer $\chi_{\mathrm{s}} / R_{\mathrm{w}}$ model, introducing, in addition to stomatal $\chi_{\mathrm{s}}$ and non-stomatal $R_{\mathrm{w}}$, a soil+ground surface emission potential (termed $\chi_{\mathrm{g}}$ in Fig. 7c), mediated by in-canopy $R_{\mathrm{ac}}$ and by a further ground surface viscous sublayer term $\left(R_{\mathrm{bg}}\right)$. This $\chi_{\mathrm{s}} / \chi_{\mathrm{g}} / R_{\mathrm{w}}$ model has been extensively tested and applied in diverse contexts, and was proposed as the optimum compromise between simplicity and accuracy, capable of describing bi-directional $\mathrm{NH}_{3}$ exchange in atmospheric transport models over a very wide range of vegetation types (Nemitz et al., 2001a; Massad 
et al., 2010b; Cooter et al., 2010). As with the 1-layer $\chi_{c}$ model, the central term in solving the resistance model is $\chi_{\mathrm{c}}$, the resolution of which provides (Nemitz et al., 2001a):

$$
\begin{aligned}
\chi_{\mathrm{c}}= & {\left[\chi_{\mathrm{a}}\left(R_{\mathrm{a}} R_{\mathrm{b}}\right)^{-1}+\chi_{\mathrm{s}}\left\{\left(R_{\mathrm{a}} R_{\mathrm{S}}\right)^{-1}+\left(R_{\mathrm{b}} R_{\mathrm{S}}\right)^{-1}+\left(R_{\mathrm{g}} R_{\mathrm{s}}\right)^{-1}\right\}+\chi_{\mathrm{g}}\left(R_{\mathrm{b}} R_{\mathrm{g}}\right)^{-1}\right] } \\
& \times\left\{\left(R_{\mathrm{a}} R_{\mathrm{b}}\right)^{-1}+\left(R_{\mathrm{a}} R_{\mathrm{s}}\right)^{-1}+\left(R_{\mathrm{a}} R_{\mathrm{W}}\right)^{-1}+\left(R_{\mathrm{b}} R_{\mathrm{g}}\right)^{-1}+\left(R_{\mathrm{b}} R_{\mathrm{S}}\right)^{-1}\right. \\
& \left.+\left(R_{\mathrm{b}} R_{\mathrm{w}}\right)^{-1}+\left(R_{\mathrm{g}} R_{\mathrm{S}}\right)^{-1}+\left(R_{\mathrm{g}} R_{\mathrm{w}}\right)^{-1}\right\}^{-1} .
\end{aligned}
$$

A three-layer model was also developed by Nemitz et al. (2000b), to account for a third potential $\mathrm{NH}_{3}$ emission/uptake layer in the inflorescences or siliques at the top of an oilseed rape canopy, in addition to foliar and ground exchange. Here, two terms were defined for $R_{\mathrm{ac}}\left(R_{\mathrm{ac} 1}\right.$ from siliques to foliage, $R_{\mathrm{ac} 2}$ from foliage to ground), as were two $R_{\mathrm{b}}$ terms and two $R_{\mathrm{w}}$ terms for the siliques and foliage layers (Fig. 7d). The authors concluded that the leaf stomata were an effective $\mathrm{NH}_{3}$ sink, whereas the leaf litter dominated nighttime emissions with the silique layer thought to dominate daytime emissions.

As modelled fluxes are highly sensitive to soil and plant surface temperatures (Sect. 2.1), an accurate description of in-canopy vertical profiles of temperature is highly desirable, such that each $\Gamma$ potential through the profile (Sect. 2.5) is expressed with the proper temperature scaling. Thus the Surface Atmosphere (SURFATM)- $\mathrm{NH}_{3}$ SVAT model of Personne et al. (2009) coupled an energy budget model (Choudhury and Monteith, 1988) with a pollutant exchange model, which was based on the $\chi_{\mathrm{s}} / \chi_{\mathrm{g}} / R_{\mathrm{w}}$ model of Nemitz et al. (2001a), and additionally included a diffusive resistance term from the topsoil layer to the soil surface. In a 3week simulation for the Braunschweig grassland, Personne et al. (2009) demonstrated that the energy balance model was suitably adapted for modelling the latent and sensible heat fluxes as the grass was cut then fertilized, based on prescribed (measured) values LAI and $h_{\mathrm{c}}$. The model reproduced the temperatures of leaf and ground surfaces satisfactorily, except for a few days during which the cut grass lay on the ground prior to lifting. The model was later successfully validated against a two-month flux measurement period over a triticale canopy, where is was found that a very small cuticular resistance $\left(R_{\mathrm{W}}<1 \mathrm{~s} \mathrm{~m}^{-1}\right.$ at $\mathrm{RH}>75 \%, R_{\mathrm{W}}=32 \mathrm{~s} \mathrm{~m}^{-1}$ at $\mathrm{RH}=50 \%$ ) was required to explain the observed fluxes (Loubet et al., 2012). In a similar fashion to SURFATM-NH $\mathrm{N}_{3}$, in the Wu et al. (2009) $\mathrm{NH}_{3}$ stomatal compensation point version of the Wu et al. (2003) MLBC model (see above), the scheme was re-parameterized in order to derive leaf temperature from the energy balance at each level $(z)$ in the canopy.

Elsewhere, earlier $R_{\mathrm{c}}$ models have also been modified to include a surface $\mathrm{NH}_{3}$ compensation point, such as: the surface exchange scheme within AURAMS (Zhang et al., 2003, 2010) with a 2-layer $\chi_{\mathrm{s}} / \chi_{\mathrm{g}} / R_{\mathrm{w}}$ structure; the revision of the DEPAC model (Erisman et al., 1994) into DEPAC3.11 with a 1-layer $\chi_{\mathrm{s}} / \chi_{\mathrm{w}} / R_{\mathrm{w}}$ structure (van Zanten et al., 2010; Wichink Kruit et al., 2010); a revised $\chi_{\mathrm{s}} / R_{\mathrm{W}}$ version of PLATIN (Grünhage and Haenel, 2008); or the inclusion of the 2-layer $\chi_{\mathrm{s}} / \chi_{\mathrm{g}} / R_{\mathrm{w}}$ by Nemitz et al. (2001a) into CMAQ for managed agricultural soils (Cooter et al., 2010, 2012; Bash et al. 2012) (see parameterization details below).

A further degree of complexity has been added by leaf surface $\mathrm{NH}_{\mathbf{x}}$ capacitance approaches, as an alternative to the steady-state, uni-directional $R_{\mathrm{w}}$ pathway in the $\chi_{\mathrm{c}}$ models described above (Fig. 7b, c, d). Dynamic numerical solutions for the variable non-stomatal leaf surface $\mathrm{NH}_{\mathrm{x}}$ pool have been grafted onto 1-layer (Fig. 7e; Sutton et al., 1998a; Flechard et al., 1999; Neirynck and Ceulemans, 2008) and 2-layer (Fig. 7f; Burkhardt et al., 2009) $\chi_{\mathrm{c}}$ models. For individual sites, such models tend to improve the overall model predictive capability only marginally, compared with steady state $R_{\mathrm{W}}$-based $\chi_{\mathrm{c}}$ models that have been optimised with sitespecific parameterizations, i.e. an $R_{\mathrm{W}}$ function fitted to reproduce local flux data. Nonetheless, the added value of dynamic chemistry approaches for the leaf surface is three-fold: (i) to better explain the temporal dynamics of emissions; (ii) to allow bi-directional cuticular exchange and $\mathrm{NH}_{3}$ desorption, especially for the morning peak; and (iii) in theory, to predict the leaf surface sink/source strength in a generic and mechanistic fashion, mostly driven by the local pollution climate and atmospheric acid/base mixing ratios, without the need for site-specific, empirical parameterizations for $R_{\mathrm{w}}$ (Flechard et al., 1999). This means that such an approach is more suitable for regional-scale and global applications where the site-specific optimised parametrizations are not generally and systematically applicable.

\subsubsection{Parameterization schemes for $\chi_{\mathrm{c}}$ models}

The canopy compensation point models presented above proposed generic frameworks, which for individual ecosystems or flux measurement sites require an optimisation with locally fitted parameters or functions (e.g. $\Gamma_{\mathrm{s}}, \Gamma_{\mathrm{g}}, R_{\mathrm{w}}$ ). Loubet et al. (2012) argue that one drawback of model/flux comparisons at given measurement sites is the non-uniqueness of parameter vectors that best fit the $\mathrm{NH}_{3}$ fluxes: it is for example often difficult to establish whether soil or stomata are the main sources.

To achieve this, it is typically necessary to add additional site evidence, such as bioassay estimates of $\Gamma$ for different ecosystem compartments (e.g. Fig. 3) and to carefully analyze the time course of differences between measurements and the estimates provided by different model appraoches.

For generalisation and application of models at larger scales, typically within regional CTMs, several parameterization schemes have been proposed recently. The new parameterizations for the 1-layer $\left(\chi_{\mathrm{s}} / \chi_{\mathrm{w}} / R_{\mathrm{w}}\right)$ DEPAC 3.11 scheme by Wichink Kruit et al. (2010) and van Zanten et al. (2010) were based on a combination of the results of three years of ammonia flux measurements over a Dutch grassland (Lolium perenne/Poa trivialis) canopy and of existing parameterizations from the literature. Values of $\chi_{\mathrm{w}}$ were derived from actual nighttime flux measurements and accounted for 
the pollution climate of the site, while their derived $R_{\mathrm{w}}$ function mostly reflected surface humidity effects. The observed seasonal variations in $\Gamma_{\mathrm{s}}$ at their grassland site (typically $>5000$ from autumn until early spring, decreasing to $\sim 1000$ in summer, see Fig. 2), presumably reflecting photosynthetic activity and GS/GOGAT activity, and were parameterized as a function of temperature with an exponential decay fit. (Note that Loubet et al. (2012) found a similar exponential decay for $\Gamma_{\mathrm{c}}$ in a triticale canopy in spring). The spatial variations of $\Gamma_{\mathrm{s}}$ were linearly linked to atmospheric pollution levels through the long-term $\mathrm{NH}_{3}$ concentration for given sites, based on a review of literature values. Two linear regressions were proposed, either based on literature $\Gamma_{\mathrm{s}}$ values derived from micrometeorological flux measurements, to be used in 1-layer $\chi_{\mathrm{s}} / R_{\mathrm{w}}$ or $\chi_{\mathrm{s}} / \chi_{\mathrm{w}} / R_{\mathrm{w}}$ models, or based on $\Gamma_{\mathrm{s}}$ values from apoplastic extraction, to be used in 2- or multilayer (e.g. $\chi_{\mathrm{s}} / \chi_{\mathrm{g}} / R_{\mathrm{W}}$ ) models (see Fig. 7). This distinction was based on the recognition that bioassay-derived $\Gamma_{\mathrm{s}}$ values were typically a factor of 3 lower than micrometeorologically derived values (e.g. Fig. 1d), presumably due to additional contributions by litter and soil emissions to the latter estimates.

Zhang et al. (2010) proposed parameterizations for their 2layer $\chi_{\mathrm{s}} / \chi_{\mathrm{g}} / R_{\mathrm{w}}$ model within AURAMS based on an extensive literature review. Their approach was to compile a large database of published $\chi_{\mathrm{s}}$ and $\chi_{\mathrm{g}}$ values, and to create a model look-up table (cf Table 5 in Zhang et al., 2010) for both parameters. For each of their 26 land-use classes (LUC), they derived representative model input values based on statistics of literature data. For LUC classes with fertilized vegetation, a much larger value was used (typically factor 10 to 100) for both $\chi_{\mathrm{s}}$ and $\chi_{\mathrm{g}}$ than for semi-natural ecosystems. For the former (fertilized), one single value was used throughout, while for the latter (semi-natural), both $\Gamma_{\mathrm{s}}$ and $\Gamma_{\mathrm{g}}$ can take either one of two default values, either "high" or "low", depending on the background atmospheric $\mathrm{N}$ input by wet and dry deposition. The parameterization for $R_{\mathrm{w}}$ (leaf cuticle) was unchanged from Zhang et al. (2003) and based on canopy wetness, leaf area, and meteorological conditions (relative humidity, friction velocity), but did not account for differences in pollution climate. Initial model runs showed that typical summer daytime $\chi_{\mathrm{c}}$ values (at a temperature of $25^{\circ} \mathrm{C}$ ), assuming a low $\mathrm{N}$ status, were less than $2 \mu \mathrm{g} \mathrm{m}^{-3}$ over forests and other semi-natural canopies, below $5 \mu \mathrm{g} \mathrm{m}^{-3}$ over grasslands, and between 5 and $10 \mu \mathrm{g} \mathrm{m}^{-3}$ over agricultural crops. In the winter, these values decreased to almost zero over the forests and to below $3 \mu \mathrm{g} \mathrm{m}^{-3}$ over the crops. The application of this new bi-directional air-surface exchange model in replacement of the original dry deposition model will reduce the dry deposition fluxes simulated in the regional scale airquality model for which it was designed, especially during the daytime and for canopies with high-N status. The reductions in simulated dry deposition fluxes will also be larger at higher temperatures, stronger wind speeds, and drier conditions (Zhang et al., 2010).
Massad et al. (2010b) also made a very comprehensive review of the $\mathrm{NH}_{3}$ flux literature, in order to derive a generalised parameterization scheme for the 2-layer $\chi_{\mathrm{s}} / \chi_{\mathrm{g}} / R_{\mathrm{W}}$ model by Nemitz et al. (2001a). Although their parameterizations were intended for application in any CTM, their scheme was to some extent taylored to fit the LUC of the EMEP model (Table 6 in Massad et al., 2010b; Simpson et al., 2012). The meta-analysis confirmed that nitrogen input was the main driver of apoplastic $\left[\mathrm{NH}_{4}^{+}\right]$and bulk tissue $\left[\mathrm{NH}_{4}^{+}\right]$. For managed ecosystems, the parameterizations derived for fertilization were reflected in peak value of $\Gamma_{\mathrm{s}}$ and $\Gamma_{\mathrm{g}}$ a few days following application, followed by a gradual return to background values. Fertilizer amounts determined the magnitude of the $\Gamma_{\mathrm{S}}$ response, regardless of fertilizer form (mineral, organic, grazing), and also the scale of the $\Gamma_{\mathrm{g}}$ response for mineral fertilizer. The initial $\Gamma_{\mathrm{g}}$ response to slurry application was equal to the $\Gamma_{\text {slurry }}$ value, while animal grazing resulted in an initial $\Gamma_{\mathrm{g}}$ value of 4000 . The sharp temporal decrease in $\Gamma_{\mathrm{s}}$ and $\Gamma_{\mathrm{g}}$ following the initial fertilization or grazing peak was parameterized by an exponential decay function with an e-folding time constant $(\tau)$ of 2.88 days. For unmanaged ecosystems, as well as managed agrosystems in background conditions, $\Gamma_{\mathrm{s}}$ was parameterized as a power law function of total $\mathrm{N}$ input $\left(\mathrm{N}_{\mathrm{in}}\right)$ to the ecosystem, i.e. atmospheric $\mathrm{N}$ deposition $\left(\mathrm{N}_{\text {dep }}\right)$ plus annual fertilizer application $\left(\mathrm{N}_{\mathrm{app}}\right)$ if applicable. Although the meta-analysis had demonstrated that the relationship of $\Gamma_{\mathrm{s}}$ to bulk tissue $\left[\mathrm{NH}_{4}^{+}\right]$ was more robust than to $\mathrm{N}_{\mathrm{in}}$ across a wide range of plant species (see also Mattsson et al., 2009a), the use of $\mathrm{N}_{\text {in }}$ as a proxy for $\Gamma_{\mathrm{s}}$ was deemed more convenient than bulk tissue $\left[\mathrm{NH}_{4}^{+}\right]$, which by contrast would not be easily available as spatial input fields for CTMs. The parameterization derived by Massad et al. (2010b) for the leaf surface resistance $R_{\mathrm{w}}$ is discussed above in Section 3.1 and Fig. 6. One of the major advantages of the Massad et al. (2010b) scheme, compared to the parameterization by Zhang et al. (2010), is the mechanistic linkage of $\Gamma_{\mathrm{s}}$ and $\Gamma_{\mathrm{g}}$ to atmospheric $\mathrm{N}$ deposition and to agricultural practices, allowing ecosystems to respond dynamically to changes in emissions and deposition patterns and to land management events.

Cooter et al. (2010) presented an upgrade of the earlier $R_{\mathrm{c}^{-}}$ based $\mathrm{NH}_{3}$ dry deposition approach of Wesely (1989) that had been used within CMAQ (Byun and Schere, 2006), into a bi-directional $\chi_{\mathrm{c}}$ model based on the $\chi_{\mathrm{s}} / \chi_{\mathrm{g}} / R_{\mathrm{w}}$ approach by Nemitz et al. (2001a). The work was motivated by the realisation that the CMAQ representation of the regional nitrogen budget was limited by its treatment of $\mathrm{NH}_{3}$ soil emission from, and deposition to, underlying surfaces as independent, rather than tightly coupled, processes. At the same time, it was recognized that $\mathrm{NH}_{3}$ emission estimates from fertilized agricultural crops needed to respond to variable meteorology and ambient chemical conditions. These objectives were met by the integration of the $\chi_{\mathrm{s}} / \chi_{\mathrm{g}} / R_{\mathrm{w}}$ approach together with elements of the EPIC model (see Sect. 3.1), which was calibrated using data collected during an intensive 2007 maize 
field study in Lillington, North Carolina (Bash et al., 2010; Walker et al., 2013). More recently, regional simulations of CMAQ coupled with EPIC have provided dynamic continental (US) scale $\mathrm{NH}_{3}$ emission estimates from fertilizer applications with a tight coupling between emissions, deposition and agricultural cropping practices (Cooter et al., 2012; Bash et al., 2012) (see Sect. 3.4).

\subsection{Landscape scale models}

The specificity of the landscape scale, especially in agricultural areas, with respect to surface/atmosphere $\mathrm{NH}_{3}$ exchange modelling is characterised by the close proximity of large agricultural point sources, or "hotspots" (Loubet et al., 2009a) and of semi-natural $\mathrm{NH}_{3}$ sink areas such as forests, moorlands and wetlands. Hotspots induce large horizontal $\mathrm{NH}_{3}$ concentration gradients downwind from sources, typically an exponential decay with distance (Walker et al., 2008), and a large spatial heterogeneity in $\mathrm{NH}_{3}$ concentrations (e.g. Dragosits et al., 2002; van Pul et al., 2008) and exchange fluxes (Sommer et al., 2009). This fine-scale variability occurs at spatial scales (typically $100 \mathrm{~m}$ to $1 \mathrm{~km}$ ) much smaller than, and therefore not "seen" by, regional CTMs (resolution typically $5 \times 5 \mathrm{~km}^{2}$ to $50 \times 50 \mathrm{~km}^{2}$ ) f from a regional modelling viewpoint the (unresolved) landscape scale generally falls under the header "sub-grid issues" (Dragosits et al., 2002). Modelling studies have been applied to determine the fraction of emitted $\mathrm{NH}_{3}$, which is recaptured locally downwind from the source (Fowler et al., 1998; Asman et al., 1998). The results vary widely, showing recapture fractions within the first $2 \mathrm{~km}$ between $2 \%$ and up to $60 \%$, but in most cases in the range between $10 \%$ and $40 \%$ (Loubet et al., 2006, 2009a).

The variability is in part due to variations in vegetation types, roughness and LAI over the patchwork of land uses, but also due to the nitrogen enrichment associated with large $\mathrm{NH}_{3}$ deposition rates close to sources (animal houses, manure storage facilities, fertilized fields) (Pitcairn et al., 2006). Given an otherwise homogeneous, large field (a few hectares) cropped with, say, wheat or maize, and located just outside a large point animal production facility, one may expect a 10- or 20-fold higher $\mathrm{NH}_{3}$ deposition at a distance of $20 \mathrm{~m}$ from the source than $200 \mathrm{~m}$ further downwind (Loubet et al., 2009a). One may thus also expect much higher bulk tissue $\mathrm{N}$ or $\left[\mathrm{NH}_{4}^{+}\right]$and higher $\Gamma_{\mathrm{s}}$ close to the farm buildings, as well as higher $\mathrm{NH}_{\mathrm{x}}$ concentrations in soil $\left(\Gamma_{\mathrm{g}}\right)$ and especially on leaf surfaces $\left(\Gamma_{\mathrm{d}}\right)$, together with higher $\mathrm{pH}$, which theoretically lead to less efficient $\mathrm{NH}_{3}$ removal by vegetation (per unit ambient $\mathrm{NH}_{3}$ concentration) (Jones et al., 2007). Such feedbacks of cuticular saturation and apoplastic $\mathrm{NH}_{4}^{+}$enrichment on $\mathrm{NH}_{3}$ deposition rates (Walker et al., 2008) can potentially affect spatial $\mathrm{NH}_{3}$ deposition budgets very significantly at the scale of the landscape, but uncertainties are very large, datasets are few, and parameterizations to account for $\mathrm{N}$ en- richment feedbacks for landscape-scale models have yet to emerge.

These processes and their coupled emission/ dispersion/deposition modelling have recently been thoroughly reviewed by Loubet et al. (2009a), and earlier by Hertel et al. (2006) and Asman (1998, 2002), and thus only a brief overview is presented here. Loubet et al. (2009a) provided a technical comparison of 7 existing local atmospheric transport and deposition models for $\mathrm{NH}_{3}$ : DDR (Asman et al., 1989); TREND/OPS (Asman and van Jaarsveld, 1992), LADD (Hill, 1998), DEPO1 (Asman, 1998), FIDES-2D (Loubet et al., 2001), MODDAAS-2D (Loubet et al., 2006), and OML-DEP (Olesen et al., 2007). All models except MODDAAS-2-D (multi-layer, see Loubet et al., 2006) used a 1-layer (big leaf) surface exchange architecture, and most models used a uni-directional dry deposition $R_{\mathrm{c}} / V_{\mathrm{d}}$ scheme by default. However, both MODDAAS-2-D and FIDES-2D (Loubet et al., 2001) allowed bi-directional exchange with stomata, though they did not account for any potential soil emissions.

Theobald et al. (2012) presented the first intercomparison of 4 short-range atmospheric dispersion models (ADMS, Carruthers et al., 1999; AERMOD, Perry et al., 2004; LADD; and OPS-st, van Jaarsveld, 2004), which they applied to the case of ammonia emitted from agricultural sources. The intercomparison focused on atmospheric $\mathrm{NH}_{3}$ concentration prediction in two case study farms in Denmark and the USA. Wet deposition processes were not included in the simulations because dry deposition is likely the dominant deposition mechanism near sources (Loubet et al., 2009a; Pitcairn et al., 2006). Similarly, chemical processing of $\mathrm{NH}_{3}$ in the atmosphere were also assumed to be negligible for short-range dispersion. Thus the only $\mathrm{NH}_{3}$ removal mechanism involved was surface dry deposition, with all models using $R_{\mathrm{c}} / V_{\mathrm{d}}$ schemes. The performance of all of the models for concentration prediction was judged to be "acceptable" according to a set of objective criteria, although there were large differences between models, depending on which source scenarios (area or volume source, elevation above ground, exit velocity) were tested. The findings highlight that the rate of removal by dry deposition near such a source leads to a rather small effect on simulated near-source $\mathrm{NH}_{3}$ concentrations, which largely depended on sound treatment of source characteristics and dispersion rates.

\subsection{Ammonia exchange in chemical transport models (CTMs) at regional scales}

Despite unequivocal evidence and widespread concensus that $\mathrm{NH}_{3}$ exchange is bi-directional in most climates and ecosystem types, including unfertilized vegetation, most CTMs operating at national, regional and continental scales still use $R_{\mathrm{c}} / V_{\mathrm{d}}$ deposition-only schemes for $\mathrm{NH}_{3}$ (see model review by van Pul et al., 2009): e.g. unified EMEP MSC$\mathrm{W}$ model (Simpson et al., 2012) and EMEP4UK $5 \times 5 \mathrm{~km}$ 


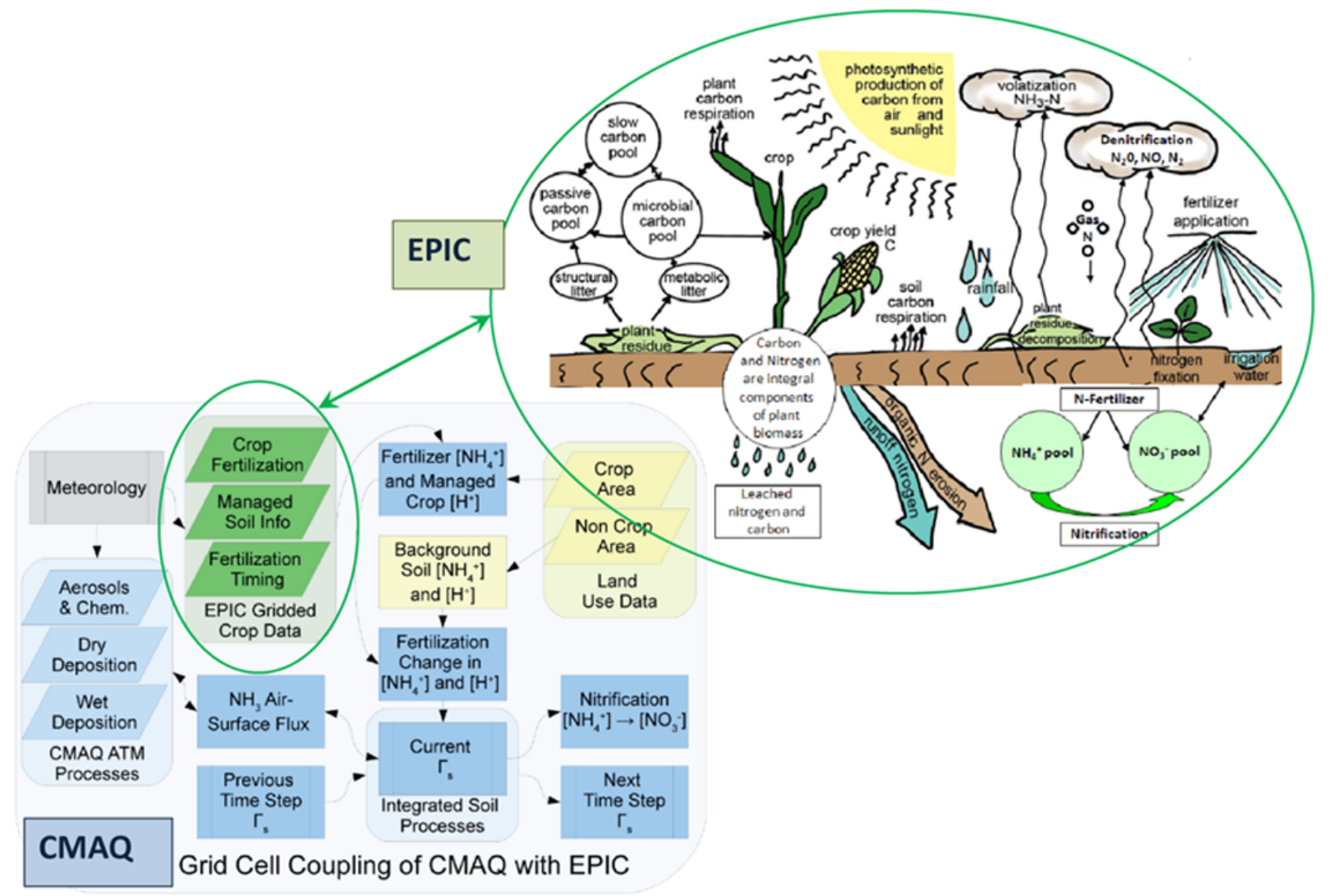

Fig. 8. Example of coupled CTM (CMAQ) and crop (EPIC) models for $\mathrm{NH}_{3}$ exchange, modified from Cooter et al. (2012). Top: Biogeochemical components of the carbon and nitrogen budgets in EPIC; bottom: flow chart of EPIC coupled with $\mathrm{CMAQ}$ bi-directional $\mathrm{NH}_{3}$ exchange. Arrows represent the flow of information, meteorological processes are shown in grey, EPIC processes in green, land use and land use-derived data in tan, and CMAQ processes in blue.

(Vieno et al., 2010); a Wesely (1989) approach is used in CHIMERE (Vautard et al., 2001; LMD, 2011); DEPAC is used in OPS-Pro 4.1 (van Jaarsveld, 2004); EMEP $R_{\mathrm{c}} / V_{\mathrm{d}}$ approach is used in the coupled Danish Ammonia Modelling System DAMOS (DEHM/OML-DEP) (Geels et al., 2012); combined DEPAC and EMEP parameterizations in MATCH (Klein et al., 2002); and LUC-specific values of $R_{\mathrm{c}}$ are used in FRAME (Singles et al., 1998). Nevertheless, a few instances of $\chi_{c}$ model implementation in CTMs have recently been reported, using new $\chi_{\mathrm{c}}$ parameterization schemes (see Sect. 3.2): e.g. the LOTOS-EUROS model (using revised DEPAC 3.11) (Wichink Kruit et al., 2012); the coupled CMAQ-EPIC model (Cooter et al., 2010, 2012; Bash et al., 2012); and AURAMS (Zhang et al., 2010). Other CTMs have meanwhile focused on improving the treatment of subgrid variability (DAMOS; Geels et al., 2012) or the spatial and temporal distribution of $\mathrm{NH}_{3}$ emissions by field-applied mineral fertiliers (CHIMERE/Volt'Air, Hamaoui-Laguel et al., 2012).

\subsubsection{Canopy compensation point implementations in regional CTMs}

The first test implementation of a $\chi_{\mathrm{c}}$ approach within a CTM was made by Sorteberg and Hov (1996) using an early version of the EMEP model and the $\chi_{\mathrm{s}} / R_{\mathrm{W}}$ model by Sutton et al. (1995b, 1998a), but the parameterizations were very crude, with only 2 fixed $\Gamma_{\mathrm{s}}$ values, 946 and 315 for grassland/cropland and other vegetation types, respectively.

In their LOTOS-EUROS model runs at the European scale $\left(25 \times 25 \mathrm{~km}^{2}\right.$ resolution), Wichink Kruit et al. (2012) found that by using the bi-directional $\mathrm{NH}_{3}$ exchange scheme by Wichink Kruit et al. (2010), the modeled ammonia concentrations increased almost everywhere (compared with the $R_{\mathrm{c}}$-based model), in particular in agricultural source areas. This was largely due to increased $\mathrm{NH}_{3}$ life time and transport distance. As a consequence, $\mathrm{NH}_{\mathrm{x}}$ deposition decreased in source areas, while it increased in large nature areas and remote regions (e.g. S. Scandinavia). The inclusion of a compensation point for sea water restricted dry deposition over sea and better reproduced the observed ma- 
rine background concentrations at coastal locations. Over the land area, the model predictive capability improved slightly, compared with $\mathrm{NH}_{3}$ network data, but concentrations in nature areas were slightly overestimated, while concentrations in agricultural source areas were still underestimated. The authors also discuss the issue of model validation using measured $\mathrm{NH}_{3}$ concentration, related to the representativeness of a single measurement point within a heterogeneous landscape, compared with the modelled grid square average $\mathrm{NH}_{3}$.

As in most other CTMs, the treatment of the atmospheric $\mathrm{NH}_{\mathrm{x}}$ budget in CMAQ v4.7 traditionally relied on: (i) a unidirectional $R_{\mathrm{c}}$ approach, and (ii) estimates of fertilizer $\mathrm{NH}_{3}$ emission that were independent of the physical and chemical variables and components of the CTM that simulate atmospheric transport, transformation and loss processes. The coupling of CMAQ v5.0 with EPIC and the Nemitz et al. (2001a) $\chi_{\mathrm{s}} / \chi_{\mathrm{g}} / R_{\mathrm{w}}$ model to simulate the bi-directional exchange of $\mathrm{NH}_{3}$ (Bash et al., 2012) allowed for the direct estimation of $\mathrm{NH}_{3}$ emissions, transport and deposition from agricultural practices, with dynamic interactions between weather, soil, vegetation and atmospheric chemistry (Fig. 8). The CMAQ-EPIC coupled model thus shifted the $\mathrm{NH}_{3}$ emissions modeling paradigm for fertilizer application from static or seasonal emission factors to a more dynamic, process-based approach. Some parameterizations were borrowed from Massad et al. (2010b), but unlike their exponential decay function to adjust $\Gamma_{\mathrm{g}}$ as a function of time after fertilization, the soil $\mathrm{NH}_{4}^{+}$budget in CMAQ v5.0 was simulated as being dynamically coupled to hourly soil $\mathrm{NH}_{4}^{+}$losses due to evasion and nitrification, and increases in soil $\mathrm{NH}_{3}$ due to deposition. Values of $\Gamma_{\mathrm{s}}$ for crops and of $\Gamma_{\mathrm{g}}$ for nonagricultural soils were modeled as a function of land cover type and ranged from 10 to 160 , which were at the low end of published values (e.g. Massad et al., 2010b; Zhang et al., 2010). The new coupled approach improved the predictive capability of CMAQ for $\mathrm{NH}_{\mathrm{x}}$ wet deposition and for ambient nitrate aerosol concentrations. The largest improvements in the aerosol simulations were during the spring and fall, when the US EPA's national emission inventory estimates at these times are particularly uncertain. In Cooter et al. (2012), the EPIC agro-ecosystem and CMAQ models were used to assess agro-ecosystem management and changes in biogeochemical processes, providing more robust model assessments of future land use, agricultural, energy and climate change scenario analyses.

\subsubsection{Improved treatment of sub-grid variability and spatial and temporal $\mathrm{NH}_{3}$ emissions}

High spatial resolution deposition modelling is crucial to determine the frequency of occurrence and magnitude of $\mathrm{N}$ critical loads and levels exceedances, since many sensitive nature areas and sites of special scientific interest (e.g. wetlands, heathlands, etc.) are very small, say a few hectares, and often located close to agricultural $\mathrm{NH}_{3}$ sources (Dragosits et al., 2002). As noted above (Sect. 3.3), this is a landscape scale issue, but it is also a CTM issue, because (i) failing to reproduce local $\mathrm{NH}_{3}$ budgets affects the predictive capability of regional modelling, and (ii) CTMs must be used to derive critical loads exceedance maps at national and regional scales in support of environmental policy development. Improving the performance of high-resolution localscale models requires high quality emission inventories with sufficiently high spatial resolution (Skjøth et al., 2011). In addition, a high temporal resolution for emissions is also crucial for the performance of CTMs, and dynamic calculations of $\mathrm{NH}_{3}$ emissions are needed for a better prediction of high particulate matter episodes (Menut and Bessagnet, 2010; Henze et al., 2009). This is especially relevant as $\mathrm{NH}_{3}$ emissions in winter will lead to a higher contribution to particulate matter than $\mathrm{NH}_{3}$ emissions in summer.

Data requirements for such models are access to detailed information about activity data and the spatial distribution in emissions on annual basis. Such requirements are met in very few countries, e.g. in Denmark and the Netherlands, where the ammonia emission inventory relies on highly detailed national agricultural registers, containing the exact location of farm houses, storages, and associated fields, as well as data on type and number of livestock, and information about applied production methods (Skjøth et al., 2004). In many other countries agricultural activity and $\mathrm{NH}_{3}$ emission data are either very crude, based on e.g. default emission factors, and/or confidential at resolutions finer than typically $10 \times 10 \mathrm{~km}^{2}$.

To address both spatial and temporal issues, the Danish Ammonia Modelling System (DAMOS) has been established as a coupled system consisting of the Danish 3-D Eulerian Hemispheric Model (DEHM) CTM covering the Northern Hemisphere $\left(6 \times 6 \mathrm{~km}^{2}\right.$ resolution $)$ and of the local-scale (up to ca. $20 \mathrm{~km}$ ) Gaussian plume dispersion and deposition model OML-DEP $\left(400 \times 400 \mathrm{~m}^{2}\right.$ resolution) (Geels et al., 2012). The model may be coupled to a code (Skjøth et al., 2011) for calculating ammonia emission on the European scale, accounting for local climate and local management, in which a modular approach is applied for deriving data as input to the temporally varying ammonia emission model. Comparisons between computed and measured ambient $\mathrm{NH}_{3}$ concentrations demonstrated considerable improvements in model performance over Denmark when the high spatial and temporal resolution emission inventory was applied, instead of the conventional (static) seasonal variations approach (Skjøth et al., 2004). Further, Geels et al. (2012) showed that the coupled DEHM/OML-DEP model system captured the measured $\mathrm{NH}_{3}$ time series in Denmark better than the regional-scale model alone, and that about $50 \%$ of the modelled concentration level at a given location originated from non-local emission sources. However, the coupled DAMOS model still overestimated observed local ammonia concentrations across Denmark, which might in part be explained by overestimated national emissions, by underestimated rates of conversion to $\mathrm{NH}_{4}^{+}$and of dry deposition, 
and, as in the LOTOS-EUROS case (Wichink Kruit et al., 2012), by the model grid square size.

Laguel-Hamaoui (2012) coupled the 1-D Volt'Air model (Génermont and Cellier, 1997), originally developed for field-applied slurry and adapted here for mineral fertilizers, to the CHIMERE CTM (Vautard et al., 2001; LMD, 2011), in order to assess the impact of fertilizer $\mathrm{NH}_{3}$ emissions on PM10 and $\mathrm{NH}_{4} \mathrm{NO}_{3}$ aerosol at the national scale. Ammonia emissions were computed from mineral fertilizer spread over agricultural soils, using datasets of crop management practices, soil properties and meteorology. Considerable effort went first into collecting management practices data at the national level, together with data processing to derive their spatial distribution. Three sets of CHIMERE runs were made, using as $\mathrm{NH}_{3}$ emission inputs to the CTM either (i) the official EMEP data under the CLRTAP convention, (ii) the French national emissions inventory (INS) data, or (iii) a combination of the coupled Volt'Air emissions for mineral fertilizers and INS data for other sources. The three options for $\mathrm{NH}_{3}$ emission inputs had different impacts on aerosol concentrations, depending on $\mathrm{HNO}_{3}$ concentrations. The comparison of modelled PM10 and $\mathrm{NH}_{4} \mathrm{NO}_{3}$ aerosol with observations showed that the new ammonia emission method lent a marginal improvement to the spatial and temporal correlations in several regions and a slight reduction of the negative bias ( 1 to $2 \mu \mathrm{g} \mathrm{m}^{-3}$ on average).

\subsection{Global scale}

Uncertainties in the global $\mathrm{NH}_{3} / \mathrm{NH}_{\mathrm{x}}$ cycle are very large, not least because the $\mathrm{NH}_{3}$ emission factors typically used for global emission upscaling, and the parameterizations for surface exchange modelling, are heavily biased towards NW European and $\mathrm{N}$ American conditions. Some sources are rather well studied, such as livestock agriculture in temperate Europe, while others are based on very few atmospheric $\mathrm{NH}_{3}$ flux measurements. The uncertainties are particularly large for natural emissions from terrestrial sources and oceans (Dentener and Crutzen, 1994; Bouwman et al., 1997), biomass burning (Andreae and Merlet, 2001) and for livestock sources and forests in tropical regions. There is a major lack of knowledge on agricultural management practices in many parts of the world and on the effect of the many climates and soils of the world on emission processes, especially the interplay of temperature and moisture. With $37 \%$ of the world's population between them, China and India's collective $\mathrm{NH}_{3}$ emissions account for around $13.5 \mathrm{Tg}$ $\mathrm{NH}_{3}-\mathrm{Nyr}^{-1}$ (Huang et al., 2012; Aneja et al., 2012), i.e. about one-third of the EDGAR (2011) global emission estimate of $40.6 \mathrm{Tg} \mathrm{N} \mathrm{NH}_{3}-\mathrm{N} \mathrm{yr}^{-1}$, but subject to huge uncertainty. Aneja et al. (2012) estimate that $\mathrm{NH}_{3}$ emissions from livestock could be a factor of 2-3 higher than their best estimate, while emissions from fertilizer application could be up to $40 \%$ lower than they estimated.
In global atmospheric CTMs, which are coupled to general circulation models (GCMs) or driven by analyzed meteorological fields, and by prescribed emissions of $\mathrm{NH}_{3}$ (e.g. Bouwman et al., 1997) and of other trace gases, ammonia exchange over terrestrial vegetation is generally modelled using $R_{\mathrm{c}} / V_{\mathrm{d}}$ resistance schemes, often following Wesely (1989) (e.g. TM5 model, Huijnen et al., 2010; Ganzeveld and Lelieveld, 1995; STOCHEM, Collins et al., 1997; Bouwman et al., 2002; GEOS-Chem, Bey et al., 2001; Wang et al., 1998). However, in the MOGUNTIA model at $10 \times 10^{\circ}$ resolution, Dentener and Crutzen (1994) - who were the first to reconcile by modelling the consistency on a global scale of upscaled $\mathrm{NH}_{3}$ emission inventories and atmospheric $\mathrm{NH}_{3} / \mathrm{NH}_{4}^{+}$concentrations and deposition - did use a canopy compensation point to calculate $\mathrm{NH}_{3}$ emissions from natural continental ecosystems. Their approach did not distinguish stomatal from non-stomatal (soil, leaf surfaces) contributions, as they applied one set value (equivalent to $\Gamma=290$ ) for the canopy, corresponding to $\left[\mathrm{NH}_{4}^{+}\right]=46 \mu \mathrm{mol} \mathrm{L}^{-1}$ and $\mathrm{pH}=6.8$ in the mesophyll, based on measurements over pine forest by Langford and Fehsenfeld (1992). To account for the short atmospheric lifetime and the sub-grid local deposition of $\mathrm{NH}_{3}$, Dentener and Crutzen (1994) directly removed $25 \%$ of all anthropogenic emissions over land, such that these emissions never entered the transport and chemistry calculations. Bouwman et al. (2002) similarly reduced their grid square emissions for the same reason; the fraction of the total emission deposited within a few kilometers from the source depended on many factors, including the height of the source and the surface roughness (Asman, 1998), and the compensation point concentration of vegetation.

Dentener et al. (2006) reported a multi-model evaluation (23 global CTMs) of current and future (2030) deposition of reactive nitrogen $\left(\mathrm{NO}_{\mathrm{y}}, \mathrm{NH}_{\mathrm{x}}\right)$ as well as sulfate $\left(\mathrm{SO}_{\mathrm{x}}\right)$ to land and ocean surfaces. Models predicted that $\mathrm{NH}_{3}$ dry deposition represents between $30-70 \%$ of total deposition. Presentday deposition using nearly all information on wet deposition available worldwide showed a good agreement with observations in Europe and North America, where $60-70 \%$ of the model-calculated wet deposition rates agreed to within $\pm 50 \%$ of quality-controlled measurements. However, models systematically overestimated $\mathrm{NH}_{\mathrm{x}}$ deposition in South Asia compared with available bulk wet deposition measurements. There were substantial differences among models for the removal mechanisms of $\mathrm{NH}_{\mathrm{x}}$, as well as for $\mathrm{NO}_{\mathrm{x}}$ and $\mathrm{SO}_{\mathrm{x}}$, leading to $\pm 1 \sigma$ variance in total deposition fluxes of about $30 \%$ in the anthropogenic emissions regions, and up to a factor of 2 outside.

The evaluation/validation of global CTMs for $\mathrm{NH}_{3}$ dry deposition (or surface exchange) is even more difficult than for regional CTMs, with scarce or no $\mathrm{NH}_{3}$ concentration and wet $\mathrm{NH}_{\mathrm{x}}$ deposition data in many parts of the world, and, where there are data, point measurements being largely de-coupled from the very large grid square modelled averages (typically $1^{\circ} \times 1^{\circ}$ to $10^{\circ} \times 10^{\circ}$ ). Satellite data providing atmospheric 
column integrated $\mathrm{NH}_{3}$ concentrations have recently offered a very welcome addition (Clarisse et al., 2009; Shephard et al., 2011; R'Honi et al., 2012), but their interpretation can prove complex in a modelling context. Despite a good qualitative agreement between satellite (IASI/MetOp) measurements and simulations by the TM5 global CTM, Clarisse et al. (2009) found that the satellite data yielded substantially higher $\mathrm{NH}_{3}$ concentrations north of $30^{\circ} \mathrm{N}$ compared with model projections, and lower concentrations than the model south of $30^{\circ} \mathrm{N}$. They concluded that ammonia emissions could have been significantly underestimated in TM5 in the Northern Hemisphere, but there were also issues with IASI's detection limit, limited thermal contrast, and an unrepresentative morning orbit time.

Similarly, Shephard et al. (2011) compared the output of global high-spectral resolution nadir measurements from the Tropospheric Emissions Spectrometer (TES) on NASA's Aura with GEOS-Chem model runs; initial comparisons showed that TES/Aura values were higher overall. These authors also invoked the possible underestimation of $\mathrm{NH}_{3}$ emissions in the GEOS-Chem inputs, but also possibly the overrepresentation of $\mathrm{NH}_{3}$ values at the $2^{\circ} \times 2.5^{\circ}$ resolution coming from TES sampling $\mathrm{NH}_{3}$ hotspots at the subgrid level. They argued that the better agreement between TES/Aura and GEOS-Chem seasonality over biomass burning regions, compared with agricultural source regions, suggested that the latter may be a more likely source of uncertainty in models.

\section{Synthesis and conclusions}

The basic processes controlling surface/atmosphere $\mathrm{NH}_{3}$ exchange are relatively well understood, at least qualitatively. A wide range of factors are important, including: thermodynamics, meteorology, surface and air column heterogeneous chemistry, plant physiology and $\mathrm{N}$ uptake, ecosystem $\mathrm{N}$ cycling, compensation points, nitrogen inputs via fertilization and atmospheric deposition, leaf litter decomposition, SOM and soil microbial turnover, soil properties. Most of the fundamental process understanding was gained during the 1980s and 1990s, while many advances in modelling logically followed from the late 1990s onwards, spurred by the canopy compensation point concept of Sutton et al. (1995b, 1998a). There has been a gradual increase in the complexity of surface/atmosphere $\mathrm{NH}_{3}$ exchange models, from simple steady-state $R_{\mathrm{c}}$ models to dynamic, multiple layer, multiple sink/source, multiple chemical species exchange models. This reflects both the improvement in process understanding and the increasing availability of flux datasets, which are needed to parameterize models.

Yet there remain substantial challenges at all spatial scales (leaf to globe). The predictive capability of existing models at the field scale is often poor when tested against new flux measurement or at new sites, and a local re-parameterization is often necessary to describe observations satisfactorily (even accounting for potentially large errors in flux measurements, as shown by intercomparison exercises). Semi-empirical parameterization schemes that are developed on the basis of a literature review and many flux datasets (Massad et al., 2010b; Zhang et al., 2010; Søgaard et al., 2002) should in principle, statistically, reproduce large-scale features of $\mathrm{NH}_{3}$ exchange, as least within the multi-dimensional climate/vegetation/soil/management matrix, from which they derive. However, if their degree of empiricism is too large, they may prove unsuitable for generalisation to other conditions and for scenario simulations (e.g. climate change). On the other hand, the more mechanistic process-oriented models should in theory be applicable in all conditions, but they typically require more input data (some of which may not be available), are more difficult to parameterize (a greater number of parameters with no established reference), and are more computationally intensive (and thus less likely candidates for large-scale models).

The ideal surface/atmosphere $\mathrm{NH}_{3}$ exchange model should treat all ecosystem $\mathrm{NH}_{\mathrm{x}}$-related processes, fluxes and pools dynamically (fertilizer volatilisation and recapture, soil biogeochemistry, plant biochemistry and physiology, air and surface chemistry, atmosphere exchange) within a multiple-layer canopy framework (in-canopy profiles of turbulence, radiation, temperature, humidity, green vs senescent leaves, soil layer). Such a coupling is possible and practicable at the field scale (e.g. coupled STAMP/CERESEGC/Volt'Air/SURFATM over crops), with a view to investigating certain aspects of the exchange, their dynamics and interactions, in parallel with detailed measurements of fluxes and pools. Clearly the task is more complex at the regional scale, although the CMAQ/EPIC example (Bash et al., 2012; Cooter et al., 2012; Fig. 8) demonstrates that it is feasible to a degree. The level of complexity of surface exchange schemes must be taylored to suit the modelling objectives, the scale and the availability of input data, while the availability of measurement data for validation assessment may prove a limiting factor in model development.

\subsection{Realistic $\mathrm{NH}_{3}$ exchange frameworks for CTMs}

The current level of complexity of $\mathrm{NH}_{3}$ surface exchange schemes in most regional and global CTMs is low relative to the advances that have been included in field scale models, i.e. static emissions from inventories and $R_{\mathrm{c}} / V_{\mathrm{d}}$ unidirectional deposition (with the exception of those few models mentioned in Sect. 3.4), and clearly does not reflect the current level of process understanding. The following list highlights features that could realistically be implemented in $\chi_{\mathrm{s}} / \chi_{\mathrm{g}} / R_{\mathrm{w}}$ two-layer schemes (Nemitz et al., 2001a; see Sect. 3.2, Fig. 7) within CTMs, at least at regional scales.

- Dynamic agricultural $\mathrm{NH}_{3}$ emissions from fieldapplied manures and fertilizers. At present these emissions are typically prescribed from national or international inventories, and independent of meteorological 
conditions and crop development stage, but seasonal and diurnal distribution factors are applied. Dynamic emissions could be simulated using process-based models (Sect. 3.1), even if the treatment does not extend all the way to soil biogeochemistry, soil $\mathrm{NH}_{4}^{+}$pools and plant uptake.

- Soil/litter emission potential (outside fertilization events). This term is likely negligible in most temperate forests and semi-natural vegetation on acidic soils, but $\Gamma_{\mathrm{g}}$ can be very large in grasslands and crops during the growing season, and might also be important in tropical forests due to large mineralisation rates and higher temperatures.

- Canopy re-capture of soil-based emissions. Emissions from fertilizers and other ground-based sources are partially re-captured by foliage (stomatal and non-stomatal pathways in a two-layer model, Fig. 7C). The degree of re-capture is controlled by canopy closure and leaf density (LAI profile), wind penetration, leaf wetness.

- Bi-directional stomatal exchange; $\mathrm{N}$ input-dependent $\Gamma_{\mathrm{s}}$. The analysis by Massad et al. (2010b, their Fig. 5) shows consistent and convincing relationships between $\mathrm{N}$ inputs and $\Gamma_{\mathrm{s}}$ for crops and grasslands, which could be implemented in CTMs. Because fertilization outweighs atmospheric deposition by a factor of 10 in such systems, the circularity issue ( $\mathrm{N}$ inputs affect $\Gamma_{\mathrm{s}}$, while $\Gamma_{\mathrm{s}}$ controls $\mathrm{NH}_{3}$ deposition) is less critical than in seminatural vegetation, though this represents a potentially important long-term negative feedback on deposition. Nevertheless, the relationship of $\Gamma_{\mathrm{s}}$ to atmospheric $\mathrm{N}$ deposition remains rather uncertain.

- Photosynthesis-dependent stomatal resistance $\left(R_{\mathrm{S}}\right)$. The widely used multiplicative algorithm by Jarvis (1976), and other simplified empirical approaches (Wesely, 1989), should be upgraded to a more mechanistic, photosynthesis-driven model (e.g. Ball et al., 1987), following the example of CTMs for $\mathrm{O}_{3}$ (Anav et al., 2012).

- Pollution-climate dependent non-stomatal uptake $\left(R_{\mathrm{w}}\right)$. This feature is present in some CTMs via the (longterm) $\mathrm{NH}_{3} / \mathrm{SO}_{2}$ ratio, but likely most regional and especially global models do not account for the effects of surface chemical loadings on non-stomatal uptake rates. Accounting for $\mathrm{NH}_{3}$ alone (Jones et al., 2007) is not sufficient away from the large agricultural point sources; rather, the ratio of Total Acids to $\mathrm{NH}_{3}$ (Fig. 6; Massad et al., 2010b) should be used generically. Wind erosion of soil particles and leaf base cation leaching may raise leaf surface moisture $\mathrm{pH}$ significantly, but there are too few available data to account for this at present.

- Offline ecosystem and leaf surface chemistry modelling. Some CTM frameworks may not be able to accommodate coupled (online, interactive) ecosystem functioning together with the transport, chemistry and exchange calculations. However, soil/plant/ecosystem models (e.g. DNDC, STAMP, PaSim) could potentially be used offline to generate many values of $\Gamma_{\mathrm{s}}, \Gamma_{\mathrm{g}}, \Gamma_{\text {litter }}, \Gamma_{\text {soil }}$ in multiple simulations of ecosystems, seasons, soil and pollution climate conditions, representative of the region in which the CTM is applied. Such $\Gamma$ values should first be validated versus values published in the literature, and could then be called during CTM simulations from look-up tables or multiple regression functions. This might prove a viable compromise between constant default values (Zhang et al., 2010), or empirical functions (e.g. exponential decay with time, Massad et al., 2010b), and fully coupled CTM/ecosystem frameworks (Cooter et al., 2012). A similar concept could be applied for dynamic leaf surface chemistry (Flechard et al., 1999), whereby typical $\Gamma_{\mathrm{d}}$ potentials could be simulated offline for a wide range of environmental conditions, and called up by the CTM in a $\chi_{\mathrm{s}} / \chi_{\mathrm{g}} / \chi_{d} / R_{\mathrm{d}}$ scheme.

\subsection{Further needs for flux measurements, model input data, and validation data}

For regional and global representativeness, model development and parameterization rely heavily on new field-scale flux measurement datasets becoming available, but it is also clear that the availability of model input data and of spatially distributed validation data can be limiting factors for CTMs at regional and global scales. The most pressing data needs are summarised below.

- Flux measurements for under-represented ecosystems in temperate regions. The $\mathrm{NH}_{3}$ flux literature is heavily dominated by grasslands, cereal crops, heathlands/moorlands and coniferous forests. There are few measurements over root crops, leguminous crops and legume-rich grasslands, deciduous forests, dry scrubland.

- Flux measurements in the tropics: data are needed for all ecosystem types including rain forests, savannah, tropical crops.

- Flux measurements near $(<500 \mathrm{~m})$ agricultural point sources in rural landscapes, together with a quantification of soil, apoplastic and epifoliar $\Gamma$ values as a function of distance from sources. Errors in measured fluxes arising from $\mathrm{NH}_{3}$ advection must be accounted for (Loubet et al., 2009b).

- Seasonal and spatial variations in bulk leaf $\mathrm{N}$ content and apoplastic $\Gamma_{\mathrm{s}}$ ratio for a range of ecosystems. Such measurements could be carried out at a large number of sites across a CTM modelling domain, without necessarily measuring $\mathrm{NH}_{3}$ fluxes above ecosystems, and 
would be useful to explore temporal and spatial patterns of modelled $\mathrm{NH}_{3}$ exchange and total $\mathrm{N}$ deposition.

- Measurements of $\Gamma$ values for the dominant crops, ecosystems and land uses in different climates and for different agricultural practices. These experimental $\Gamma$ estimates should be collected with a view to both i) underpinning the development of empirical parameterizations for bi-directional models and ii) validating process-based ecosystem model $\Gamma$ predictions. Longterm (e.g. annual, growing season) flux and $\Gamma$ datasets are needed to better represent background conditions, as campaign-based measurements over fertilised systems have traditionally tended to focus on emission events. Wherever possible, the determination of $\Gamma_{\mathrm{s}}$ values should be attempted using different techniques (micrometeorological surface concentration extrapolation; controlled gas exchange chamber experiments; apoplastic extraction), as they tend to yield different results and the discrepancies between techniques are as yet poorly understood, given the current paucity of parallel measurements.

- Collection of critical ancillary data wherever $\mathrm{NH}_{3}$ flux are measured in the field. In addition to classical (micro-) meteorological data, measured ancillary data must include variables that are likely to be useful later for model parameterization or validation. Efforts should be made to measure the following according to the issues being addressed: LAI and leaf density profile; leaf wetness profile; soil texture, porosity, wilting point, organic matter content, $\mathrm{pH},\left[\mathrm{NH}_{4}^{+}\right]$and $\left[\mathrm{NO}_{3}^{-}\right]$; slurry $\mathrm{pH}$, TAN, dry matter content and application rate; bulk leaf $\mathrm{N}$ and $\mathrm{NH}_{4}^{+}$content; leaf litter $\mathrm{pH}$ and $\left[\mathrm{NH}_{4}^{+}\right]$; leaf surface water (dew, rain) $\mathrm{pH}$ and $\left[\mathrm{NH}_{4}^{+}\right]$. More difficult to measure, but equally important, would be apoplastic $\mathrm{pH}$ and $\left[\mathrm{NH}_{4}^{+}\right]$, such as by the vaccuum infiltration technique (Husted and Schjoerring, 1995); in-canopy vertical $\mathrm{NH}_{3}$ profiles; ambient concentrations of $\mathrm{SO}_{2}$, $\mathrm{HNO}_{3}, \mathrm{HNO}_{2}$ and $\mathrm{HCl}$, and particulate $\mathrm{NH}_{4}^{+}$and $\mathrm{NO}_{3}^{-}$. Studies quantifying base cation and other ion exchange with leaf surfaces are also needed.

- Fundamental analytical research is needed to provide guidance on the most appropriate soil $\mathrm{NH}_{4}^{+}$extraction method for the development of representative soil $\Gamma$ values. Many studies have demonstrated the variability of extracted/extractable $\mathrm{NH}_{4}^{+}$depending on the electrolyte used (eg KCl, $\left.\mathrm{CaCl}_{2}\right)$ and its concentration in the extraction solution (see for example Fig. 1 in the Supplement on http://www.biogeosciences-discuss.net/10/C2954/ 2013/bgd-10-C2954-2013-supplement.pdf). Provided a better understanding of the relationships between extractable $\mathrm{NH}_{4}^{+}$and soil $\Gamma$, historical soil chemistry datasets from long-term ecological sites, agricultural experiment stations, soil surveys, etc, could be put to use within the context of soil/vegetation/atmosphere $\mathrm{NH}_{3}$ modelling.

- Use of environmental microscopy (e.g. Burkhardt et al., 2012) as a powerful set of tools for improving our fundamental understanding of the chemical dynamics of leaf surface water during the transition from wet to dry conditions. Further testing and development of dynamic leaf surface chemistry models is currently hindered by the fact that the chemistry of microscale cuticular water layers present on leaves and needles during the day cannot be measured. In the absence of suitable techniques for field measurements, such laboratory techniques should be encouraged.

- Development, testing, validation and deployment of low-cost instrumentation for long-term $\mathrm{NH}_{3}$ flux estimates. Given the complexity and elevated costs associated with intensive and high-resolution $\mathrm{NH}_{3}$ flux measurement campaigns, there have been endeavours to develop robust "low-cost, low-tech" methods for longterm flux estimates and parameterizations, such as the COTAG (COnditional Time-Averaged Gradient) system (Famulari et al., 2010). However, such systems have been successfully deployed at only a handful of sites to date, and further they lack consistent validation against established reference methods.

- Spatial fields of measured atmospheric $\mathrm{NH}_{3}$ and $\mathrm{NH}_{4}^{+}$ concentrations. Satellite-derived column $\mathrm{NH}_{3}$ data offer much promise for CTM evaluation at regional and global scales, but there are still large uncertainties in the retrieved concentrations. Ground-based monitoring networks for both $\mathrm{NH}_{3}$ and $\mathrm{NH}_{4}^{+}$by low-cost denuder/filter methods (Tang et al., 2009; Flechard et al., 2011; Adon et al., 2010) are available in only a handful of countries worldwide and should be encouraged, both for CTM evaluation and for ground truthing of satellite data. The vertical dimension of the concentration field in the atmospheric boundary layer should also be explored; aircraft measurements provide such information but are expensive; the extent to which low-cost measurement techniques could be deployed in profile configurations on tall towers should be investigated.

- Fine-resolution $\left(\sim 1 \mathrm{~km}^{2}\right)$ agricultural census data, and management practices. These model input data for CTMs are often only poorly known. The former are in many countries either classified information or not documented, and only available at much coarser resolution $(>10 \mathrm{~km} \times 10 \mathrm{~km})$. Data on typical management practices with respect to manure and fertilizer application (timing, amounts, machinery) should be easier to obtain, but require extensive survey work.

- Development of methods for sub-grid assessments. The accuracy and evaluation of models close to sources is 
a source of uncertainty, since especially $\mathrm{NH}_{3}$ deposition can occur at scales substantially smaller than the horizontal and vertical extent of CTMs (e.g. Sect. 3.3, and Loubet et al., 2009a). Even where network data are available, the application and evaluation of CTMs for $\mathrm{NH}_{3}$ concentrations is hindered by such local-scale gradients and variability (Wichink Kruit et al., 2012). Use of plume or Lagrangian 1-D models close to the source (see Asman, 2001; Hertel et al., 2006, 2011) or coupling of sub-grid dispersion models to CTMs (e.g. Geels et al., 2012) should help bridge the gap between groundbased, single-point observations and spatially averaged CTM outputs, and could be used to help parameterize larger scale CTM models in future.

Acknowledgements. We gratefully acknowledge financial support from the project "Effects of Climate Change on Air Pollution Impacts and Response Strategies for European Ecosystems" (ÉCLAIRE), funded under the EC 7th Framework Programme (Grant Agreement No. 282910), from the COST Action ES0804 "Advancing the integrated monitoring of trace gas exchange between biosphere and atmosphere" (ABBA), and from the project "Pan-European Gas-AeroSOl-climate interaction Study" (PEGASOS) funded under the EC 7th Framework Programme (FP7-ENV-2010-265148). We are thankful to the UK National Environment Research Council and Centre for Ecology and Hydrology for underpinning input through National Capacity funding and contributing to open access page charges. This review paper was originally written as a background document in preparation for the international workshop "From process scale to global scale: integrating our knowledge on biosphere atmosphere exchange modelling of trace gases and volatile aerosols", co-organised by INRA, AgroParisTech, ÉCLAIRE and COST action ES0804, and held in Paris, 25-27 September 2012. We are grateful to Albrecht Neftel for his comments on the manuscript. Although this work was reviewed by EPA and approved for publication, it may not necessarily reflect official Agency policy.

Edited by: C. Spirig

\section{References}

Adon, M., Galy-Lacaux, C., Yoboué, V., Delon, C., Lacaux, J.P., Castera, P., Gardrat, E., Pienaar, J., Al Ourabi, H., Laouali, D., Diop, B., Sigha-Nkamdjou, L., Akpo, A., Tathy, J. P., Lavenu, F., and Mougin, E.: Long term measurements of sulfur dioxide, nitrogen dioxide, ammonia, nitric acid and ozone in Africa using passive samplers, Atmos. Chem. Phys., 10, 7467-7487, doi:10.5194/acp-10-7467-2010, 2010.

Ainsworth, E. A. and Rogers, A.: The response of photosynthesis and stomatal conductance to rising $\left[\mathrm{CO}_{2}\right]$ : mechanisms and environmental interactions, Plant Cell Environ., 30, 258-270, 2007.

Anav, A., Menut, L., Khvorostyanov, D., and Viovy, N.: A comparison of two canopy conductance parameterizations to quantify the interactions between surface ozone and vegetation over Europe, J. Geophys. Res.-Biogeo., 117, G3, doi:10.1029/2012JG001976, 2012.
Andreae, M. O. and Merlet, P.: Emission of trace gases and aerosols from biomass burning, Global Biogeochem. Cy., 15, 955-966, 2001.

Aneja, V. P., Schlesinger, W. H., Erisman, J. W., Behera, S. N., Sharma, M., and Battye, W.: Reactive nitrogen emissions from crop and livestock farming in India, Atmos. Environ., 47, 92103, 2012.

Asman, W. A. H.: Factors influencing local dry deposition of gases with special reference to ammonia, Atmos. Environ., 32, 415421, 1998.

Asman, W. A. H.: Modelling the atmospheric transport and deposition of ammonia and ammonium: an overview with special reference to Denmark, Atmos. Environ., 35, 1969-1983, 2001.

Asman, W. A. H.: Die Modellierung lokaler AmmoniakDepositionen im Umfeld von Stallgebäuden (Modelling local ammonia deposition near livestock buildings, in German), in: Emissionen der Tierhaltung. Grundlagen, Wirkungen, Minderungsmassnahmen, KTBL-Schrift 406, KTBL-SchriftenVertrieb im Landwirtschaftsverlag GmbH, Münster, Germany, 295-319, 2002.

Asman, W. A. H. and van Jaarsveld, H. A.: A variable-resolution transport model applied for $\mathrm{NH}_{\mathrm{X}}$ in Europe, Atmos. Environ., 26A, 445-464, 1992.

Asman, W. A. H., Pinksterboer, E. F., Maas, H. F. M., and Erisman, J. W.: Gradients of the ammonia concentration in a nature reserve: model results and measurements, Atmos. Environ., 23, 2259-2265, 1989.

Asman, W. A. H., Sutton, M. A., and Schjoerring, J. K.: Ammonia: Emission, atmospheric transport and deposition, New Phytol., 139, 27-48, 1998.

Baldocchi, D. D., Hicks, B. B., and Camara, P.: A canopy stomatal resistance model for gaseous deposition to vegetated surfaces, Atmos. Environ., 21, 91-101, 1987.

Ball, J. T., Woodrow, I. E., and Berry, J. A.: A model predicting stomatal conductance and its contribution to the control of photosynthesis under different environmental conditions, in: Progress in Photosynthesis Research, 4, edited by: Biggins, J., M. Nijhoff Publishers, Dordrecht, 221-224, 1987.

Barrett, K.: Oceanic ammonia emissions in Europe and their transboundary fluxes, Atmos. Environ., 32, 381-391, 1998.

Bash, J. O., Walker, J. T., Jones, M., Katul, G., Nemitz, E., and Robarge, W.: Estimation of in-canopy ammonia sources and sinks in a fertilized Zea mays field, Environ. Sci. Technol., 44, 16831689, 2010.

Bash, J. O., Cooter, E. J., Dennis, R. L., Walker, J. T., and Pleim, J. E.: Evaluation of a regional air-quality model with bidirectional NH3 exchange coupled to an agroecosystem model, Biogeosciences, 10, 1635-1645, doi:10.5194/bg-10-1635-2013, 2013.

Berge, E., Bartnicki, J., Olendrzynski K., and Tsyro, S. G.: Longterm trends in emissions and transboundary transport of acidifying air pollution in Europe, J. Environ. Manage., 57, 31-50, 1999.

Berry, J. A. and Farquhar, G. D.: The $\mathrm{CO}_{2}$ concentration function of $\mathrm{C} 4$ photosynthesis: A biochemical model, in: Proceedings of the 4th International Congress of Photosynthesis, edited by: Hall, D., Coombs, J., and Goodwin, T., Biochemical Society, London, 119-131, 1978.

Beuning, J. D., Pattey, E., Edwards, G., and van Heyst, B. J.: Improved temporal resolution in process-based modelling of agri- 
cultural soil ammonia emissions, Atmos. Environ., 42, 32533265, 2008.

Beusen, A. H. W, Bouwman, A. F., Heuberger, P. S. C., Van Drecht, G., and Van Der Hoek, K. W.: Bottom-up uncertainty estimates of global ammonia emissions from global agricultural production systems, Atmos. Environ., 42, 6067-6077, 2008.

Bey, I., Jacob, D. J., Yantosca, R. M., Logan, J. A., Field, B., Fiore, A. M., Li, Q., Liu, H., LMickley, L. J., and Schultz, M.: Global modeling of tropospheric chemistry with assimilated meteorology: Model description and evaluation, J. Geophys. Res.-Atmos., 106, 23073-23095, doi:10.1029/2001JD000807, 2001.

Blackall, T. D., Wilson, L. J., Theobald, M. R., Milford, C., Nemitz, E., Bull, J., Bacon, P. J., Hamer, K. C., Wanless, S., and Sutton, M. A.: Ammonia emissions from seabird colonies, Geophys. Res. Lett., 34, 5-17, 2007.

Blatter, A., Neftel, A., Dasgupta, P. K., and Simon, P. K.: A combined wet effluent denuder and mist chamber system for deposition measurements of $\mathrm{NH}_{3}, \mathrm{NH}_{4}^{+}, \mathrm{HNO}_{3}$ - and $\mathrm{NO}_{3}^{-}$, in: Physicochemical Behaviour of Atmospheric Pollutants, edited by: Angeletti, G. and Restelli, G., European Commission, Brussels, 767-772, 1994.

Bouwman, A. F., Lee, D. S., Asman, W. A. H., and Dentener, F. J., Van Der Hoek, K.W. and Olivier, J.G.J.: A global high-resolution emission inventory for ammonia, Global Biogeochem. Cy., 11, 561-587, 1997.

Bouwman, A. F., Van Vuuren, D. P., Derwent, R. G., and Posch, M.: A global analysis of acidification and eutrophication of terrestrial ecosystems, Water Air Soil Poll., 141, 349-382, 2002.

Brimblecombe, P.: "Dew" as a sink for sulphur dioxide, Tellus, 30, 151-157, 1978.

Brost, R. A., Delany, A. C., and Huebert, B. J.: Numerical modeling of concentrations and fluxes of $\mathrm{HNO}_{3}, \mathrm{NH}_{3}$ and $\mathrm{NH}_{4} \mathrm{NO}_{3}$ near the surface, J. Geophys. Res., 93, 7137-7152, 1988.

Burkhardt, J. and Eiden, R.: Thin water films on coniferous needles, Atmos. Environ., 28, 2001-2011, 1994.

Burkhardt, J., Flechard, C. R., Gresens, F., Mattsson, M., Jongejan, P. A. C., Erisman, J. W.,Weidinger, T., Meszaros, R., Nemitz, E., and Sutton, M. A.: Modelling the dynamic chemical interactions of atmospheric ammonia with leaf surface wetness in a managed grassland canopy, Biogeosciences, 6, 67-84, doi:10.5194/bg-667-2009, 2009.

Burkhardt, J., Basi, S., Pariyar, S., and Hunsche, M.: Stomatal uptake of aqueous solutions - an update involving leaf surface particles, New Phytol., 196, 774-787, 2012.

Byun, D. W. and Schere, K. L.: Review of the governing equations, computational algorithms, and other components of the Models3 Community Multiscale Air Quality (CMAQ) Modeling System, Appl. Mech. Rev., 59, 51-77, 2006.

Carozzi, M., Loubet, B., Acutis, M., Rana, G., and Ferrara, R.M.: Inverse dispersion modelling highlights the efficiency of slurry injection to reduce ammonia losses by agriculture in the Po Valley (Italy), Agr. Forest Meteorol., 171/172, 306-318, 2013.

Carruthers D. J., McKeown A. M., Hall D. J., and Porter S.: Validation of ADMS against Wind Tunnel Data of Dispersion from Chemical Warehouse Fires, Atmos. Environ., 33, 1937-1953, 1999.

Choudhury, B. J. and Monteith, J. L.: A four-layer model for the heat budget of homogeneous land surfaces, Q. J. Roy. Meteor. Soc., 114, 373-398, 1988.
Clarisse, L., Clerbaux, C., Dentener, F., Hurtmans, D., and Coheur, P.-F.: Global ammonia distribution derived from infrared satellite observations, Nat. Geosci., 2, 479-483, doi:10.1038/NGEO551, 2009.

Collins, W. J., Stevenson, D. S., Johnson, C. E., and Derwent, R G.: Tropospheric ozone in a global-scale three-dimensional Lagrangian model and its response to $\mathrm{NO}_{\mathrm{x}}$ emission controls, J. Atmos. Chem., 26, 223-274, 1997.

Cooter, E. J., Bash, J. O., Walker, J. T., Jones, M., and Robarge, W.: Estimation of $\mathrm{NH}_{3}$ bidirectional flux from managed agricultural soils, Atmos. Environ., 44, 2067-2166, 2010.

Cooter, E. J., Bash, J. O., Benson, V., and Ran, L.: Linking agricultural crop management and air quality models for regional to national-scale nitrogen assessments, Biogeosciences, 9, 40234035, doi:10.5194/bg-9-4023-2012, 2012

David, M., Loubet, B., Cellier, P., Mattsson, M., Schjoerring, J. K., Nemitz, E., Roche, R., Riedo, M., and Sutton, M. A.: Ammonia sources and sinks in an intensively managed grassland canopy, Biogeosciences, 6, 1903-1915, doi:10.5194/bg-6-19032009, 2009.

Dawson, G. A.: Atmospheric ammonia from undisturbed land, J. Geophys. Res., 82, 3125-3133, 1977.

Denmead, O. T., Freney, J. R., and Simpson, J. R.: A closed ammonia cycle within a plant canopy, Soil Biol. Biochem., 8, 161-164, 1976.

Denmead, O. T., Freney, J. R., and Dunin, F. X.: Gas exchange between plant canopies and the atmosphere: case-studies for ammonia, Atmos. Environ., 42, 3394-3406, 2008.

Dentener, F. J. and Crutzen, P. J.: A Three-Dimensional Model of the Global Ammonia Cycle, J. Atmos. Chem., 19, 331-369, 1994.

Dentener, F., Drevet, J., Lamarque, J. F., Bey, I., Eickhaut, B., Fiore, A.M., Hauglustaine, D., Horowitz, L. W., Krok, M., Kulshrestha, U.C., Lawrence, M., Galy-Lacaux, C., Rast, S., Shindell, D., Stevenson, D., van Noije, T., Atherton, C., Bell, N., Bergman, D., Butler, T., Cofala, J., Collins, B., Docherty, R., Ellingsen, K., Galloway, J., Gauss, M., Montanaro, V., Müller, J. F., Pitari, G., Rodriguez, J., Sanderson, M., Solmon, F., Strahan, S., Schulz, M., Sudo, K., Szopa, S. and Wild, O.: Nitrogen and sulfur deposition on regional and global scales: a multimodel evaluation, Global Biogeochem. Cy. 20, GB4003, doi:10.1029/2005GB002672, 2006

Dragosits, U., Theobald, M. R., Place, C. J., Lord, E., Webb, J., Hill, J., ApSimon, H. M., and Sutton, M. A.: Ammonia emission, deposition and impact assessment at the field scale: a case study of sub-grid spatial variability, Environ. Pollut., 117, 147-158, 2002.

EDGAR - Emissions Database for Global Atmospheric Research, European Commission - JRC Joint Research Centre, IES Institute for Environment and Sustainability, http://edgar.jrc.ec. europa.eu/, 2011.

Ellis, R. A., Murphy, J. G., Pattey, E., van Haarlem, R., O’Brien, J. M., and Herndon, S. C.: Characterizing a Quantum Cascade Tunable Infrared Laser Differential Absorption Spectrometer (QCTILDAS) for measurements of atmospheric ammonia, Atmos. Meas. Tech., 3, 397-406, doi:10.5194/amt-3-397-2010, 2010.

Ellis, R. A., Murphy, J. G., Markovic, M. Z., VandenBoer, T. C., Makar, P. A., Brook, J., and Mihele, C.: The influence of gasparticle partitioning and surface-atmosphere exchange on ammonia during BAQS-Met, Atmos. Chem. Phys., 11, 133-145, 
doi:10.5194/acp-11-133-2011, 2011.

Emberson, L. D., Ashmore, M. R., Simpson, D., Tuovinen, J.P., and Cambridge, H. M.: Towards a model of ozone deposition and stomatal uptake over Europe, EMEP/MSC-W report 6/2000, Norwegian Meteorological Institute, Oslo, Norway, 57 pp., 2000a.

Emberson, L. D., Ashmore, M.R., Simpson, D., Tuovinen, J.-P., and Cambridge, H.M.: Modelling stomatal ozone flux across Europe, Water Air Soil Poll., 109, 403-413, 2000b.

Erisman, J. W. and Wyers, G. P.: Continuous measurements of surface exchange of $\mathrm{SO}_{2}$ and $\mathrm{NH}_{3}$; implications for their possible interaction in the deposition process, Atmos. Environ., 27A, 1937-1949, 1993.

Erisman, J. W., van Pul, A., and Wyers, P.: Parametrization of surface resistance for the quantification of atmospheric deposition of acidifying pollutants and ozone, Atmos. Environ., 28, 25952607, 1994.

Erisman, J. W., Otjes, R., Hensen, A., Jongejan, P., van den Bulk, P., Khlystov, A., Moels, H., and Slanina, S.: Instrument development and application in studies and monitoring of ambient $\mathrm{NH}_{3}$, Atmos. Environ., 35, 1913-1922, 2001.

European Environment Agency, National emissions reported to the Convention on Long-range Transboundary Air Pollution (LRTAP Convention), http://www.eea.europa.eu, 2012.

Famulari, D., Fowler, D., Hargreaves, K. J., Milford, C., Nemitz, E., Sutton, M. A., and Weston, K.: Measuring eddy covariance fluxes of ammonia using tunable diode laser absorption spectroscopy, Water Air Soil Poll.: Focus, 4, 151-158, 2004.

Famulari, D., Fowler, D., Nemitz, E., Hargreaves, K. J., StoretonWest, R. L., Rutherford, G., Tang, Y. S., Sutton, M. A., and Weston, K. J.: Development of a low-cost system for measuring conditional time-averaged gradients of $\mathrm{SO}_{2}$ and $\mathrm{NH}_{3}$, Environ. Monit. Assess., 161, 11-27, doi:10.1007/s10661-008-07236, 2010.

Farquhar, G. D., Firth, P. M., Wetselaar, R., and Weir, B.: On the gaseous exchange of ammonia between leaves and the environment: determination of the ammonia compensation point, Plant Physiol., 66, 710-714, 1980.

Felber, R., Conen, F., Flechard, C. R., and Neftel, A.: Theoretical and practical limitations of the acetylene inhibition technique to determine total denitrification losses, Biogeosciences, 9, 41254138, doi:10.5194/bg-9-4125-2012, 2012.

Felle, H. H. and Hanstein, S.: The apoplastic pH of the substomatal cavity of Vicia faba leaves and its regulation responding to different stress factors, J. Exp. Bot., 53, 73-82, 2002.

Flechard, C. R. and Fowler, D.: Atmospheric ammonia at a moorland site. I: The meteorological control of ambient ammonia concentrations and the influence of local sources, Q. J. Roy. Meteor. Soc., 124, 733-757, 1998a.

Flechard, C. R. and Fowler, D.: Atmospheric ammonia at a moorland site. II: Long-term surface-atmosphere micrometeorological flux measurements, Q. J. Roy. Meteor. Soc., 124, 759-791, 1998b.

Flechard, C. R. and Fowler, D.: Effects of Changing Temperature on Leaf Surface Water-Film Chemistry and Trace Gas Exchange Processes over Terrestrial Vegetation, in: The Impact of Climate Change on Air Quality, The 4th ACCENT Barnsdale Expert Workshop, edited by: Builtjes, P., Fowler, D., Feichter, J., Lewis, A., Monks, P., and Borrell, P., ACCENT Secretariat,
Urbino, Italy, 155-161, 2008.

Flechard, C. R., Fowler, D., Sutton, M. A., and Cape, J. N.: A dynamic chemical model of bi-directional ammonia exchange between semi-natural vegetation and the atmosphere, Q. J. Roy. Meteor. Soc., 125, 2611-2641, 1999.

Flechard, C. R., Spirig, C., Neftel, A., and Ammann, C.: The annual ammonia budget of fertilized cut grassland - Part 2: Seasonal variations and compensation point modeling, Biogeosciences, 7 , 537-556, doi:10.5194/bg-7-537-2010, 2010.

Flechard C. R., Nemitz E., Smith R. I., Fowler D., Vermeulen A. T., Bleeker A., Erisman J. W., Simpson D., Zhang L., Tang Y. S., and Sutton M. A.: Dry deposition of reactive nitrogen to European ecosystems: a comparison of inferential models across the NitroEurope network, Atmos. Chem. Phys., 11, 2703-2728, doi:10.5194/acp-11-2703-2011, 2011.

Flesch, T. K., Wilson, J. D., Harper, L. A., Todd, R. W., and Cole, N. A.: Determining ammonia emissions from a cattle feedlot with an inverse dispersion technique, Agr. Forest Meteorol., 144, 139155, 2007.

Foley, K. M., Roselle, S. J., Appel, K. W., Bhave, P. V., Pleim, J. E., Otte, T. L., Mathur, R., Sarwar, G., Young, J. O., Gilliam, R. C., Nolte, C. G., Kelly, J. T., Gilliland, A.B. and Bash, J.O.: Incremental testing of the Community Multiscale Air Quality (CMAQ) modeling system version 4.7, Geosci. Model Develop., 3, 204-226, 2010.

Fowler, D. and Unsworth, M. H.: Turbulent transfer of sulphur dioxide to a wheat crop, Q. J. Roy. Meteor. Soc., 105, 767-783, 1979.

Fowler, D., Pitcairn, C. E. R., Sutton, M. A., Flechard, C. R., Loubet, B., Coyle, M., and Munro, R. C.: The mass budget of atmospheric ammonia in woodland within $1 \mathrm{~km}$ of livestock buildings, Environ. Pollut., 102, 343-348, 1998.

Fowler, D., Pilegaard, K., Sutton, M. A., Ambus, P., Raivonen, M., Duyzer, J., Simpson, D., Fagerli, H., Fuzzi, S., Schjoerring, J. K., Granier, C., Neftel, A., Isaksen, I. S. A., Laj, P., Maione, M., Monks, P. S., Burkhardt, J., Daemmgen, U., Neirynck, J., Personne, E., Wichink-Kruit, R., Butterbach-Bahl, K., Flechard, C., Tuovinen, J. P., Coyle, M., Gerosa, G., Loubet, B., Altimir, N., Gruenhage, L., Ammann, C., Cieslik, S., Paoletti, E., Mikkelsen, T. N., Ro-Poulsen, H., Cellier, P., Cape, J. N., Horváth, L., Loreto, F., Niinemets, Ü., Palmer, P. I., Rinne, J., Misztal, P., Nemitz, E., Nilsson, D., Pryor, S., Gallagher, M. W., Vesala, T., Skiba, U., Brüggemann, N., Zechmeister-Boltenstern, S., Williams, J., O’Dowd, C., Facchini, M. C., de Leeuw, G., Flossman, A., Chaumerliac, N., Erisman, J. W.: Atmospheric composition change: Ecosystems-Atmosphere interactions, Atmos. Environ., 43, 5193-5267, 2009.

Gabrielle, B., Menasseri, S., and Houot, S.: Analysis and fieldevaluation of the CERES models' water balance component, Soil Sci. Soc. Am. J., 59, 1402-1411, 1995.

Galloway, J. N., Aber, J. D., Erisman, J. W., Seitzinger, S. P., Howarth, R. W., Cowling, E. B., and Cosby, B. J.: The nitrogen cascade, Bioscience, 53, 341-356, 2003.

Ganzeveld, L. and Lelieveld, J.: Dry deposition parameterization in a chemistry general circulation model and its influence on the distribution of reactive trace gases, J. Geophys. Res., 100, 20999-21012, 1995.

Garcia, L., Bedos C., Génermont, S., Braud, I., and Cellier, P.: Assessing the ability of mechanistic volatilization models to simulate soil surface conditions, A study with the Volt'Air model, Sci. 
Total Environ., 409, 3980-3992, 2011.

Garland, J. A.: The dry deposition of sulphur dioxide to land and water surfaces, P. R. Soc. London A, 354, 245-268, 1977.

Geels, C., Andersen, H. V., Skjøth, C. A., Christensen, J. H., Ellermann, T., Løfstrøm, P., Gyldenkærne, S., Brandt, J., Hansen, K. M., Frohn, L. M., and Hertel, O.: Improved modelling of atmospheric ammonia over Denmark using the coupled modelling system DAMOS, Biogeosciences, 9, 2625-2647, doi:10.5194/bg-9-2625-2012, 2012.

Génermont, S. and Cellier, P.: A mechanistic model for estimating ammonia volatilization from slurry applied to bare soil, Agr. Forest Meteorol., 88, 145-167, 1997.

Génermont, S., Cellier, P., Flura, P., Morvan, T., and Laville, P.: Measuring ammonia fluxes after slurry spreading under actual field conditions, Atmos. Environ., 32, 279-284, 1998.

Godwin, D. C., Jones, C. A., Ritchie, J. T., Vlek, P. L. G., and Youngdahl, L.G.: The water and nitrogen components of the CERES models, in: International Symposium on Minimum Data Sets for Agrotechnology Transfer, International Crops Research Institute for the Semi-Arid Tropics, Patancheru, India, 95-100, 1984.

Grünhage, L. and Haenel, H.-D.: PLATIN (PLanteATmosphere INteraction) I: a model of plant-atmosphere interaction for estimating absorbed doses of gaseous air pollutants, Environ. Pollut., 98, 37-50, 1997.

Grünhage, L. and Haenel, H.-D.: Detailed documentation of the PLATIN (PLanteATmosphere INteraction) model, Landbauforschung Völkenrode, Special Issue 319, http://www. uni-giessen.de/cms/ukl-en/PLATIN, 1-85, 2008.

Hamaoui-Laguel, L., Meleux, F., Beekmann, M., Bessagnet, B., Génermont, S., Cellier, P., and Létinois, L.: Improving ammonia emissions in air quality modelling for France, Atmos. Environ., in press, doi:10.1016/j.atmosenv.2012.08.002, 2012.

Hanstein, S. and Felle, H. H.: The influence of atmospheric $\mathrm{NH}_{3}$ on the apoplastic $\mathrm{pH}$ of green leaves: a non-invasive approach with pH-sensitive microelectrodes, New Phytol., 143, 333-338, 1999.

Harper, L. A., Scharpe, R. R., Langdale, G. W., and Giddens, J. E.: Nitrogen cycling in a wheat crop: soil, plant and aerial nitrogen transport, Agron. J., 79, 965-973, 1987.

Harper, L. A., Denmead, O. T., and Sharpe, R. R.: Identifying sources and sinks of scalars in a corn canopy with inverse Lagrangian dispersion analysis II. Ammonia, Agr. Forest Meteorol., 104, 75-83, 2000.

Hensen, A., Nemitz, E., Flynn, M.J., Blatter, A., Jones, S.K., Sørensen, L.L., Hensen, B., Pryor, S. C., Jensen, B., Otjes, R. P., Cobussen, J., Loubet, B., Erisman, J. W., Gallagher, M. W., Neftel, A., and Sutton, M. A.: Inter-comparison of ammonia fluxes obtained using the Relaxed Eddy Accumulation technique, Biogeosciences, 6, 2575-2588, doi:10.5194/bg-6-25752009, 2009a.

Hensen, A., Loubet, B., Mosquera, J., van den Bulk, W. C. M., Erisman, J. W., Dämmgen, U., Milford, C., Löpmeier, F. J., Cellier, P., Mikuška, P., and Sutton, M. A.: Estimation of $\mathrm{NH}_{3}$ emissions from a naturally ventilated livestock farm using local-scale atmospheric dispersion modelling, Biogeosciences, 6, 2847-2860, doi:10.5194/bg-6-2847-2009, 2009b.

Henze, D. K., Seinfeld, J. H., and Shindell, D. T.: Inverse modeling and mapping US air quality influences of inorganic PM2.5 precursor emissions using the adjoint of GEOS-Chem, At- mos. Chem. Phys., 9, 5877-5903, doi:10.5194/acp-9-5877-2009, 2009.

Hertel, O., Skjøth, C. A., Løfstrøm, P., Geels, C., Frohn, L. M., Ellermann, T. , and Madsen, P. V.: Modelling Nitrogen Deposition on a Local Scale-A Review of the Current State of the Art, Environ. Chem., 3, 317-337, 2006.

Hertel, O., Theobald, M., Cellier, P., Bleeker, A., Druce, D., Frohn, L. M., Hill, R., Noordijk, E., Sharp, M., van Pul, A., and van Zanten, M.: Approaches to modelling local nitrogen deposition and concentrations in the context of Natura 2000, in: Nitrogen Deposition and Natura 2000, Science and Practice in Determining Environmental Impacts, edited by: Hicks, W. K., Whitfield, C. P., Bealey, W. J., and Sutton, M. A., COST 729/Nine/ESF/CCW/JNCC/SEI Workshop Proceedings, 201-207, 2011.

Hertel, O., Skjøth, C. A., Reis, S., Bleeker, A., Harrison, R. M., Cape, J. N., Fowler, D., Skiba, U., Simpson, D., Jickells, T., Kulmala, M., Gyldenkærne, S., Sørensen, L. L., Erisman, J. W., and Sutton, M. A.: Governing processes for reactive nitrogen compounds in the European atmosphere, Biogeosciences, 9, 49214954, doi:10.5194/bg-9-4921-2012, 2012.

Herrmann, B., Mattsson, M., Jones, S. K., Cellier, P., Milford, C., Sutton, M. A., Schjoerring, J. K., and Neftel, A.: Vertical structure and diurnal variability of ammonia exchange potential within an intensively managed grass canopy, Biogeosciences, 6 , 15-23, doi:10.5194/bg-6-15-2009, 2009.

Hill, J.: Application of computation modelling to ammonia dispersion from agricultural sources, Ph.D. thesis, Imperial College, Centre for Environmental Technology, University of London, 1998.

Hill, P. W., Raven, J. A., Loubet, B., Fowler, D., and Sutton, M. A.: Comparison of gas exchange and bioassay determinations of the ammonia compensation point in Luzula sylvatica (Huds.) Gaud, Plant Physiol. 125, 476-487, 2001.

Hill, P. W., Raven, J. A., and Sutton, M. A.: Leaf age-related differences in apoplastic $\mathrm{NH}_{4}^{+}$concentration, $\mathrm{pH}$ and the $\mathrm{NH}_{3}$ compensation point for a wild perennial, J. Exp. Bot., 53, 277-286, 2002.

Hoffmann, B., Planker, R., and Mengel, K.: Measurements of $\mathrm{pH}$ in the apoplast of sunflower leaves by means of fluorescence, Physiol. Plantarum, 84, 146-153, 1992.

Huang, X., Song, Y, Li, M. M., Li, J. F., Huo, Q., Cai, X. H., Zhu, T., Hu, M., and Zhang, H. S.: A high-resolution ammonia emission inventory in China, Global Biogeochem. Cy., 26, GB1030, doi:10.1029/2011GB004161, 2012.

Huijnen, V., Williams, J., van Weele, M., van Noije, T., Krol, M., Dentener, F., Segers, A., Houweling, S., Peters, W., de Laat, J., Boersma, F., Bergamaschi, P., van Velthoven, P., Le Sager, P., Eskes, H., Alkemade, F., Scheele, R., Nédélec, P., and Pätz, H.-W.: The global chemistry transport model TM5: description and evaluation of the tropospheric chemistry version 3.0, Geosci. Model Develop., 3, 445-473, doi:10.5194/gmd-3-445-2010, 2010.

Husted, S. and Schjoerring, J. K.: Apoplastic pH and ammonium concentration in leaves of Brassica napus L., Plant Physiol., 109, 1453-1460, 1995.

Husted, S., Mattsson, M., and Schjoerring, J. K.: Ammonia compensation points in two cultivars of Hordeum vulgare L. during vegetative and generative growth, Plant Cell Environ., 19, 1299 1306, 1996. 
Husted, S., Schjoerring, J. K., Nielsen, K. H., Nemitz, E., and Sutton, M. A.: Stomatal compensation points for ammonia in oilseed rape plants under field conditions, Agr. Forest Meteorol., 105, 371-383, 2000.

Hutchinson, G. L., Millington, R. J., and Peters, D. B.: Atmospheric ammonia: absorption by plant leaves, Science, 175, 771-772, 1972.

Jarvis, P. G.: The interpretation of the variations in leaf water potential and stomatal conductance found in canopies in the field, Philos. T. R. Soc. Lond., B273, 593-610, 1976.

Jones, M. R., Leith, I. D., Fowler, D., Raven, J. A., Sutton, M. A., Nemitz, E., Cape, J. N., Sheppard, L. J., Smith, R. I., and Theobald, M. R.: Concentration-dependent $\mathrm{NH}_{3}$ deposition processes for mixed moorland semi-natural vegetation, Atmos. Environ., 41, 2049-2060, 2007.

Joy, K. W.: Ammonia, glutamine and asparagine: a carbon-nitrogen interface, Can. J. Bot., 66, 2103-2109, 1988.

Klein, T., Bergström, R., and Persson, C.: Parameterization of dry deposition in MATCH. Swedish Meteorological and Hydrological Institute (SMHI), Norrköping, Sweden, 2002.

Kramm, G. and Dlugi, R.: Modeling of the vertical fluxes of nitric acid, ammonia, and ammonium-nitrate, J. Atmos. Chem., 18, 319-357, 1994.

Laguel-Hamaoui, L.: Les Emissions d'Ammoniac par les Activités Agricoles : Impact sur la Qualité de l'Air, Ph. D. thesis, Université Paris Diderot, Paris, 196 pp., 2012.

Langford, A. O. and F. C. Fehsenfeld: Natural vegetation as a source or sink for atmospheric ammonia: a case study, Science, 255, 581-583, 1992.

Laubach, J., Taghizadeh-Toosib, A., Sherlock, R. R., and Kelliher, F. M.: Measuring and modelling ammonia emissions from a regular pattern of cattle urine patches, Agr. Forest Meteorol., 156, 1-17, 2012.

Lemon, E. and Van Houtte, R.: Ammonia exchange at the land surface, Agron. J., 72, 876-883, 1980.

Li, C. S., Frolking, S., and Frolking, T. A.: A model of nitrous oxide evolution from soil driven by rainfall events: 1 . Model structure and sensitivity, J. Geophys. Res., 97, 9759-9776, 1992.

Li, C. S.: Modeling trace gas emissions from agricultural ecosystems, Nutr. Cycl. Agroecosys., 58, 259-276, 2000.

Lim, Y., Moon, Y.-S., and Kim, T.-W.: Artificial neural network approach for prediction of ammonia emission from field-applied manure and relative significance assessment of ammonia emission factors, Eur. J. Agron., 26, 425-434, 2007.

LMD: Documentation of the chemistry-transport model CHIMERE [version chimere2011]. Laboratoire de Météorologie Dynamique, Institut Pierre-Simon Laplace, Palaiseau, France, http: //www.lmd.polytechnique.fr/chimere/, 2011.

Loubet, B., Milford, C., Sutton, M. A., and Cellier, P.: Investigation of the interaction between sources and sinks of atmospheric ammonia in an upland landscape using a simplified dispersionexchange model, J. Geophys. Res., 106, 24183-24195, 2001.

Loubet, B., Milford, C., Hill, P. W., Tang, Y. S., Cellier, P., and Sutton, M. A.: Seasonal variability of apoplastic $\mathrm{NH}_{4}^{+}$and $\mathrm{pH}$ in an intensively managed grassland, Plant Soil, 238, 97-110, 2002.

Loubet, B., Cellier, P., Milford, C., and Sutton, M. A.: A coupled dispersion and exchange model for short-range dry deposition of atmospheric ammonia, Q. J. Roy. Meteor. Soc., 132, 1733-1763, 2006.
Loubet, B., Asman, W. A. H., Theobald, M. R., Hertel, O., Tang, Y. S., Robin, P., Hassouna, M., Dämmgen, U., Genermont, S., Cellier, P., and Sutton, M. A.: Ammonia deposition near hotspots: processes, models and monitoring methods, in: UNECE Expert Workshop on Atmospheric Ammonia - Detecting Emission Changes And Environmental Impacts, Sutton, M.A., Reis S. and Baker S.M.H. (Eds), Springer, Dordrecht, The Netherlands, ISBN: 978-1-4020-9120-9, 205-267, 2009a.

Loubet, B., Milford, C., Hensen, A., Daemmgen, U., Erisman, J.W., Cellier, P., and Sutton, M. A.: Advection of NH3 over a pasture field and its effect on gradient flux measurements, Biogeosciences, 6, 1295-1309, doi:10.5194/bg-6-1295-2009, 2009b.

Loubet, B., Decuq, C., Personne, E., Massad, R. S., Flechard, C., Fanucci, O., Mascher, N., Gueudet, J.-C., Masson, S., Durand, B., Genermont, S., Fauvel, Y., and Cellier, P.: Investigating the stomatal, cuticular and soil ammonia fluxes over a growing tritical crop under high acidic loads, Biogeosciences, 9, 1537-1552, doi:10.5194/bg-9-1537-2012, 2012.

Massad, R. S., Loubet, B., Tuzet, A., and Cellier, P.: Relationship between ammonia stomatal compensation point and nitrogen metabolism in arable crops: Current status of knowledge and potential modelling approaches, Environ. Pollut., 154, 390-403, 2008.

Massad, R.-S., Loubet, B., Tuzet, A., Autret, H., and Cellier, P.: Ammonia stomatal compensation point of young oilseed rape leaves during dark/light cycles under various nitrogen nutritions, Agr. Ecosyst. Environ., 133, 170-182, 2009.

Massad, R.-S., Tuzet, A., Loubet, B., Perrier, A., and Cellier, P.: Model of stomatal ammonia compensation point (STAMP) in relation to the plant nitrogen and carbon metabolisms and environmental conditions, Ecol. Model., 221, 479-494, 2010a.

Massad, R.-S., Nemitz, E., and Sutton, M. A.: Review and parameterisation of bi-directional ammonia exchange between vegetation and the atmosphere, Atmos. Chem. Phys., 10, 10359-10386, doi:10.5194/acp-10-10359-2010, 2010b.

Massman, W. J.: Foliage distribution in old-growth coniferous tree canopies, Can. J. Forest Res., 12, 10- 17, 1982.

Massman, W. J.: An analytical one-dimensional model of momentum transfer by vegetation of arbitrary structure, Bound.-Lay. Meteorol., 83, 407-421, 1997.

Mattsson, M. and Schjoerring, J.K.: Ammonia emission from young barley plants: influence of $\mathrm{N}$ source, light/dark cycles and inhibition of glutamine synthetase, J. Exp. Bot., 47, 477-484, 1996.

Mattsson, M. and Schjoerring, J. K.: Dynamic and steady-state responses of inorganic nitrogen pools and $\mathrm{NH}_{3}$ exchange in leaves of Lolium perenne and Bromus erectus to changes in root nitrogen supply, Plant Physiol., 128, 742-750, 2002.

Mattsson, M. and Schjoerring, J. K.: Senescence-induced changes in apoplastic and bulk tissue ammonia concentrations of ryegrass leaves, New Phytol., 160, 489-499, 2003.

Mattsson, M., Herrmann, B., Jones, S., Neftel, A., Sutton, M. A., and Schjoerring, J. K.: Contribution of different grass species to plant-atmosphere ammonia exchange in intensively managed grassland, Biogeosciences, 6, 59-66, doi:10.5194/bg-6-59-2009, 2009a.

Mattsson, M., Herrmann, B., David, M., Loubet, B., Riedo, M., Theobald, M. R., Sutton, M. A., Bruhn, D., Neftel, A., and Schjoerring, J. K.: Temporal variability in bioassays of the stomatal ammonia compensation point in relation to plant and soil 
nitrogen parameters in intensively managed grassland, Biogeosciences, 6, 171-179, doi:10.5194/bg-6-171-2009, 2009b.

McCalley, C. and Sparks, J.: Controls over nitric oxide and ammonia emissions from Mojave Desert soils, Oecologia, 156, 871881,2008

Meixner, F. X., Wyers, P. G. and Neftel, A.: Bi-directional exchange of ammonia over cereals, in: Proceedings of EUROTRAC'96, edited by: Borrell, P. M., Borell, P., Kelly, K., Cavitaš, T., and Seiler, W., Computer Mechanics Publications, Southampton, 129-135, 1996.

Menut, L. and Bessagnet, B.: Atmospheric composition forecasting in Europe, Ann. Geophys., 28, 61-74, doi:10.5194/angeo-28-612010, 2010.

Menzi, H., Katz, P. E., Fahrni, M., Neftel, A., and Frick, R.: A simple empirical model based on regression analysis to estimate ammonia emissions after manure application, Atmos. Environ., 32, 301-307, 1998.

Meyer, M. W.: Absorption and release of ammonia from and to the atmosphere by plants, $\mathrm{Ph}$. D. thesis, University of Maryland, College Park, MD, USA, 63 pp., 1973.

Meyers, T. P., Finkelstein, P. L., Clarke, J., Ellestad, T. G., and Sims, P.: A multilayer model for inferring dry deposition using standard meteorological measurements, J. Geophys. Res., 103, 645-661, 1998.

Meyers, T. P., Luke, W. T., and Meisinger, J. J.: Fluxes of ammonia and sulfate over maize using relaxed eddy accummulation, Agr. Forest Meteorol., 136, 203-213, 2006.

Milford, C.: Dynamics of atmospheric ammonia exchange with intensively-managed grassland, Ph.D. Thesis, University of Edinburgh, UK, 218 pp., 2004.

Milford, C., Hargreaves, K. J., Sutton, M. A., Loubet, B., and Cellier, P.: Fluxes of $\mathrm{NH}_{3}$ and $\mathrm{CO}_{2}$ over upland moorland in the vicinity of agricultural land, J. Geophys. Res., 106, 2416924181, 2001a.

Milford, C., Theobald, M. R., Nemitz, E., and Sutton, M. A.: Dynamics of ammonia exchange in response to cutting and fertilizing in an intensively-managed grassland, Water Air Soil Poll.: Focus, 1, 167-176, 2001b.

Monteith, J. L. and Unsworth, M. H.: Principles of Environmental Physics, 2nd Ed., Edward Arnold, London, 291 pp., 1990.

Montes, F., Rotz, C. A., and Chaoui, H.: Process modelling of ammonia volatilization from ammonium solution and manure surfaces: a review with recommended models, T. Am. Soc. Agr. Biol. Eng. 52, 1707-1719, 2009.

Mozurkewich, M.: The dissociation constant of ammonium nitrate and its dependence on temperature, relative humidity and particle size, Atmos. Environ., 27A, 261-270, 1993.

Neftel, A., Blatter, A., Gut, A., Hoegger, D., Meixner, F. X., Ammann, C., and Nathaus, F. J.: $\mathrm{NH}_{3}$ soil and soil surface gas measurements in a tritical wheat field, Atmos. Environ., 32, 499-505, 1998.

Neftel, A., Sintermann, J., Häni, C., Kupper, T., Hansen, M., Flechard, C.R., Loubet, B., Hensen, A., Huijsmans, J., Mosquera, J., Misselbrook, T., Ammann, C., Menzi, H., Zundel, C., Weber, R., Theis, G., and Achermann, B.: Reassessment of $\mathrm{NH}_{3}$ emission factors for field application of slurry, Expert Workshop, 1213 March 2013, Bern University of Applied Sciences, School of Agricultural, Forest and Food Sciences (HAFL), Zollikofen, Switzerland, available on http://www.agrammon.ch, 2013.
Neirynck, J. and Ceulemans, R.: Bidirectional ammonia exchange above a mixed coniferous forest, Environ. Pollut., 154, 424-438, 2008 .

Nemitz, E. G.: Surface-atmosphere exchange of ammonia and chemically interacting species, $\mathrm{Ph}$. D. thesis, University of Manchester Institute of Science and Technology, 302 pp., 1998.

Nemitz, E., Sutton, M. A., Fowler, D., and Choularton, T. W.: Application of a $\mathrm{NH}_{3}$ gas-to-particle conversion model to measurement data, in: Proceedings of the International conference on atmospheric ammonia, Oxford, UK, 2-4 October 1995, edited by: Sutton, M. A., Lee, D. S., Dollard, G., and Fowler, D., Institute of Terrestrial Ecology (ITE), Edinburgh, UK, 98-103, 1996.

Nemitz, E., Sutton, M. A., Gut, A., San Jose, R., Husted, S., and Schjoerring, J. K.: Sources and sinks of ammonia within an oilseed rape canopy, Agr. Forest Meteorol., 105, 385-404, 2000 a.

Nemitz, E., Sutton, M. A., Schjoerring, J. K., Husted, S., and Wyers, G. P.: Resistance modelling of ammonia exchange over oilseed rape, Agr. Forest Meteorol., 105, 405-425, $2000 \mathrm{~b}$.

Nemitz, E., Sutton, M. A., Wyers, G. P., Otjes, R. P., Schjoerring, J. K., Gallagher, M. W., Parrington, J., Fowler, D., and Choularton, T. W.: Surface/atmosphere exchange and chemical interaction of gases and aerosols over oilseed rape. Agr. Forest Meteorol., 105, 427-445, 2000c.

Nemitz, E., Milford, C., and Sutton, M. A.: A two-layer canopy compensation point model for describing bi-directional biosphere/atmosphere exchange of ammonia, Q. J. Roy. Meteor. Soc., 127, 815-833, 2001a.

Nemitz, E., Flynn, M., Williams, P. I., Milford, C., Theobald, M. R., Blatter, A., Gallagher, M. W., and Sutton, M. A.: A relaxed eddy accumulation system for the automated measurement of atmospheric ammonia fluxes, Water Air Soil Poll., Focus 1, 189-202, 2001b.

Nemitz, E. and Sutton, M. A.: Gas-particle interactions above a Dutch heathland: III. Modelling the influence of the $\mathrm{NH}_{3}-\mathrm{HNO}_{3}-$ $\mathrm{NH}_{4} \mathrm{NO}_{3}$ equilibrium on size-segregated particle fluxes, Atmos. Chem. Phys., 4, 1025-1045, doi:10.5194/acp-4-1025-2004, 2004.

Nemitz, E., Sutton, M. A., Wyers, G. P., Otjes, R. P., Mennen, M. G., van Putten, E. M., and Gallagher, M. W.: Gas-particle interactions above a Dutch heathland: II. Concentrations and surface exchange fluxes of atmospheric particles, Atmos. Chem. Phys. 4, 1007-1024, 2004.

Nemitz, E., Loubet, B., Lehmann, B. E., Cellier, P., Neftel, A., Jones, S.K., Hensen, A., Ihly, B., Tarakanov, S. V., and Sutton, M. A.: Turbulence characteristics in grassland canopies and implications for tracer transport, Biogeosciences, 6, 1519-1537, doi:10.5194/bg-6-1519-2009, 2009a.

Nemitz, E., Dorsey, J. R., Flynn, M. J., Gallagher, M. W., Hensen, A., Erisman, J.-W., Owen, S. M., Dämmgen, U., and Sutton, M. A.: Aerosol fluxes and particle growth above managed grassland, Biogeosciences, 6, 1627-1645, doi:10.5194/bg-6-16272009, 2009.

Nemitz, E.: Surface/atmosphere exchange of atmospheric acids and aerosols, including the effect and model treatment of chemical interactions, in: Proceedings of the COST-ABBA/ECLAIRE workshop, 25-27 September 2012, INRA-AgroParisTech, Paris, 2012.

Nicolardot, B., Lagacherie, B., Cheneby, D., and Mariotti, M.: Decomposition of $15 \mathrm{~N}$-labelled catch-crop residues in soil: evalu- 
ation of $\mathrm{N}$ mineralization and plant- $\mathrm{N}$ uptake potentials under controlled conditions, Eur. J. Soil Sci. 46, 115-123, 1995.

Olesen, H. R., Berkowicz, R., and Løfstrøm, P.: OML: Review of model formulation, NERI Technical Report 609, National Environmental Research Institute, University of Aarhus, available at: http://dce.au.dk/old/danmarksmiljoeundersoegelser/ udgivelser/faglige_rapporter/nr._600-649/, 2007.

Parton, W. J., Ojima, D. S., Cole, C. V., and Schimel, D. S.: A general model for soil organic matter dynamics: Sensitivity to litter chemistry, texture and management, in: Quantitative Modeling of Soil Forming Processes, SSSA Spec. Public. No. 39, SSSA, Madison, WI, 147-167, 1994.

Perry, S. G., Cimorelli, A. J., Paine, R. J., Brode, R. W., Weil, J. C., Venkatram, A., Wilson, R. B., Lee, R. F., and Peters, W. D.: AERMOD: a dispersion model for industrial source applications, Part II: model performance against 17 field study databases, J. Appl. Meteorol., 44, 694-708, 2004.

Personne, E., Loubet, B., Herrmann, B., Mattsson, M., Schjoerring, J. K., Nemitz, E., Sutton, M. A., and Cellier, P.: SURFATM-NH3: a model combining the surface energy balance and bi-directional exchanges of ammonia applied at the field scale, Biogeosciences, 6, 1371-1388, doi:10.5194/bg-6-1371-2009, 2009.

Pinder, R. W., Adams, P. J., and Pandis, S. N.: Ammonia Emission Controls as a Cost-Effective Strategy for Reducing Atmospheric Particulate Matter in the Eastern United States, Environ. Sci. Technol., 41, 380-386, 2007.

Pitcairn, C., Fowler, D., Leith, I. D., Sheppard, L., Tang, Y. S., Sutton, M. A., and Famulari, D.: Diagnostic indicators of elevated nitrogen deposition, Environ. Pollut., 144, 941-950, 2006.

Raven, J.: Acquisition of nitrogen by the shoots of land plants: its occurrence and implications for acid-base regulation, New Phytol., 109, 1-20, 1988.

Raupach, M. R.: Applying Lagrangian fluid mechanics to infer scalar source distributions from concentration profiles in plant canopies, Agr. Forest Meteorol., 47, 85-108, 1989.

Reddy, K. R., Khaleel, R., Overcash, M. R., and Westerman, P. W.: A nonpoint source model for land areas receiving animal wastes: II. Ammonia volatilization, T. Am. Soc. Agr. Eng., 22, 13981404, 1979.

R'Honi, Y., Clarisse, L., Clerbaux, C., Hurtmans, D., Duflot, V., Turquety, S., Ngadi, Y., and Coheur, P.-F.: Exceptional emissions of $\mathrm{NH}_{3}$ and $\mathrm{HCOOH}$ in the 2010 Russian wildfires, Atmos. Chem. Phys., 13, 4171-4181, doi:10.5194/acp-13-41712013, 2013.

Riddick, S. N.: Global ammonia emissions from seabird colonies, $\mathrm{Ph}$. D. thesis, Department of Geography, King's College, London, 287 pp., 2012.

Riddick, S. N., Dragosits, U., Blackall, T. D., Daunt, F., Wanless, S., and Sutton, M. A.: The global distribution of ammonia emissions from seabird colonies, Atmos. Environ., 55, 319-327, 2012.

Riedo, M., Grub, A., Rosset, M., and Fuhrer, J.: A pasture simulation model for dry matter production, and fluxes of carbon, nitrogen, water and energy, Ecol. Model., 105, 141-183, 1998.

Riedo, M., Milford, C., Schmid, M., and Sutton, M. A.: Coupling soil-plant-atmosphere exchange of ammonia with ecosystem functioning in grasslands, Ecol. Model., 158, 83-110, 2002.

Ryder, J.: Emission, deposition and chemical conversion of atmospheric trace substances in and above vegetation canopies, $\mathrm{Ph}$. D. thesis, University of Manchester, 241 pp., 2010.
Schjoerring, J. K., Kyllingsbaek, A., Mortensen, J. V., and ByskovNielsen, S.: Field investigations of ammonia exchange between barley plants and the atmosphere, I. Concentration profiles and flux densities of ammonia, Plant Cell Environ., 16, 161-167, 1993.

Schjoerring, J. K., Husted, S., and Mattsson, M.: Physiological parameters controlling plant-atmosphere ammonia exchange, Atmos. Environ., 32, 491-498, 1998.

Schjoerring, J. K., Husted, S., Mack, G., and Mattsson, M.: The regulation of ammonium translocation in plants, J. Exp. Bot., 53, 883-890, 2002.

Schlesinger, W. H. and Hartley, A. E.: A global budget for atmospheric $\mathrm{NH}_{3}$, Biogeochemistry 15, 191-211, 1992.

Seinfeld, J. H. and Pandis, S. N.: Atmospheric Chemistry and Physics - From Air Pollution to Climate Change, 2nd Edition, John Wiley \& Sons, New York, 1203 pp., 2006.

Sharp, R. G. and Davies, W. J.: Variability among species in the apoplastic $\mathrm{pH}$ signalling response to drying soils, J. Exp. Bot., 60, 4363-4370, doi:10.1093/jxb/erp273, 2009.

Shephard, M. W., Cady-Pereira, K. E., Luo, M., Henze, D. K., Pinder, R. W., Walker, J. T., Rinsland, C. P., Bash, J. O., Zhu, L., Payne, V. H., and Clarisse, L.: TES ammonia retrieval strategy and global observations of the spatial and seasonal variability of ammonia, Atmos. Chem. Phys., 11, 10743-10763, doi:10.5194/acp-11-10743-2011, 2011.

Simpson, D., Benedictow, A., Berge, H., Bergström, R., Emberson, L. D., Fagerli, H., Flechard, C.R., Hayman, G. D., Gauss, M., Jonson, J. E., Jenkin, M. E., Nyíri, A., Richter, C., Semeena, V. S., Tsyro, S., Tuovinen, J.-P., Valdebenito, Á., and Wind, P.: The EMEP MSC-W chemical transport model - technical description, Atmos. Chem. Phys., 12, 7825-7865, doi:10.5194/acp-127825-2012, 2012.

Singles, R., Sutton, M. A., and Weston, K. J.: A multi-layer model to describe the atmospheric transport and deposition of ammonia in Great Britain, Atmos. Environ., 32, 393-399, 1998.

Sintermann, J., Spirig, C., Jordan, A., Kuhn, U., Ammann, C., and Neftel, A.: Eddy covariance flux measurements of ammonia by high temperature chemical ionisation mass spectrometry, Atmos. Meas. Tech., 4, 599-616, doi:10.5194/amt-4-599-2011, 2011.

Sintermann, J., Neftel, A., Ammann, C., Häni, C., Hensen, A., Loubet, B., and Flechard, C. R.: Are ammonia emissions from fieldapplied slurry substantially over-estimated in European emission inventories?, Biogeosciences, 9, 1611-1632, doi:10.5194/bg-91611-2012, 2012.

Skjøth, C. A., Hertel, O., Gyldenkærne, S., and Ellerman, T.: Implementing a dynamical ammonia emission parameterization in the large-scale air pollution model ACDEP, J. Geophys. Res., 109, D06306, doi:10.1029/2003JD003895, 2004.

Skjøth, C. A., Geels, C., Berge, H., Gyldenkærne, S., Fagerli, H., Ellermann, T., Frohn, L. M., Christensen, J., Hansen, K. M., Hansen, K., and Hertel, O.: Spatial and temporal variations in ammonia emissions - a freely accessible model code for Europe, Atmos. Chem. Phys., 11, 5221-5236, doi:10.5194/acp-11-52212011, 2011.

Smith, R. I., Fowler, D., Sutton, M. A., Flechard, C., and Coyle, M.: Regional estimation of pollutant gas deposition in the UK: model description, sensitivity analyses and outputs, Atmos. Environ., 34, 3757-3777, 2000. 
Søgaard, H. T., Sommer, S. G., Hutchings, N. J., Huijsmans, J. F. M., Bussink, D. W., and Nicholson, F.: Ammonia volatilization from field-applied animal slurry - the ALFAM model, Atmos. Environ., 36, 3309-3319, 2002.

Sommer, S. G., Génermont, S., Cellier, P., Hutchings, N. J., Olesen, J. E., and Morvan, T.: Processes controlling ammonia emission from livestock slurry in the field, Eur. J. Agron., 19, 465-486, doi:10.1016/S1161-0301(03)00037-6, 2003.

Sommer, S. G., Østergård, H. S., Løfstrøm, P., Andersen, H. V. and Jensen, L. S.: Validation of model calculation of ammonia deposition in the neighbourhood of a poultry farm using measured $\mathrm{NH}_{3}$ concentrations and $\mathrm{N}$ deposition, Atmos. Environ., 43, 915920, 2009

Sorteberg, A. and Hov, Ø.: Two parametrizations of the dry deposition exchange for $\mathrm{SO}_{2}$ and $\mathrm{NH}_{3}$ in a numerical model, Atmos. Environ., 30, 1823-1840, 1996.

Spindler, G., Teichmann, U., and Sutton, M. A.: Ammonia dry deposition over grassland - micrometeorological flux-gradient measurements and bidirectional flux calculations using an inferential model, Q. J. Roy. Meteor. Soc., 127, 795-814, 2001.

Spirig, C., Flechard, C. R., Ammann, C., and Neftel, A.: The annual ammonia budget of fertilized cut grassland - Part 1: Micrometeorological flux measurements and emissions after slurry application, Biogeosciences, 7, 521-536, doi:10.5194/bg-7-5212010, 2010.

Sutton, M. A., Moncrieff, J. B., and Fowler, D.: Deposition of atmospheric ammonia to moorlands, Environ. Pollut., 75, 15-24, 1992.

Sutton, M. A., Fowler, D., and Moncrieff, J. B.: The exchange of atmospheric ammonia with vegetated surfaces. I: Unfertilized vegetation, Q. J. Roy. Meteor. Soc., 119, 1023-1045, 1993a.

Sutton, M. A., Fowler, D., Moncrieff, J. B., and Storeton-West, R. L.: The exchange of atmospheric ammonia with vegetated surfaces, II: Fertilized vegetation, Q. J. Roy. Meteor. Soc., 119, 1047-1070, 1993b.

Sutton, M. A., Pitcairn, C. E. R., and Fowler, D.: The exchange of ammonia between the atmosphere and plant communities, Adv. Ecol. Res., 24, 301-393, 1993c.

Sutton, M. A., Asman, W. A. H., and Schjoerring, J. K.: Dry deposition of reduced nitrogen, Tellus 46B, 255-273, 1994.

Sutton, M. A., Fowler, D., Burkhardt, J. K., and Milford, C.: Vegetation atmosphere exchange of ammonia: canopy cycling and the impacts of elevated nitrogen inputs, Water Air Soil Poll., 85, 2057-2063, 1995a.

Sutton, M. A., Schjørring, J. K., and Wyers, G. P.: Plant atmosphere exchange of ammonia, Philos. T. R. Soc. Lond., A351, 261-276, 1995b.

Sutton, M. A., Burkhardt, J. K., Guérin, D., and Fowler, D.: Measurements and modelling of ammonia exchange over arable croplands, in: Acid rain research: do we have enough answers?, edited by: Heij, G. J. and Erisman, J. W., Proceedings of a Specialty Conference, 's-Hertogenbosch, The Netherlands, 10-12 October 1994, Elsevier, Amsterdam, 71-80, 1995c.

Sutton, M. A., Burkhardt, J. K., Guerin, D., Nemitz, E., and Fowler, D.: Development of resistance models to describe measurements of bi-directional ammonia surface-atmosphere exchange, Atmos. Environ., 32, 473-480, 1998a.

Sutton, M. A., Milford, C., Dragosits, U., Place, C.J., Singles, R. J., Smith, R. I., Pitcairn, C. E. R., Fowler, D., Hill, J., ApSimon, H.
M., Ross, C., Hill, R., Jarvis, S. C., Pain, B. F., Phillips, V. C., Harrison, R., Moss, D., Webb, J., Espenhahn, S. E., Lee, D. S., Hornung, M., Ullyett, J., Bull, K. R., Emmett, B. A., Lowe, J., and Wyers, G. P.: Dispersion, deposition and impacts of atmospheric ammonia: quantifying local budgets and spatial variability, Environ. Pollut., 102, 349-361, 1998b.

Sutton, M. A., Nemitz, E., Fowler, D., Wyers, G. P., Otjes, R. P., Schjoerring, J. K., Husted, S., Nielsen, K. H., San Jose, R., Moreno, J., Gallagher, M. W., and Gut, A.: Fluxes of ammonia over oilseed rape. Overview of the EXAMINE experiment, Agr. Forest Meteorol., 105, 327-349, 2000.

Sutton, M. A., Nemitz, E., Erisman, J. W., Beier, C., Butterbach Bahl, K., Cellier, C., de Vries, W., Cotrufo, F., Skiba, U., Di Marco, C., Jones, S., Laville, P., Soussana, J. F., Loubet, B., Twigg, M., Famulari, D., Whitehead, J., Gallagher, M. W., Neftel, A., Flechard, C., Herrmann, B., Calanca, P.L., Schjoerring, J. K., Daemmgen,U.,Horvath, L., Tang, Y. S., Emmett, B. A., Tietema, A., Peňuelas, J., Kesik, M., Brueggemann, N., Pilegaard, K., Vesala, T., Campbell, C. L., Olesen, J. E., Dragosits, U., Theobald, M. R., Levy, P., Mobbs, D. C., Milne, R., Viovy, N., Vuichard, N., Smith, J. U., Smith, P. E., Bergamaschi, P., Fowler, D., and Reis, S.: Challenges in quantifying biosphereatmosphere exchange of nitrogen species, Environ. Pollut. 150, 125-139, 2007.

Sutton, M. A., Nemitz, E., Theobald, M. R., Milford, C., Dorsey, J. R., Gallagher, M. W., Hensen, A., Jongejan, P. A. C., Erisman, J. W., Mattsson, M., Schjoerring, J. K., Cellier, P., Loubet, B., Roche, R., Neftel, A., Hermann, B., Jones, S. K., Lehman, B. E., Horvath, L., Weidinger, T., Rajkai, K., Burkhardt, J., Löpmeier, F. J., and Dämmgen, U.: Dynamics of ammonia exchange with cut grassland: strategy and implementation of the GRAMINAE Integrated Experiment, Biogeosciences, 6, 309331, doi:10.5194/bg-6-309-2009, 2009a.

Sutton, M. A., Nemitz, E., Milford, C., Campbell, C., Erisman, J. W., Hensen, A., Cellier, P., David, M., Loubet, B., Personne, E., Schjoerring, J. K., Mattsson, M., Dorsey, J. R., Gallagher, M. W., Horvath, L., Weidinger, T., Meszaros, R., Dämmgen, U., Neftel, A., Herrmann, B., Lehman, B. E., Flechard, C., and Burkhardt, J.: Dynamics of ammonia exchange with cut grassland: synthesis of results and conclusions of the GRAMINAE Integrated Experiment, Biogeosciences, 6, 2907-2934, doi:10.5194/bg-6-29072009, 2009b.

Sutton, M. A., Howard, C. M., Erisman, J. W., Bealey, W. J., Billen, G., Bleeker, A., Bouwman, A. F., Grennfelt, P., van Grinsven, H. and Grizzetti, B.: The challenge to integrate nitrogen science and policies: the European Nitrogen Assessment approach, in: The European Nitrogen Assessment: Sources, Effects and Policy Perspectives, edited by: Sutton, M. A., Howard, C. M., Erisman, J. W., Billen, G., Bleeker, A., Grennfelt, P., van Grinsven, H., and Grizzetti, B., Cambridge University Press, Cambridge, ISBN 978-1-107-00612-6, 82-96, 2011

Sutton, M. A, Reis, S., Riddick, S. N., Dragosits, U., Nemitz, E., Theobald, M. R., Tang, Y. S., Braban, C. F., Vieno, M., Dore, A. J., Mitchell, R. F., Wanless, S., Daunt, F., Fowler, D., Blackall, T. D., Milford, C., Flechard, C. R., Loubet, B., Massad, R. S., Cellier, P., Personne, E., Coheur, P. F., Clarisse, L., Van Damme, M., Ngadi, Y., Clerbaux, C., Skjøth, C. A., Geels, C., Hertel, O., Wichink Kruit, R. J., Pinder, R. W., Bash, J. O., Walker, J. T., Simpson, D., Horváth, L., Misselbrook, T. H., 
Bleeker, A., Dentener, F., and de Vries, W.: Towards a climatedependent paradigm of ammonia emission and deposition, Philos. T. R. Soc. B, 368, 20130166, http://dx.doi.org/10.1098/rstb. 2013.0166, 2013.

Tang, Y. S., Simmons, I., v. Dijk, N., de Marco, C., Nemitz, E., Dammgen, U., Gilke, K., Djuricic, V., Vidic, S., Gliha, Z., Borovecki, D., Mitosinkova, M., Hanssen, J. E., Uggerud, T. H., Sanz, M. J., Sanz, P., Chorda, J. V., Flechard, C. R., Fauvel, Y., Ferm, M., Perrino C., and Sutton, M. A.: European scale application of atmospheric reactive nitrogen measurements in a low-cost approach to infer dry deposition fluxes, Agr. Ecosyst. Environ., 133, 183-195, 2009.

Theobald, M. R., Dragosits, U., Place, C. J., Smith, J. U., Sozanska, M., Brown, L., Scholefield, D., Del Prado, A., Webb, J., Whitehead, P. G., Angus, A., Hodge, I.D., Fowler, D., Sutton, M.A.: Modelling nitrogen fluxes at the landscape scale, Water Air Soil Poll., Focus 4, 135-142, 2004.

Theobald, M. R., Williams, A. G., Rosnoblet, J., Campbell, C., Cumby, T.R., Demmers, T. G. M., Loubet, B., Parsons, D. J., Gabrielle, B., Nemitz, E., Génermont, S., Le Cadre, E., Dragosits, U., van Oijen, M., Cellier, P. and Sutton, M. A.: An assessment of how process modelling can be used to estimate agricultural ammonia emissions and the efficacy of abatement techniques, Final report DEFRA project AM0130, Centre for Ecology and Hydrology (CEH), Penicuik, UK, 2005.

Theobald, M. R., Bealey, W. J., Tang, Y. S., Vallejo, A., and Sutton, M. A.: A simple model for screening the local impacts of atmospheric ammonia, Sci. Total. Environ., 407, 6024-6033, 2009.

Theobald, M. R., Løfstrøm, P., Walker, J., Andersen, H. V., Pedersen, P., Vallejo, A., and Sutton, M. A.: An intercomparison of models used to simulate the short-range atmospheric dispersion of agricultural ammonia emissions, Environ. Modell. Softw., 37, 90-102, 2012.

Thomas, R. M., Trebs, I., Otjes, R., Jongejan, P. A. C., ten Brink, H., Phillips, G., Kortner, M., Meixner, F. X., and Nemitz, E.: An automated analyzer to measure surface-atmosphere exchange fluxes of water soluble inorganic aerosol compounds and reactive trace gases, Environ. Sci. Technol., 43, 1412-1418, doi:10.1021/es8019403, 2009.

Trebs, I., Lara, L. L., Zeri, L. M. M., Gatti, L. V., Artaxo, P., Dlugi, R., Slanina, J., Andreae, M. O., and Meixner, F. X.: Dry and wet deposition of inorganic nitrogen compounds to a tropical pasture site (Rondônia, Brazil), Atmos. Chem. Phys., 6, 447-469, doi:10.5194/acp-6-447-2006, 2006.

van Aardenne, J. A., Dentener, F. J., Olivier, J. G. J., Klijn Goldewijk, C. G. M., and Lelieveld, J.: A $1^{\circ} \times 1^{\circ}$ resolution dataset of historical anthropogenic trace gas emissions for the period 18901990, Global Biogeochem. Cy., 15, 909-928, 2001.

Van der Molen, J., Beljaars, A. C. M., Chardon, W. J., Jury, W. A., and van Faassen, H.G.: Ammonia volatilization from arable land after application of cattle slurry: 2. Derivation of a transfer model, Neth. J. Agr. Sci., 38, 239-254, 1990.

van Hove, L. W. A. and Adema, E. H.: The effective thickness of water films on leaves (Short communication), Atmos. Environ., 30, 2933-2936, 1996.

van Hove, L. W. A., Heeres, P., and Bossen, M. E.: The annual variation in stomatal ammonia compensation point of rye grass (Lolium perenne L.) leaves in an intensively managed grassland, Atmos. Environ., 36, 2965-2977, 2002. van Jaarsveld, J. A.: The Operational Priority Substances Model: Description and Validation of OPS-Pro 4.1, RIVM report 500045001/2004, Bilthoven, The Netherlands, 156 pp., 2004.

van Oss, R., Duyzer, J., and Wyers, P.: The influence of gas-toparticle conversion on measurements of ammonia exchange over forest, Atmos. Environ., 32, 3, 465-471, 1988.

van Pul, W. A. J., van Jaarsveld, J. A., Vellinga, O. S., van den Broek, M., and Smits, M. C. J.: The VELD experiment: an evaluation of the ammonia emissions and concentrations in an agricultural area, Atmos. Environ., 42, 8086-8095, 2008.

van Pul, A., Hertel, O., Geels, C., Dore, A. J., Vieno, M., van Jaarsveld, H.A., Bergström, R., Schaap, M., and Fagerli, H.: Modelling of the atmospheric transport and deposition of ammonia at a national and regional scale, in: UNECE Expert Workshop on Atmospheric Ammonia - Detecting Emission Changes And Environmental Impacts, edited by: Sutton, M. A., Reis S., and Baker, S. M. H., Springer, Dordrecht, The Netherlands, ISBN: 978-1-4020-9120-9, 301-358, 2009.

Van Zanten, M. C., Sauter, F. J., Wichink Kruit, R. J., Van Jaarsveld, J. A., and Van Pul, W. A. J.: Description of the DEPAC module: Dry deposition modelling with DEPAC GCN2010, RIVM report 680180001/2010, Bilthoven, The Netherlands, 74 pp., 2010.

Vautard, R., Beekmann, M., Roux, J., and Gombert, D.: Validation of a hybrid forecasting system for the ozone concentrations over the Paris area, Atmos. Environ. 35, 2449-2461, 2001.

Vieno, M., Dore, A. J., Stevenson, D. S., Doherty, R., Heal, M. R., Reis, S., Hallsworth, S., Tarrason, L., Wind, P., Fowler, D., Simpson, D., and Sutton, M.A.: Modelling surface ozone during the 2003 heat-wave in the UK, Atmos. Chem. Phys., 10, 7963-7978, doi:10.5194/acp-10-7963-2010, 2010.

von Bobrutzki, K., Braban, C. F., Famulari, D., Jones, S. K., Blackall, T., Smith, T. E. L., Blom, M., Coe, H., Gallagher, M., Ghalaieny, M., McGillen, M. R., Percival, C. J., Whitehead, J. D., Ellis, R., Murphy, J., Mohacsi, A., Pogany, A., Junninen, H., Rantanen, S., Sutton, M. A., and Nemitz, E.: Field inter-comparison of eleven atmospheric ammonia measurement techniques, Atmos. Meas. Tech., 3, 91-112, doi:10.5194/amt-3-91-2010, 2010.

Walker, J. T., Robarge, W. P., Wu, Y., and Meyers, T. P.: Measurement of bi-directional ammonia fluxes over soybean using the modified Bowen-ratio technique, Agr. Forest Meteorol., 138, 5468, 2006.

Walker, J., Spence, P., Kimbrough, S., and Robarge, W.: Inferential model estimates of ammonia dry deposition in the vicinity of a swine production facility, Atmos. Environ., 42, 3407-3418, 2008.

Walker, J. T., Jones, M. R., Bash, J. O., Myles, L., Meyers, T., Schwede, D., Herrick, J., Nemitz, E., and W. Robarge: Processes of ammonia air-surface exchange in a fertilized Zea mays canopy, Biogeosciences, 10, 981-998, doi:10.5194/bg-10-9812013, 2013.

Wang, L. and Schjoerring, J. K.: Seasonal variation in nitrogen pools and $15 \mathrm{~N} / 13 \mathrm{C}$ natural abundances in different tissues of grassland plants, Biogeosciences, 9, 1583-1595, doi:10.5194/bg9-1583-2012, 2012.

Wang, Y., Jacob, D. J., and Logan, J. A.: Global simulation of tropospheric $\mathrm{O}_{3}-\mathrm{NO}_{\mathrm{x}}$-hydrocarbon chemistry, 1. Model formulation, J. Geophys. Res., 103, 10713-10726, 1998.

Wang, L., Xu, Y., and Schjoerring, J. K.: Seasonal variation in ammonia compensation point and nitrogen pools in beech leaves 
(Fagus sylvatica), Plant Soil, 343, 51-66, 2011.

Wang, L., Ibrom, A., Korhonen, J. F. J., Arnoud Frumau, K. F., Wu, J., Pihlatie, M., and Schjoerring, J. K.: Interactions between leaf nitrogen status and longevity in relation to $\mathrm{N}$ cycling in three contrasting European forest canopies, Biogeosciences, 10, 9991011, doi:10.5194/bg-10-999-2013, 2013.

Wesely, M. L.: Parameterization of surface resistances to gaseous dry deposition in regional-scale numerical models, Atmos. Environ., 23, 1293-1304, 1989.

Wesely, M. L. and Hicks, B. B.: A review of the current status of knowledge in dry deposition, Atmos. Environ., 34, 2261-2282, 2000 .

Wexler, A. S. and Seinfeld, J. H.: The distribution of ammonium salts among a size and composition dispersed aerosol, Atmos. Environ., A 24, 1231-1246, 1990.

Whitehead, J. D., Twigg, M., Famulari, D., Nemitz, E., Sutton, M. A., Gallagher, M. W., and Fowler, D.: Evaluation of Laser Absorption Spectroscopic Techniques for Eddy Covariance Flux Measurements of $\mathrm{NH}_{3}$, Environ. Sci. Technol., 42, 2041-2046, 2008.

Wichink-Kruit, R. J., van Pul, W. A. J., Sauter, F. J., van den Broek, M., Nemitz, E., Sutton, M. A., Krol, M., and Holtslag, A. A. M.: Modeling the surface-atmosphere exchange of ammonia, Atmos. Environ., 44, 945-957, 2010.

Wichink Kruit, R. J., Schaap, M., Sauter, F. J., van Zanten, M. C., and van Pul, W. A. J.: Modeling the distribution of ammonia across Europe including bi-directional surface-atmosphere exchange, Biogeosciences, 9, 5261-5277, doi:10.5194/bg-9-52612012, 2012.

Williams, J. R., Izuarralde, R. C., and Steglich, E. M.: Agricultural Policy/Environmental eXtender Model: Theoretical documentation version 0604, Blackland Research and Extension Center, Texas, AgriLIFE Research, Texas A\&M University, Temple, TX, http://epicapex.brc.tamus.edu, 2008.

Wilson, J. D., Thurtell, G. W., Kidd, G. E., and Beauchamp, G. E.: Estimation of the rate of gaseous mass-transfer from a surface source plot to the atmosphere, Atmos. Environ., 16, 1861-1867, 1982.

Wilson, L. J., Bacon, P. J., Bull, J., Dragosits, U., Blackall, T. D., Dunn, T. E., Hamer, K. C., Sutton, M. A., and Wanless, S.: Modelling the spatial distribution of ammonia emissions from seabirds, Environ. Pollut., 131, 173-185, 2004.

Winiwarter, W., Hettelingh, J.-P., Bouwman, A. F., de Vries, W., Erisman, J. W., Galloway, J., Klimont, Z., Leach, A., Leip, A., Pallière, C., Schneider, U. A., Spranger, T., Sutton, M. A., Svirejeva-Hopkins, A., van der Hoek, K. W., and Witzke, P.: Future scenarios of nitrogen in Europe, in: The European Nitrogen Assessment: Sources, Effects and Policy Perspectives, edited by: Sutton, M. A., Howard, C. M., Erisman, J. W., Billen, G., Bleeker, A., Grennfelt, P., van Grinsven, H., and Grizzetti, B., Cambridge University Press, Cambridge, ISBN 978-1-10700612-6, 551-569, 2011.
Wittig, V. E., Ainsworth, E. A., and Long, S. P.: To what extent do current and projected increases in surface ozone affect photosynthesis and stomatal conductance of trees? A meta-analytic review of the last 3 decades of experiments, Plant Cell Environ. 30, 1150-1162, 2007.

Wolff, V., Trebs, I., Ammann, C., and Meixner, F. X.: Aerodynamic gradient measurements of the $\mathrm{NH}_{3}-\mathrm{HNO}_{3}-\mathrm{NH}_{4} \mathrm{NO}_{3}$ triad using a wet chemical instrument: an analysis of precision requirements and flux errors, Atmos. Meas. Tech., 3, 187-208, 2010a, http://www.atmos-meas-tech.net/3/187/2010/.

Wolff, V., Trebs, I., Foken, T., and Meixner, F. X.: Exchange of reactive nitrogen compounds: concentrations and fluxes of total ammonium and total nitrate above a spruce canopy, Biogeosciences, 7, 1729-1744, doi:10.5194/bg-7-1729-2010, 2010 b.

Wu, S.-Y., Hub, J.-L., Zhang, Y., and Aneja, V. P.: Modeling atmospheric transport and fate of ammonia in North Carolina-Part II: Effect of ammonia emissions on fine particulate matter formation, Atmos. Environ. 42, 3437-3451, 2008.

Wu, Y. H., Brashers, B., Finkelstein, P. L., and Pleim, J. E.: A multiplayer biochemical dry deposition model. I. Model formulation, J. Geophys. Res., 108, D14013, doi:10.1029/2002JD002293, 2003.

Wu, Y. H., Walker, J., Schwede, D., Peters-Lidard, C., Dennis, R., and Robarge, W.: A new model of bi-directional ammonia exchange between the atmosphere and biosphere: Ammonia stomatal compensation point, Agr. Forest Meteorol., 149, 263-280, 2009.

Wyers, G. P. and Erisman, J. W.: Ammonia exchange over coniferous forest, Atmos. Environ., 32, 441-451, 1998.

Wyers, G. P., Otjes, R. P., and Slanina, J.: A continuous flow denuder for the measurement of ambient concentrations and surface fluxes of $\mathrm{NH}_{3}$, Atmos. Environ., 27A, 2085-2090, 1993.

Zhang, L., Brook, J. R., and Vet, R.: A revised parameterization for gaseous dry deposition in air-quality models, Atmos. Chem. Phys., 3, 2067-2082, doi:10.5194/acp-3-2067-2003, 2003.

Zhang, L., Vet, R., O'Brien, J. M., Mihele, C., Liang, Z., and Wiebe, A.: Dry deposition of individual nitrogen species at eight Canadian rural sites, J. Geophys. Res., 114, D02301, doi:10.1029/2008JD010640, 2009.

Zhang, L., Wright, P. L., and Asman, W. A. H.: Bi-directional airsurface exchange of atmospheric ammonia - A review of measurements and a development of a big-leaf model for applications in regional-scale air-quality models, J. Geophys. Res., 115, D20310, doi:10.1029/2009JD013589, 2010.

Zimmermann, F., Plessow, K., Queck, R., Bernhofer, C., and Matschullat, J.: Atmospheric $\mathrm{N}$ - and S-fluxes to a spruce forest - Comparison of inferential modelling and the throughfall method, Atmos. Environ., 40, 4782-4796, doi:10.1016/j.atmosenv.2006.03.056, 2006. 